ARBEITSHEFTE AUS DEM OTTO-STAMMER-ZENTRUM

NR. 16

\title{
Rechtsextremismus, Sexismus und Gender Gap
}

von

Richard Stöss

Berlin, Februar 2009 
Die "Arbeitshefte aus dem Otto-Stammer-Zentrum" stehen (bis auf Nr. 3) im Internet als Downloads (PDF) zur Verfügung:

http://www.polsoz.fu-berlin.de/polwiss/forschung/systeme/empsoz/schriften/arbeitshefte/index.html

Das Manuskript wurde im April 2008 abgeschlossen.

\section{Impressum:}

\section{Prof. Dr. Richard Stöss}

Freie Universität Berlin

Fachbereich Politik- und Sozialwissenschaften

Otto-Suhr-Institut für Politikwissenschaft

Otto-Stammer-Zentrum (Arbeitsstelle für Empirische Politische Soziologie)

Ihnestr. 21, 14195 Berlin

Tel.: (030) 838-54959; Fax: (030) 838-54960

Internet: http://www.polsoz.fu-berlin.de/polwiss/forschung/systeme/empsoz/mitarbeiter/stoess/index.html E-Mail: rstoess@zedat.fu-berlin.de 
Inhalt

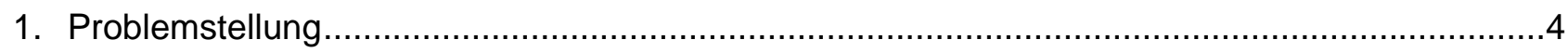

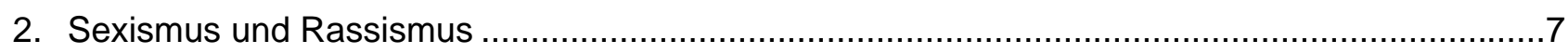

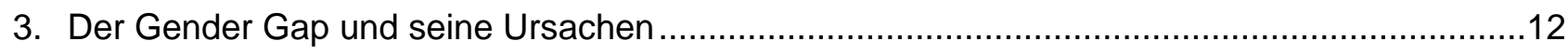

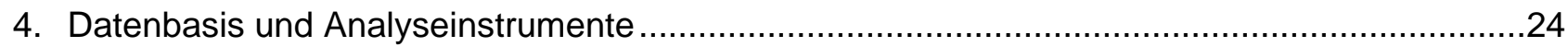

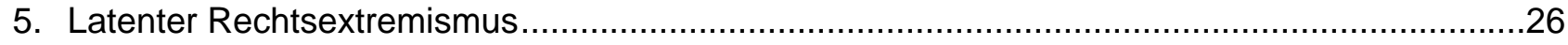

a) Geschlechtsspezifische Aspekte der Potenzialbestimmung .........................................26

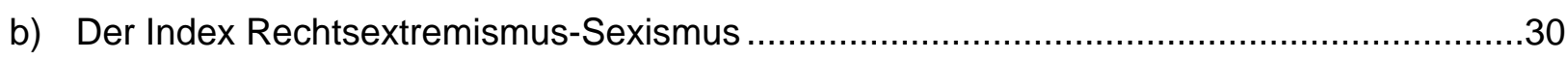

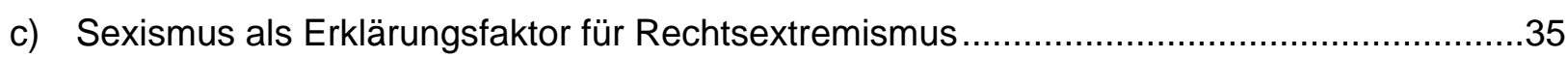

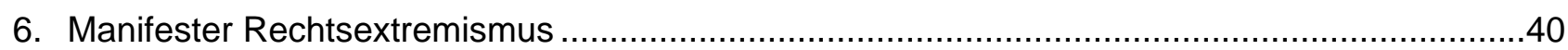

a) Die NPD-Wähler bei der Bundestagswahl 2005 .........................................................40

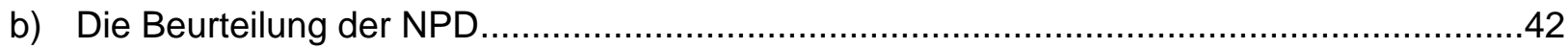

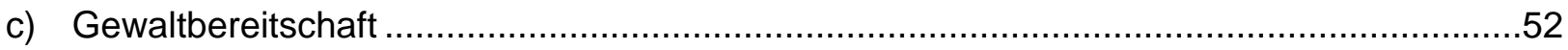

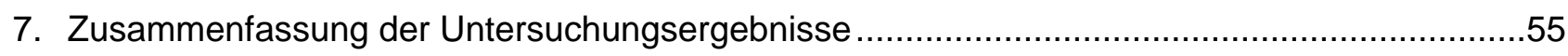

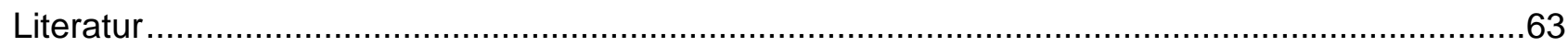

Anhang:

Datenquellen, Messinstrumente, Erläuterungen und ergänzende Tabellen ................................70 


\section{Problemstellung}

Das Thema "Frauen und Rechtsextremismus" hat seinen Zenith als Untersuchungsgegenstand längst überschritten ${ }^{1}$. Dem umfangreichen, hauptsächlich aus den neunziger Jahren stammenden Schrifttum $^{2}$ ist zu entnehmen, dass sich Männer und Frauen mit Blick auf rechtsextreme Einstellungen nicht grundsätzlich unterscheiden. Von den OMGUS- und HICOG-Surveys seit 1945 (Merritt/Merritt 1970, 1980) über die SINUS-Studie (SINUS 1981: 115) bis hin zu zeitgenössischen Untersuchungen (Stöss/Fichter/Kreis/Zeuner 2004: Anhang 43, Tab. 61; Decker/Brähler 2006: 48; Stöss 2007: 92) hat sich immer wieder gezeigt, dass mal das eine und mal das andere Geschlecht bei der Beantwortung von einzelnen Statements zu Autoritarismus, Nationalismus, Ethnozentrismus und zur Verharmlosung des Nationalsozialismus (zumeist leicht, gelegentlich aber auch deutlich) überdurchschnittlich vertreten ist, dass sich insgesamt aber keine besondere geschlechtsspezifische Resistenz gegenüber rechtsextremen Einstellungen zeigt (Ottens 1997a).

Hinsichtlich des Wahlverhaltens von Frauen zugunsten der NSDAP konnte Falter (1991: 136 ff.) nachweisen, dass diese der Hitler-Partei nur unwesentlich schwächer zuneigten als die Männer. Die Differenz betrug zwischen 1924 und 1932 maximal zwei Prozentpunkte. Erst 1933 war die NSDAP bei den Frauen etwas erfolgreicher als bei den Männern. Nach 1945 entschieden sich bei Wahlen deutlich weniger Frauen für rechtsextreme Parteien als Männer. Beispielsweise konnte die Deutsche Reichspartei (DRP) 1961 1,1 Prozent der Männer und 0,7 Prozent der Frauen mobilisieren (Sänger/Liepelt 1965: Nr. 3.35). Dieses Verhältnis setzte sich grosso modo bei der NPD (Kühnl u.a. 1969: 237 ff.) und bei den Republikanern fort (Roth 1989: 10 ff., 1990: 30 ff.; Hofmann-Göttig 1989a, 1989b; Däubler-Gmelin/Kießler 1990; Falter 1994: 99), und auch gegenwärtig ist die Anhängerschaft rechtsextremer Parteien - wie später noch zu zeigen sein wird, im Schnitt etwa zu zwei Dritteln männlich und zu einem Drittel weiblich ${ }^{3}$.

Noch stärker äußert sich der Geschlechterunterschied darin, dass Frauen in rechtsextremen Gruppierungen nur eine randständige Rolle spielen. Über die soziale Zusammensetzung der Mitgliedschaften von rechtsextremen Parteien und Organisationen liegen nur wenige Informationen vor (Sturhan 1997) ${ }^{4}$. Etwa sechs Prozent der Neumitglieder der NSDAP waren Frauen (Falter

1 Bei den wenigen Arbeiten aus neuerer Zeit handelt es sich zumeist um international vergleichende Studien (woran aber immer noch großer Bedarf besteht), z.B. Amesberger/Halbmayr 2002a; Brück 2005; Geden 2006.

2 Einen Überblick über den Forschungsstand geben Siller 1994; Birsl 1996; Ottens 1997c; Rommelspacher 2000; Amesberger/Halbmayr 2002a; Bitzan 2002. Vgl. auch den Diskussionsbeitrag von Kötting 2005.

3 Eine international vergleichende Fünf-Länder-Studie konstatiert allerdings teilweise "beträchtliche Annäherungen" und empfiehlt einen "differenzierten Blick" (Amesberger/Halbmayr 2002c: 410) auf das geschlechtsspezifische Wahlverhalten zugunsten von rechtsextremen Parteien.

4 Über die Situation, die Motive und das Selbstbild von Frauen in rechtsextremen Strukturen liegen viele, zumeist Interview-gestützte, Berichte vor: Balbach 1994; Bitzan 2000; Brück 2005; Döhring/Feldmann 2005; Dörr 1995; Fantifa 1996; Fichte 1997; Hewicker 2001; Hofmann 2003; Jansen 1989; Köttig 1997; 
1993, S. $206^{5}$ ). Der Anteil der Frauen in der Sozialistischen Reichspartei (SRP) betrug rund acht Prozent (Gnad 2005a: 464), und bei der NPD waren es Anfang 196711 Prozent, 1968 dann neun Prozent (Kühnl u.a. 1969: 224). 2001 meldeten die Republikaner einen Frauenanteil von 20 Prozent und die NPD von 18 Prozent (Bitzan 2002: 88). Als Hinweis auf die marginale innerparteiliche Bedeutung des weiblichen Geschlechts mag der Frauenanteil an den Bundestagskandidaten rechtsextremer Parteien dienen: Er betrug zischen 1949 und 1990 rund neun Prozent $^{6}$, bei der Bundestagswahl 2005 waren auf den Landeslisten der Republikaner insgesamt 15 Frauen vertreten (15\%), auf denen der NPD $24(11 \%)^{7}$. Unter den 61 Landtagsabgeordneten der NPD in den sechziger Jahren befanden sich drei Frauen (Gnad 2005b: 690), und von den 18 für die NPD 2004 bzw. 2006 in die Landtage von Sachsen und Mecklenburg-Vorpommern gewählten Personen war nur eine einzige weiblichen Geschlechts. Die sechsköpfige brandenburgische DVU-Fraktion zählt gegenwärtig zwei Frauen, wobei allerdings eine den Fraktionsvorsitz innehat. Dem 21 Personen umfassenden Bundesvorstand der Republikaner gehören derzeit sechs Frauen an (29\%), im zwanzigköpfigen Bundesvorstand der NPD sitzen gerade einmal zwei Frauen ${ }^{8}$.

Der Frauenanteil am kriminellen Rechtsextremismus ist noch geringer. Im Zeitraum von September 1978 bis Dezember 1982 befanden sich unter den knapp 800 wegen rechtsextremer Aktivitäten abgeurteilten Personen nur zwei Prozent Frauen (Kalinowsky u.a. 1985: 93). Der Anteil der Frauen unter den zwischen Januar 1991 und April 1992 ermittelten rund 1400 Tatverdächtigen im Zusammenhang mit fremdenfeindlichen Straftaten betrug vier Prozent (Willems u.a. 1993: 112), und das Bundesinnenministerium bezifferte den Frauenanteil an Gewalttaten mit erwiesener oder zu vermutender rechtsextremistischer Motivation für 1996 ebenfalls mit vier Prozent (Verfassungsschutzbericht des Bundesinnenministeriums 1996, S. 97). Nach Peucker/Gaßebner/Wahl (2001: 27) ist der Anteil von weiblichen fremdenfeindlichen Tatverdächtigen in den neunziger Jahren jedoch von fünf Prozent (1992/93) auf neun Prozent (1997) angewachsen.

Männer und Frauen reagieren also - wenigstens teilweise - verschieden auf rechtsextreme Politikangebote. Wenn Rechtsextremismus auf der individuellen Ebene eine spezifische Form der Bewältigung von problematischen sozialen Erfahrungen und sozialen Lagen bedeutet (Stöss/Fichter/Kreis/Zeuner 2004: 46 ff; Stöss 2007: 55 ff.), dann besteht - jedenfalls nach vorherrschender Meinung - kein relevanter geschlechtsspezifischer Unterschied bei der Deutung und mentalen Verarbeitung derartiger Erfahrungen und Lagen im Sinne des Rechtsextremismus, wohl

Orde 1991; Renz 1995; Ritter 1997; Schnurbein 1996; Schwarzmeier/Wunderlich 1996; Skrzydlo/Wohllaib 1996; Skrzydlo u.a. 1992; Tenner 1996.

5 Falter (206 f.) zitiert in diesem Zusammenhang den Reichsorganisationsleiter der NSDAP Robert Ley: "Diese niedrige Zahl der weiblichen Mitglieder erklärt sich ohne weiteres dadurch, dass die Partei kämpferischen und politischen Charakter trägt und damit naturnotwendigerweise im wesentlichen Männer zur tätigen Mitarbeit an sich zog."

6 Berechnet nach Angaben des Bundeswahlleiters.

7 Angaben des Bundeswahlleiters.

8 Die aktuellen Angaben wurden im Internet recherchiert (Dezember 2007). 
aber bei den praktischen Konsequenzen, die daraus gezogen werden (Wahlverhalten, politisches Engagement, Gewalt). Dieser Gender Gap war zentraler Gegenstand einer vor allem von Frauen ${ }^{9}$ seit Ende der achtziger, Anfang der neunziger Jahre betriebenen Rechtsextremismusforschung. Obwohl die Thematik mittlerweile offenbar als weithin "abgeforscht" gilt, bedürfen einige Aspekte aus der Perspektive der empirischen Einstellungsforschung durchaus noch einer genaueren Betrachtung.

Das gilt zunächst für die Frage, ob sich Frauen dem Rechtsextremismus trotz oder gerade wegen seines reaktionären, sexistischen Weiblichkeitsideals zuwenden (Amesberger/Halbmayr 2002b: 42). Wenn das rechtsextreme Frauenbild - was zu vermuten ist - wenigstens für Teile des weiblichen Geschlechts attraktiv sein sollte, wäre zu untersuchen, in welchem Zusammenhang die Diskriminierung aufgrund der ethnischen Herkunft und die aufgrund des Geschlechts stehen. Über die Beziehungen von Rassismus und Sexismus ist in der Frauenforschung in den neunziger Jahren intensiv diskutiert worden. Während einige Autorinnen die Unterschiede zwischen beiden Diskriminierungsformen hervorhoben, wurden auch gute Argumente vorgetragen, dass es sich dabei um "zwei Seiten einer Medaille" (Tillner 1994: 8) handelt. Sollte sich Sexismus als Bestandteil des rechtsextremen Weltbilds herausstellen, dann müsste Sexismus bei der Definition von Rechtsextremismus und folglich auch bei der Konstruktion von Rechtsextremismus-Skalen Berücksichtigung finden. Da das in der Regel nicht der Fall ist, wären alle bisherigen Messergebnisse, gerade auch geschlechtsspezifische Potenzialbestimmungen, mit einem Fehler behaftet. Und dieser Fehler dürfte sich einseitig zum Nachteil von Frauen auswirken, da sie vermutlich weniger zu sexistischen Einstellungen neigen als Männer. Sollten sich jedoch größere Unterschiede zwischen Sexismus und Rassismus offenbaren, wäre zu untersuchen, ob Sexismus als Prädiktor für Rechtsextremismus in Betracht kommt und über welche Erklärungskraft er - gerade auch für geschlechtsspezifische Differenzen - verfügt.

Dies verweist auf die generelle Problematik des Gender Gap: Worauf bezieht sich die Geschlechterdifferenz? Nur auf Verhalten oder auch auf Einstellungen? Bei früheren Untersuchungen habe ich festgestellt, dass bei rechtsextremen Einstellungen oft durchaus erhebliche Unterschiede zwischen Frauen und Männern bestehen, und zwar eher im Westen als im Osten. Schließlich ist mir aufgefallen, dass sich Vergleiche immer nur auf Männer und Frauen beziehen, niemals auf rechtsextreme Männer und rechtsextreme Frauen. So kann zwar als gesichert gelten, dass Männer häufiger als Frauen rechtsextreme Parteien wählen. Allerdings ist noch nie untersucht worden, ob dies auch für rechtsextreme Männer und für rechtsextreme Frauen gilt. Damit stellt sich auch die Frage, ob ein Geschlechterunterschied innerhalb des Rechtsextremismus besteht, ob es womöglich sogar - wie viele Autorinnen vermuten - einen geschlechtsspezifischen Rechtsextremismus gibt. Kurz 
und gut: Der Gender Gap bedarf einer genaueren empirischen Analyse auf der Einstellungs- und Verhaltensebene. Diese Analyse muss sich zudem auf Daten stützen, die repräsentativ für die deutsche Bevölkerung sind. Wenn überhaupt Survey-Studien vorliegen, dann basieren die Befunde hauptsächlich auf Befragungen von speziellen Bevölkerungsgruppen (zumeist von - oft sogar willkürlich ausgewählten - Jugendlichen), werden aber sorglos verallgemeinert.

Ich werde zunächst den Forschungs- und Diskussionsstand zum Verhältnis von Sexismus und Rassismus (Abschn. 2) sowie zum Gender Gap (Abschn. 3) ausführlich darstellen und dabei auch kurz auf den Hintergrund der Debatten eingehen, die vor allem in den neunziger Jahren innerhalb der Frauenforschung geführt worden sind. Am Ende des 3. Abschnitts werde ich das Programm für die empirischen Analysen (Abschn. 5 u. 6) skizzieren. Im 4. Abschnitt erfolgen einige Hinweise zur Datenbasis und zu den Analyseinstrumenten.

\section{Sexismus und Rassismus}

Das Interesse von Wissenschaftlerinnen für den Rechtsextremismus setzte 1989/90 ein, kurz nachdem die Republikaner ihre ersten Wahlerfolge in (West-) Berlin und bei der Europawahl erzielt hatten - und zwar mehr bei Männern als bei Frauen. Dieses Interesse war allerdings weniger tagespolitischen Entwicklungen geschuldet, sondern beruhte wohl in erster Linie darauf, dass Frauenforschung damals allenthalben quantitativ und qualitativ expandierte und der männlich geprägten Wissenschaft nachhaltig - und zwar personell und inhaltlich - zu Leibe rückte. Die seinerzeit nicht ohne weiteres von der Hand zu weisende Kritik reichte von "Geschlechterblindheit" (Meyer 1993: 212; Brück 2005: 139) oder "Entsexualisierung" (Rommelspacher 1991: 76) bis zum Vorwurf, dass bei Einstellungsuntersuchungen "immer noch männerspezifische Orientierungsmuster abgefragt" (Birsl u.a. 1993; s. auch Birsl 1996: 41) und verallgemeinert würden ${ }^{10}$.

"Die Verdrängung der Geschlechtsspezifik in der Analyse rechtsextremer Programmatik, in der Analyse des Wahlverhaltens sowie in der Analyse rechtsextremer Orientierungsmuster kann nur Ausdruck einer männlichen Wissenschaft sein, die in ihrer Dominanz sich eine solche Ignoranz leisten kann." (Rommelspacher 1991: 83)

Möller (1991a: 35) brachte das Problem damals kurz und prägnant auf die Formel: "Wer vom (weiblichen) Rechtsextremismus redet, darf vom Patriarchat nicht schweigen."

10 In diesem Zusammenhang wurde auch bezweifelt, dass das Verständnis der Statements zur Messung von Rechtsextremismus bzw. Rassismus bei Männern und Frauen identisch ist. Rippl/Seipel (1999) konnten jedoch nachweisen, dass Geschlechterunterschiede auch bei Kontrolle mit der Gleichwertigkeit der Bedeutung der Messinstrumente bestehen bleiben. 
Zuvor, in den siebziger und achtziger Jahren, war der bundesdeutsche Feminismus "von der Vorstellung eines weltumspannenden homogenen Patriarchats geprägt, das alle Frauen gleichermaßen betreffe und zu universellen Opfern der Männergewalt mache" (Eichhorn 1992: 95). Die Stärke des feministischen Ansatzes bestand darin, dass er sich auf eine griffige Gesellschaftstheorie berufen konnte, während sich die "patriarchale Argumentationskunst" (Rommelspacher 1991: 76) der empirischen Einstellungsforschung auf messbare Konzepte beschränkte, die gesellschaftstheoretisch zumeist nicht oder nur schwach fundiert waren. Die mit dem Rechtsextremismus befassten Wissenschaftlerinnen betrachteten das "Geschlecht [als] eine zentrale Kategorie bei der Erforschung der Ursachen" des Rechtsextremismus (Birsl u.a. 1993) und diesen wiederum als Konsequenz gesellschaftlicher Herrschafts- bzw. Gewaltverhältnisse. In der empirischen Sozialforschung bilde das Geschlecht dagegen nur eine von vielen Variablen, der auch nur in seltenen Ausnahmefällen besondere Beachtung zuteil werde (vgl. auch Ottens 1997b). "Dabei ist das Geschlechterverhältnis notwendiger Teil des Herrschaftszusammenhangs dieser unserer Dominanzkultur." (Holzkamp 1994: 40)

Die Theorie vom Geschlecht als "Hauptwiderspruch" wurde allerdings schon Anfang der siebziger Jahre (insbesondere von afro-amerikanischen Frauen in den USA) als "reduktionistisch" kritisiert. Denn deren Erfahrungen mit Diskriminierung bezogen sich nicht nur auf ihr Geschlecht, sondern auch und vor allem auf ihre ethnische Herkunft und auf ihre soziale Lage (gender, race, class; vgl. auch Anthias/Yuval-Davis 1993; Ludvig 1999).

"Die gemeinsame soziale Erfahrung von Sklaverei und Lynchjustiz für Schwarze, des Völkermordes an der Urbevölkerung Amerikas und den zahllosen Eroberungskriegen gegen US-amerikanische MexikanerInnen oder Puerto RicanerInnen ist substantiell nicht mit den physischen Leiden, sozialen Diskriminierungen und der kulturellen Missachtung, die Frauen erlitten haben, vergleichbar." (King 1992: 5 f.)

So gingen farbige Frauen davon aus, "dass Rassismus, Sexismus und Klassismus drei eng miteinander verwobene Systeme der sozialen Kontrolle und Herrschaft darstellen" (King 1992: 6). Da farbige Männer ebenfalls und weithin gleichermaßen von Rassismus und Klassismus betroffen waren $^{11}$, gehörte es zum Alltag farbiger Frauen, dass sie unterschiedlichen und bisweilen auch widersprüchlichen Rollenerwartungen und Solidaritätsanforderungen ausgesetzt waren, wobei wohl die antirassistische Orientierung überwog. Denn die Erfahrungen mit "weißen" Gewerkschafterinnen und Gewerkschaftern waren häufig ebenso durch Benachteiligung und Ablehnung gekennzeichnet (Scharenberg 1992), wie die mit der ("weißen") Frauenbewegung in den USA ${ }^{12}$, an der afro-amerikanische Frauen kaum beteiligt waren (ausführlich Davis 1982).

11 Dass auch afro-amerikanische Männer über ein reaktionäres Frauenbild verfügten, zeigt Collins 1993/94.

12 Zu den entsprechenden Erfahrungen farbiger Frauen in Kanada: Ng 1992. 
"Die Annahme, dass die Familie per Definition patriarchalisch sei, die Privilegierung einer individualistischen Weltsicht und die Befürwortung eines 'feministischen Separatismus' stehen oft antithetisch zu den Werten und Zielen schwarzer Frauen und erschweren so unsere Assoziation mit dem Feminismus...

Viele weiße Feministinnen gehen davon aus, dass ihr antisexistischer Standpunkt gleichzeitig die Ablehnung aller rassistischen Vorurteile und Verhaltensweisen beinhaltet. Diese Einstellung ist bestenfalls naiv und zeigt eine ernsthafte Ignoranz gegenüber der Tiefe, mit der der Rassismus die US-amerikanische Gesellschaft durchdrungen hat. Viele Schwarze, Männer und Frauen gleichermaßen, empfinden derartige Postulate als arrogant, rassistisch und gefährlich gegenüber den eigenen Interessen." (King 1992: 11)

Da sich der Vorwurf eines impliziten Rassismus an die "weiße" Frauenbewegung schlechthin richtete, hatten sich bald auch bundesdeutsche Feministinnen, die sich "lange in selbstzufriedener Weise von vornherein auf der 'richtigen Seite' im antirassistischen Kampf wähnten" (Eichhorn 1992: 95), mit derartigen Vorhaltungen auseinanderzusetzen:

"Die weiße Mittelschichten-Frauenbewegung in Deutschland fühlt sich einzigartig, universell und ignoriert Unterschiede zwischen Frauen wie Klasse und Hautfarbe. Die Frauenbewegung wird zum 'Ort' gemacht, an dem die weißen Frauen sich wohl fühlen sollen." (Basu 1992: 19)

Die afro-amerikanische Feministin Bell Hooks (1990: 84) warf den "weißen" Feministinnen vor, "dass sie völlig ungewillt sind, auf ihre hegemonistische Dominanz in der Theorie und Praxis zu verzichten, eine Dominanz, die sie nicht hätten durchsetzen können, wenn dies [die USA] nicht ein kapitalistischer Staat weißer Vorherrschaft wäre". Basu (1992: 20) mokierte sich:

"Die Solidarität mit Nicaragua oder die Flüchtlinge in Deutschland oder auch die Identitätskrise der weißen deutschen Frauen während des Golfkrieges: Die Themen bestimmen die weißen Feministinnen nicht für sich. Sie forschen in der ganzen Welt, sie erforschen die Frauen der Zwei-Drittel-Welt (Danke für Eure Bemühung). Die Objekte [der Frauenforschung] können natürlich nicht Prioritäten setzen, Definitionen bestimmen. Ob die Frauen der Zwei-Drittel-Welt sich Feministinnen nennen 'wollen - sollen - können', ist die Entscheidung, welche das Prärogativ der weißen Feministinnen ist. Es geht noch weiter. Wie die Frauen im 'Hinterland' zu kämpfen haben, wird in Westeuropa und/oder in Nordamerika bestimmt. Wir wundern uns nicht, wenn einer indischen Journalistin die Frage gestellt wird, warum es in Indien so wenige Frauenhäuser gebe. Es wird von innen erwartet, dass sie den feministischen 'Standard' des Westens nachahmen."

Abgesehen einmal davon, dass derartige Vorwürfe auch gegenüber nicht-farbigen Männern erhoben wurden und sich darin generell das gewachsene Selbstbewusstsein in der "Dritten Welt" gegenüber eurozentristischer Bevormundung ausdrückte, zeigt diese Diskussion einmal mehr, dass reduktionistische Sichtweisen wenig hilfreich sind. Mit der Zunahme von Fremdenfeindlichkeit in (West-) Europa seit Anfang der achtziger Jahre wurde jedenfalls unübersehbar, dass Rassismus keineswegs nur auf den Nationalsozialismus, auf Südafrika oder die USA beschränkt ist und dass er auch nicht nur im Kontext kolonialer oder imperialer Politik auftritt (Pinn 1990: 149; Eichhorn 1992: 96), sondern auch unsere eigene politische Kultur prägt. Die Erkenntnis griff Platz, dass nicht nur die Zugehörigkeit zu einem Geschlecht "über den Zugang zu gesellschaftlichen Ressourcen, Reichtum, Macht" (Hentges 1993: 45) entscheidet, sondern auch die Ethnizität und der soziale Status. Damit war auch der Verabsolutierung der Geschlechtskategorie bei der Beschreibung 
hiesiger gesellschaftlicher Verhältnisse eine klare Grenze gesetzt ${ }^{13}$, und die feministische Wissenschaft stand vor dem Problem, Sexismus und Rassismus ${ }^{14}$ (und die Klassenzugehörigkeit) in Beziehung zu setzen ${ }^{15}$.

Hier setzten die Untersuchungen über Frauen und Rechtsextremismus ein. Eine Initialwirkung hatte der Aufsatz von Christine Holzkamp und Birgit Rommelspacher (1991a bzw. 1991b), die einen herrschaftstheoretischen Ansatz verfolgen. Einleitend heißt es:

"Die Verdrängung der Hierarchie zwischen Frauen und damit auch der Hierarchie zwischen Frauen und ethnischen Minderheiten überhaupt hat so auch den Blick für die Beteiligung von Frauen am Rechtsextremismus verstellt." (1991a: 17)

Um den Zusammenhang von Sexismus und Rassismus theoretisch zu fassen, prägten die Autorinnen den (mittlerweile in diesem Kontext häufig verwendeten) Begriff der Dominanzkultur, die der Sicherung von Privilegien (patriarchaler, ethnischer, nationaler oder sozialer Art) diene und in der Probleme und Widersprüche durch Dominanzverhalten, "durch einseitige Verfügung über andere und deren Existenzrechte" (Rommelspacher 1991: 84) sowie durch Hierarchisierung und Unterwerfung gelöst würden. Kern der Dominanzkultur sei das Geschlechterverhältnis, denn die geschlechtsspezifische Sozialisation erzeuge Dominanzverhalten, Hierarchisierung und Unterwerfung $^{16}$. Da die Ausgrenzungsmechanismen gegenüber Frauen und ethnischen Minderheiten aufgrund von biologischen Merkmalen "kulturgeschichtlich in vielen Dimensionen nahezu identisch" seien, bestehe ein "enger Zusammenhang zwischen Rassismus und Sexismus" (Rommelspacher 1993b: 205). Aus der Unterdrückung der Frauen durch das Patriarchat folge allerdings nicht notwendigerweise Widerstand oder gar Rebellion. Frauen seien keineswegs weniger rassistisch als Männer, sie könnten sich anpassen oder sogar unterwerfen, womit sie zur Reproduktion von Sexismus und Rassismus beitrügen. Damit gerieten jene Frauen ins Blickfeld,

13 "Der Hinweis, dass weiße Frauen in dieser Gesellschaft Macht über Männer ethnischer Minderheiten haben, ruft [in der Frauenbewegung] meist Proteste hervor." (Schultz 1990: 55)

14 Zum Verhältnis von Sexismus und Antisemitismus Heß 2005.

15 Selbstkritisch hieß es im Editorial zum Heft 27 der "Beiträge zur feministischen Theorie und Praxis" (13. Jg., Köln 1990, S. 7), das unter dem Titel "Geteilter Feminismus: Rassismus - Antisemitismus - Fremdenhass" erschienen ist: "Die sichere Gewissheit, als Feministin ohnehin auf der richtigen Seite zu sein, schon immer gewesen zu sein, gerät ins Wanken. Die Frau, die Feministin ist nicht per se gut. Sie tut sich schwer mit dem Hinsehen, solange es nicht um ihre eigene Unterdrückung geht oder sich das Ganze nicht geographisch oder historisch möglichst weit weg abspielt. Der Versuchung, sich mittels Definition des 'Anderen' und seiner Abgrenzung/Ausgrenzung selbst zu definieren und so Geltung im System der Herrschenden zu erlangen, sind auch Feministinnen erlegen. Die selbstverständliche Solidarität der Unterdrückten ist eine Utopie, deren Verwirklichung hart erkämpft werden muss."

16 "Der Umgang mit Andersartigem als etwas zu Unterwerfendem [wie beim Rassismus] hat einen elementaren Ursprung im herrschenden Umgang mit dem Geschlechtsunterschied. Die Differenz der Geschlechter ist die erste Begegnung mit einer prinzipiellen Andersartigkeit von Menschen. Die Sozialisation weist die Jungen von früh auf an, ihre Männlichkeit in Form von Selbstbehauptung und Abwertung alles Weiblichen zu beweisen. Mädchen hingegen müssen ihre Weiblichkeit im Rückzug, im Fürsorgeverhalten und in der Selbstentwertung entwickeln. So lernen beide mit einem Unterschied qua Hierarchisierung umzugehen, qua Dominanz resp. Unterwerfung. Die Hierarchisierung der Geschlechter in allen Bereichen bestätigt diese Grundmuster immer wieder aufs Neue." (Holzkamp/Rommelspacher 1991a: 18) 
"die die Werte und Normen der männlichen Dominanzkultur ... internalisiert haben und daran mitwirken, sie aufrecht zu erhalten. Frauen projizieren eigene, nicht-erlaubte Machtbedürfnisse und nicht-gelebte Gewaltphantasien auf das 'starke' Geschlecht: sie lassen kämpfen, sie lassen (sich) dominieren und erhalten dafür männlichen Schutz und Teilhabe an der symbolischen (und oft auch materiellen) Macht des Stärkeren." (Meyer 1993: 215)

Gerade die Unterdrückung durch die patriarchale Herrschaft, so Rommelspacher (1993a: 48), könne für die Frau Grund genug sein, "sich nun ihrerseits wiederum an den Schwächeren schadlos zu halten". Aber: "Die subtile Machtausübung von Frauen gegenüber Schwächeren - Kindern, ethnischen Minderheiten, sozial niedriger Stehenden - sind die Kehrseite unbegriffener Selbstunterwerfung und unbegriffener gesellschaftlicher Zustände." (Holzkamp/Rommelspacher 1991b: 38)

Frauen seien mithin weder das "friedfertige" Geschlecht (so Mitscherlich 1987) noch notwendigerweise besonders sensibel gegenüber Benachteiligung und Ungleichbehandlung. Sie könnten auch von dem tief in den patriarchalen Strukturen verankerten Dominanzstreben profitieren:

"Frauen der hoch industrialisierten Länder partizipieren an der Ausbeutung der Dritten Welt, können somit für eine Politik der Privilegiensicherung der Ersten gegenüber der Dritten Welt durchaus gewonnen werden. Innenpolitisch bedeutet dies, dass einer 'Dritten Welt' im eigenen Land eine Absage erteilt wird, eine Politik der Ausgrenzung und Stigmatisierung auch von Frauen geteilt und reproduziert wird." (Hentges 1993: 45)

Rommelspacher (1993b: 205) unterscheidet zwei Formen von weiblichem Rechtsextremismus (s. auch Meyer 1993: 213):

- Passive Akzeptanz der Dominanzkultur durch Frauen. Sie schlagen sich gewissermaßen als Zuschauerinnen oder Mitläuferinnen auf die Seite der Herrschenden.

- Frauenspezifischer Rassismus. Dabei handelt es sich um Aktivitäten im Sinne einer Mittäterschaft, zum Beispiel wenn sich Tagesmütter weigerten, ausländische Kinder zu betreuen. Frauen gingen nur dann auf Distanz, "wenn rassistisches Verhalten mit männlichchauvinistischem Gebaren amalgiert".

Folgt man Rommelspacher, dann besteht zwar ein enger Zusammenhang zwischen Rassismus und Sexismus, es sei jedoch nicht "hilfreich", beides gleichzusetzen, weil Rassismus bei Frauen auf sehr unterschiedliche Weise in Erscheinung träte und für Frauen eine andere Funktion habe als für Männer (Rommelspacher 1993a: 48; ähnlich Ottens 1997b: 173 f.). Von Identität mag auch Wippermann (1990) nicht sprechen. Er bezeichnet nur den "antifeministischen Rassismus" als sexistisch, den er gegenüber dem "anthropologischen" und dem "sozialbiologischen" Rassismus abgrenzt. Noch differenzierter argumentiert Lenz (1994: 62):

"Die Individuen sind also nicht einfach durch sex, race, class als geschlossene Größen determiniert. Zu beachten sind vielmehr einerseits gesellschaftliche Hierarchien und Ungleichheiten und andererseits 'konfiguratives Handeln' als Balanceakt der einzelnen im Spannungsfeld von Geschlecht, Klasse und Ethnie."

Gewissermaßen in Klammern sei angemerkt, dass sich die neuere Forschung immer mehr von der Rechtsextremismus- bzw. Rassismusproblematik entfernt, Geschlecht und Ethnie (und Klasse) als 
"Dimensionen sozialer Ungleichheit" betrachtet und nach der "gegenseitigen Überschneidung, Verstärkung, Schwächung und Beeinflussung" (Müller 2003: 7) fragt ${ }^{17}$. Eine theoretische Systematisierung der "zahlreichen Möglichkeiten der Verknüpfung zwischen Ethnie, Geschlecht, Klasse etc." liege allerdings noch nicht vor. Insbesondere sei unklar, welche relative Bedeutung den einzelnen Ungleichheitsdimensionen zukomme und welche Wechselwirkungen zwischen ihnen bestünden: Sie könnten sich gegenseitig beeinflussen, überlagern, verstärken oder gar summieren (Müller 2003: 178 ff.).

Hier geht es jedoch nicht um soziale Ungleichheit im Allgemeinen sondern um Diskriminierung und Unterordnung. Das Weiblichkeitsideal des Rechtsextremismus entspringt schließlich völkischnationalistischen Vorstellungen und richtet sich diametral gegen demokratische Emanzipationsbestrebungen. Was zumeist in kritischer Absicht als Sexismus bezeichnet wird, stell in der Perspektive des Rechtsextremismus eine naturgegebene Rollenzuweisung dar, die angeblich bedroht ist und daher bewahrt bzw. gestärkt werden müsse. Auf der Angebotsseite bilden Sexismus und Rassismus daher zwei Seiten derselben Medaille. Folgt man dem herrschaftstheoretischen Ansatz, dann besteht auch im Bewusstsein der Frauen eine enge Verbindung zwischen Sexismus und Rassismus und daher neigten Frauen keineswegs seltener zum Rassismus als Männer. Frauen seien nicht nur Opfer von Diskriminierung, sie seien auch Täter. So gesehen entspricht die Nachfrage durchaus dem Angebot. Zum Gender Gap heißt es: Frauen gingen zu Männern "offensichtlich nur dann auf Distanz, wenn rassistisches Verhalten mit männlich-chauvinistischem Gebaren amalgiert. Ebenso haben sie wenig Interesse an einer Partei, die vornehmlich Männerinteressen vertritt." (Rommelspacher 1993b: 205). Schließlich wird darauf hingewiesen, dass beim Rassismus ein Geschlechterunterschied hinsichtlich der Motive und Funktionen bestehe.

\section{Der Gender Gap und seine Ursachen}

Neben dem und teilweise auch in Konkurrenz zum herrschaftstheoretischen Ansatz ${ }^{18}$ wurde Anfang der neunziger Jahre in der Frauenforschung ein modernisierungstheoretischer Ansatz entwickelt $^{19}$, der sich eingehender mit dem Geschlechterunterschied im Rechtsextremismus befasste. Er wird von Kötting (2005: 59) kurz und prägnant wie folgt charakterisiert:

"Vertreterinnen, die an diesen Erklärungsansatz anknüpfen (zu nennen sind hier u.a. Ursula Birsl, Birgit Meyer und Gertrud Siller) gehen mit unterschiedlichen Nuancierungen und Schwerpunktsetzungen davon aus, dass gesellschaftliche Bedingungen und geschlechtsspezifische Sozialisationserfahrungen von 
Mädchen und Jungen dafür ausschlaggebend seien, in welchem Maß und in welcher Ausprägung sie extrem rechten Ideologien zustimmen."

Dieser Ansatz orientierte sich ursprünglich an Ulrich Beck und Wilhelm Heitmeyer ${ }^{20}$, die wiederum von Holzkamp und Rommelspacher sehr kritisch rezipiert wurden ${ }^{21}$. Nach Beck werden die Menschen mit dem Wandel von der klassischen Industriegesellschaft zur industriellen Risikogesellschaft aus den bewährten sozialen Beziehungen der sich verabschiedenden Industriegesellschaft entlassen. Biete diese Freisetzung auch die Chance für mehr Unabhängigkeit und Gestaltungsfreiheit, so bürde sie den Einzelnen doch die alleinige Last ihrer Lebensplanung und Existenzsicherung auf und versetze sie damit in vermehrte Abhängigkeit vom Arbeitsmarkt und damit von Bildung, Konsum, sozialer Versorgung, Verkehrsplanungen, von "Möglichkeiten und Methoden der medizinischen, psychologischen und pädagogischen Beratung und Betreuung" (Beck 1986: 210). Mit der Lösung aus den traditionellen industriegesellschaftlichen Sozialbeziehungen vollziehe sich die umfassende Vergesellschaftung des Individuums. Einerseits vermehrten sich mit fortschreitender Modernisierung Entscheidungsmöglichkeiten und -zwänge, andererseits werde "die individualisierte Privatexistenz immer nachdrücklicher und offensichtlicher von Verhältnissen und Bedingungen abhängig, die sich ihrem Zugriff vollständig entziehen. Parallel entstehen Konflikt-, Risiko- und Problemlagen, die sich ihrem Ursprung und Zuschnitt nach gegen jede individuelle Bearbeitung sperren" (ebda: 211). Da der Mensch in der Risikogesellschaft nicht in soziale Beziehungssysteme eingebunden sei, finde eine "Individualisierung sozialer Risiken" statt:

"In der Konsequenz schlagen gesellschaftliche Probleme unmittelbar um in psychische Dispositionen: in persönliches Ungenügen, Schuldgefühle, Ängste, Konflikte und Neurosen. Es entsteht - paradox genug eine neue Unmittelbarkeit von Individuum und Gesellschaft, die Unmittelbarkeit von Krise und Krankheit in dem Sinne, dass gesellschaftliche Krisen als individuelle erscheinen und nicht mehr oder nur noch sehr vermittelt in ihrer Gesellschaftlichkeit wahrgenommen werden." (Ebda: 158 f.)

Hier setzten die Thesen von Heitmeyer über die Ursachen des (jugendlichen) Rechtsextremismus ein. Er beschäftigte sich mit der Sozialisation von Jugendlichen im Rahmen des sozialen Wandels moderner Industriegesellschaften und hob dabei besonders die Individualisierungstendenzen hervor: Mit dem Bedeutungsverlust sozialer Milieus, die ehedem eine kollektive Identitätsbildung ermöglichten, seien die Jugendlichen heute auf sich selbst zurückgeworfen. Sie müssten allein mit Ambivalenzkonflikten und Widerspruchskonstellationen fertig werden und folglich höheren Belastungen bei ihrer Identitätsbildung, bei der Ausprägung autonomer Handlungsfähigkeit standhalten.

20 Heitmeyer bezieht sich seinerseits auf Beck.

21 Dabei handele es sich um "patriarchale Argumentationskunst, indem die Ungleichheit zwischen den Geschlechtern nicht wahrgenommen und die Privilegierung und Vorteilnahme von Männern geleugnet wird. Die Ursachen männlicher Dominanz und Gewalt werden immer in den bedauernswerten sozialen Verhältnissen oder der persönlichen Biographie gesucht. Männer werden so gleichermaßen wie Frauen zu Opfern, wenn sie nicht gar die eigentlichen Opfer sind. (...) Das Bedürfnis zur Täterentlastung versteigt sich gar so weit, rechtsextreme Gewalttäter oder Gewaltbefürworter nicht nur zu Opfern widriger Umstände und bedauerlicher Verhältnisse zu machen, sondern sogar ihr Gewalthandeln gegenüber Schwächeren zum Widerstand gegen soziale Ungerechtigkeit hochzustilisieren." (Rommelspacher 1991: 76, 77) 
Das Fehlen sozialer Beziehungen könne dazu führen, dass Jugendliche auf "surrogathafte kollektive Identitäten" (Heitmeyer 1987: 101) setzen, bei denen sie Stärke, Schutz oder Geborgenheit vermuten. Rechtsextreme Orientierungen deuteten auf einen "niedrigen Entwicklungsstand autonomie-orientierter Handlungsfähigkeit und auf einen hohen Anteil von Abhängigkeit" (ebda: 104) hin. Unterschiede zwischen Männern und Frauen wurden von Heitmeyer nicht herausgearbeitet. Nach der Logik des Ansatzes sind beide jedoch gleichermaßen anfällig für Rechtsextremismus.

In dem von Beck entwickelten Modell der postindustriellen Gesellschaft hätten sich durchaus geschlechtsspezifische Anknüpfungspunkte finden lassen: Dauerhafte Konfliktlinien entstünden in der individualisierten Gesellschaft mehr und mehr entlang "zugewiesener", "quasi-naturvermittelter" Merkmale, die nach wie vor mit Benachteiligungen verbunden seien. Beck hob insbesondere Rasse, Hautfarbe, Geschlecht und ethnische Zugehörigkeit hervor (Beck 1986: 159) und beschäftigte sich ausführlich mit der Lage und Beziehung der Geschlechter in der Risikogesellschaft (ebda: 161 ff.). Die der Industriegesellschaft immanente Ungleichheit der Geschlechter stehe "im Widerspruch zu den Prinzipien der Moderne" (ebda: 174) und werde durch fortschreitende Gleichstellung abgelöst $^{22}$, womit die Grundlagen der Familie ins Wanken gerieten. Während bei Männern "selbständige ökonomische Existenzsicherung und alte Rollenidentität" (ebda: 185) zusammenfielen, ergäbe sich für Frauen eine widersprüchliche Situation:

"Unter den Bedingungen der Massenarbeitslosigkeit und der Verdrängung aus dem Arbeitsmarkt sind Frauen zwar freigesetzt von der Eheversorgung, aber nicht frei zu einer eigenständigen Sicherung durch Erwerbsarbeit. Dies bedeutet aber auch: Sie sind nach wie vor zu einem großen Teil auf die ökonomische Sicherung durch den Mann angewiesen, die keine mehr ist. Dieses Zwischenstadium ... wird durch die Rückbindung an Mutterschaft zusätzlich bestärkt... So werden die Frauen durch den Widerspruch zwischen Freisetzung und Rückbindung an die alten Zuweisungen in den weiblichen Lebenszusammenhang hin- und her gerissen." (Ebda: 184)

Diese geschlechtsspezifische Asymmetrie bildete häufig den Ausgangspunkt für die Ursachenanalyse von Rechtsextremismus in der Frauenforschung. Vor allem Gertrud Siller hat sich damals ausführlich mit dieser Thematik beschäftigt und gelangte (ähnlich wie Beck) zu dem Ergebnis, dass die "Diskrepanz zwischen eigenen Lebensplänen und deren Verwirklichungschancen" bei Frauen besonders groß seien, woraus sich auch ihr vergleichsweise hohes anomisches Einstellungspotential erkläre (Siller 1991: 25). Zwar sei eine "Liberalisierung von Weiblichkeitsbildern" zu konstatieren (Siller 1993: 222) und die Frauen hätten auch mehr Selbstverwirklichungsansprüche und höhere Gleichheitserwartungen entwickelt, aber die geschlechtsspezifische Diskriminierung sei faktisch keineswegs geringer geworden ${ }^{23}$. Mithin sei die Lage von Frauen durch einen "größeren historisch-sozialen Kontinuitätsbruch" (Siller 1991: 27) gekennzeichnet als die von Männern.

22 Diese These fand in der feministischen Frauenforschung keine Zustimmung (z.B. Siller 1991: $26 \mathrm{u}$. 1993: 222).

23 Lohmeier (1991: 34) verweist darauf, dass rund 90 Prozent der Mädchen die Vereinbarkeit von Beruf und Familie anstreben und die Hausarbeit mit ihren Männern teilen wollen, wohingegen etwa 80 Pro- 
Auch Birsl ging auf ihrer Suche nach "gravierenden geschlechtsspezifischen Unterschiede(n) in der Verbreitung rechtsextremistischer Orientierungen" davon aus, dass Frauen andere Motivationen für Rechtsextremismus hätten als Männer. Sie seien "das Resultat politischer Umformungsprozesse frauenspezifischer Lebenslagen" (Birsl 1992: 22). Sozialer Wandel, Modernisierung und Individualisierung brächten für Frauen eine wesentlich konfliktreichere Lebenssituation mit sich, als für Männer. Frauen unterlägen

"wesentlich stärker sozialen und historischen Kontinuitätsbrüchen und individuellen Konflikten. Einerseits entsprechen die Sozialisationsnormen und die geschlechtsspezifische Arbeitsteilung der frauenspezifischen Normalbiographie, andererseits haben sich neue Handlungsperspektiven für Frauen geöffnet, die auf ein familienunabhängiges Leben zielen" (ebda: 28).

Sowohl durch den Versuch, Familie und Beruf unter diesen Bedingungen zu vereinbaren (was nach Siller [1991: 29] zu besonders starken Rollenkonflikten führt), als auch der Rückzug in den familiären Bereich könnten ein "Identitätsvakuum" (ebda: 29) verursachen, in das der Rechtsextremismus mit seinen Vorstellungen von der Aufwertung traditioneller Geschlechtsrollen hinein stößt. In einer umfangreichen Studie gelangte Siller später zu der Erkenntnis, dass rechtsextreme Neigungen von Frauen weniger auf erfahrenen Belastungen ihrer doppelten Vergesellschaftung beruhen, sondern vor allem davon abhängen, wie sie diese Erfahrungen deuten und welche Handlungsorientierungen sie daraus entwickeln (Siller 1997: 244).

Birgit Meyer bemühte sich um eine Zusammenschau der Befunde des herrschaftstheoretischen und des modernisierungstheoretischen Ansatzes und arbeitete drei Gesichtspunkte heraus, die Frauen in Dominanzkulturen für Rechtsextremismus zugänglich machten:

- Das Bedürfnis nach Anpassung, Unterwerfung und Selbstaufgabe komme dem Rechtsextremismus bei seiner Anziehungskraft auf Frauen ${ }^{24}$ zugute: $^{2}$

"Das in rechtskonservativen Kreisen wieder belebte und in unserer Gesellschaft mit ihrem Ehe- und Mutterkult nie ganz verschwundene traditionelle Frauenleitbild von aufopfernder Weiblichkeit oder Mütterlichkeit könnte - zur weiblichen Urkraft hochstilisiert - unzweifelhaft wieder Anreiz auf Frauen ausüben. Ein ideologisch propagierter Zwang zur Anerkennung der Sphäre der Mütterlichkeit ist immer, verglichen mit der üblichen Nichtbeachtung, ein perverser Fortschritt. Das kulturell bereitliegende Repertoire der Unterordnung von Frauen unter Männer, die Flucht in einen neuen Privatismus und Familialismus sind in ihrer Anziehungskraft für (junge) Frauen nicht zu unterschätzen." (Meyer 1993: 215)

- Die Bestätigung und Bestärkung dominanter Männlichkeit bedeute für Frauen nicht nur Selbstentwertung, sondern eben auch "Anerkennung, Liebe und Aufwertung" ihrer "quasi natürlichen Eigenschaften" (ebda).

zent der jungen Männer die Ansicht vertreten, dass Frauen auf eine Berufstätigkeit verzichten sollten, wenn in einer Familie kleine Kinder vorhanden sind. Und Meyer (1991: 606) spricht von "eine(r) besondere(n) Konflikthaftigkeit für Mädchen in der strukturellen Widersprüchlichkeit von neuen gesellschaftlichen Lebenslagen und alten, unverändert gebliebenem patriarchalischem Bewusstsein."

24 Möller (1991b: 40): "Die Identifikation mit den alten Bewusstseins- und Verhaltensmustern schafft einen Grundbestand von Orientierungssicherheit, der erlittenen oder antizipierten Modernisierungsverlusten entgegengesetzt werden kann." Ähnlich auch Hentges (1993: 45). 
- Da Angst und Selbsthass als zentrale Ursachen für Rechtsextremismus anzusehen seien, wäre es durchaus denkbar, dass Frauen anfälliger für "projektives Ausagieren" seien als Männer:

"Die unbewusste Verachtung für die eigene Person, die auf andere, eben auf die 'Fremden', umgeleitet werden kann, ist in unserer patriarchalen Kultur aufs engste verbunden mit einer Frauenmissachtung, mit einer Verachtung von so genannten weiblichen Werten und Eigenschaften, und somit kulturell auch bei Frauen selbst tief verwurzelt." (Ebda: 216)

Rechtsextreme Ideologien könnten also, so bilanzierte Hentges, für Frauen "funktional" sein, "weiblicher Rechtsextremismus" sei "eine Ideologie der Überlegenheit der Unterlegenen" (Hentges 1993: 45, 46). In diesem Zusammenhang steht auch die Kontroverse um die Bedeutung des althergebrachten Frauen- und Familienbilds rechtsextremer Parteien und Gruppierungen für die Hinwendung von Frauen zum Rechtsextremismus. Mehrheitsmeinung war wohl, dass bei allen Unterschieden im Detail die patriarchale Familie im völkisch-nationalistischen Denken als Keimzelle des Volkes und des Staates gilt (Rommelspacher 2000: 207 ff.). Die Unterschiede zwischen den Geschlechtern würden nicht als historische und soziale Konstrukte (Müller 2005: 87 ff.), sondern als naturgegeben angesehen, die Rolle der Frau als Hausfrau und Mutter werde nicht in Frage gestellt, auch nicht für berufstätige Frauen. Die familienpolitischen Vorstellungen des Rechtsextremismus verbänden sich oft mit bevölkerungspolitischen Zielen (Jäger 1992) und richteten sich ausschließlich an Frauen, Reformvorschläge zielten auf die Verbesserung ihrer Lage als Hausfrauen und Mütter (Vereinbarkeit von Familie und Beruf, soziale Absicherung) (Amesberger/Halbmayr 2002c: 415 ff.). Zwar wendeten sich rechtsextreme Frauen teilweise gegen eine geschlechtsspezifische Arbeitsteilung und forderten Gleichberechtigung in Beruf und Politik (für deutsche Frauen), das "naturalistisch und biologistisch begründete Verständnis von der Ungleichheit der Menschen" (Birsl 1992: 22) werde aber nicht in Zweifel gezogen.

Diese Sichtweise, die (explizit oder implizit) einen Zusammenhang von Sexismus und Rassismus unterstellte, wurde von einigen Wissenschaftlerinnen in Frage gestellt, die ausführliche Interviews mit rechtsextremen Frauen (vor allem allerdings mit Aktivistinnen) geführt hatten (v.a. Bitzan 2005) und zu dem Ergebnis gelangt waren, dass ihre Interviewpartnerinnen teilweise über ein recht modernes, auf Gleichberechtigung pochendes Frauenbild verfügten. Dies löste eine Debatte darüber aus, ob unter rechtsextremen Frauen eine "Modernisierung" ihres Selbstbildes oder sogar "Antisexismus" zu beobachten sei, ob es einen "rechten Feminismus" gäbe ${ }^{25}$ und ob der Feminismus Anknüpfungspunkte für rechtsextreme Frauen bietet (zusammenfassend Rommelspacher 2000: $214 \mathrm{ff}$.). Dieses Problem kann hier vernachlässigt werden, da auf einer hoch aggregierten Ebene geforscht und argumentiert wird. Entscheidend ist, dass daraus die Schlussfolgerung gezogen wurde, dass die Hinwendung von Frauen zum Rechtsextremismus nicht auf dem von inm propa- 
gierten Frauenbild beruht, sie erfolge vielmehr wegen der Ideologie im Allgemeinen und wegen der Zielvorstellungen in der Ausländerpolitik, in der Wirtschafts- und Sozialpolitik und in der inneren Sicherheit oder wegen des Geschichtsrevisionismus (Amesberger/Halbmayr 2002b: 45, 2002c: 419 ff.; Dettling/Goltz 1995: 43; Ottens 1997a: 186; Schwarzmeier/Wunderlich 1996: 71).

Dass Rechtsextremismus gerade auch für Männer "funktional" sein kann, wurde mit anderen Motiven und Zielen dieses Geschlechts begründet. Nach Siller (1991: 28 f.) wird das Selbstverständnis des für den Schutz und die Ernährung der Familie allein zuständigen Mannes angesichts von Massenarbeitslosigkeit und Frauenemanzipation ausgehöhlt, was zu Verunsicherung und Identitätskrisen führen könne. Der Rechtsextremismus kitte mit seinem reaktionären Frauenbild das angeschlagene männliche Selbstwertgefühl, indem er den starken Mann, die Höherwertigkeit des deutschen Mannes propagiert.

Möller wähnte nicht die Frauen sondern die Männer infolge des sozialen Wandels als besonders bedroht und sah im neuerlichen Aufschwung des Rechtsextremismus "eines der letzten Gefechte braun behemdeter Männerbataillone im verzweifelten Abwehrkampf gegen den allmählichen Untergang des Patriarchats" (Möller 1991b: 40). Und weiter:

"Unter der Perspektive geschlechtsspezifischer Anfälligkeit erscheint es so, als sei das männliche Geschlecht verschärft von den Schattenseiten dieser gesamt-gesellschaftlichen Entwicklung betroffen. Die Auflösung tradierter 'Normalitäten' und Selbstverständlichkeiten an den verschiedenen Fronten, u.a. die Erosion der um den Ernährer zentrierten 'Normalfamilie', das Obsoletwerden der 'Normalität' einer engen Verknüpfung von Erstausbildungsniveau und Platz in der späteren Berufshierarchie, das allmähliche Verschwinden von 'Normalarbeitsverhältnissen', das Zerbröseln der 'Normalität' einer selbstverständlichen Einbindung in Arbeitskollektiv und Gewerkschaft, die Auflösung der geschlechtsspezifischen 'Normalbiographien', führt in Verbindung mit dem Aufkommen weiblicher Emanzipationsinteressen und ihrer allmählichen Durchsetzung zu einer tief greifenden Verunsicherung der Männerrolle und des Bildes von Männlichkeit." (Ebda: 39)

Nach Ogrzall (1990: 22 f.) sind es vor allem Resignation, fehlendes Selbstwertgefühl, Verunsicherungen und Brüche in der eigenen Identitätsbildung der männlichen Jugendlichen, ihre Angst, kein richtiger Mann zu sein, die das männliche Selbstbildnis ins Wanken bringen. Daraus erwachse das Bestreben, Männlichkeit zu beweisen, die Suche nach starken Männergemeinschaften. Es seien gerade Jungen aus den unteren sozialen Schichten, die auf derartige Verunsicherungen mit einer "extremen Überbetonung männlicher Eigenschaften reagieren". Damit sei die Instrumentalisierung des eigenen Gefühlslebens verbunden:

"Wenn keine Ängste und Schwächen nach außen hin sichtbar zugelassen werden dürfen, wenn Männlichkeit demonstriert werden muss, dann erfolgt nahezu zwangsläufig eine Panzerung des eigenen Gefühlslebens, um die äußere Fassade überhaupt aufrechterhalten zu können. Die Folgen davon sind u.a. die Unterdrückung bestimmter Affekte, die Reduzierung der Sexualität 'auf das einzige Lustzentrum Penis' und die Unterdrückung vielfältiger Bedürfnisse (Nähe, Wärme, Zulassen von Unsicherheiten)... Aber dieser Panzer ist keineswegs stabil. Einflüsse von außen gefährden und bedrohen ihn... Alles Fremde, Andersartige (z.B. Homosexualität), alles was durch seine bloße Existenz an die eigenen verdrängten und unterdrückten Persönlichkeitsanteile erinnert, muss beseitigt werden." (Ebda: 23) 
Zu einem ähnlichen Ergebnis gelangten auch Rippl u.a. (1998) mit ihrer streng empirisch ausgerichteten, auf einer übersichtlichen Variablenstruktur basierenden Studie. Sie führten den Geschlechterunterschied bei rechtsextremen Einstellungen auf unterschiedliche Wertorientierungen zurück: Individualisierungstendenzen verstärkten besonders bei Männern Leistungsorientierung, Konkurrenzdenken und Durchsetzungsfähigkeit, während Frauen humanistische und prosoziale Orientierungen höher bewerteten. Das männliche Bedürfnis nach Dominanz, Macht und Erfolg weise eine stärkere Affinität zum Rechtsextremismus auf als weibliche Attribute wie Fürsorglichkeit, Rücksichtnahme und Anpassungsfähigkeit (ebda: 762 f.). Diese Ausgangsthesen konnten im Großen und Ganzen auch empirisch bestätigt werden. Entscheidend für den Geschlechterunterschied beim Rechtsextremismus sind offenbar nicht - wie schon Siller konstatierte - soziale Erfahrungen sondern ihre subjektive Verarbeitung zu spezifischen Überzeugungen.

In der Quersumme aller Diskussionsbeiträge bleibt offen, ob Männer oder Frauen vom sozialen Wandel, von den Individualisierungs- und Desintegrationsvorgängen besonders betroffen sind und welches der beiden Geschlechter mehr Anlass hat, seine problematische soziale Lage mit Hilfe von rechtsextremen Angeboten im Sinne einer patriarchalen Dominanzkultur zu verarbeiten. Diese Unklarheit wurde vermutlich deshalb nicht als besonders dramatisch empfunden, weil alle Beteiligten davon ausgegangen sind, dass Frauen genauso häufig rechtsextreme Einstellungen entwickeln wie Männer und dass die Aufgabe vor allem darin bestanden habe, die rechtsextremen Neigungen von Frauen zu erklären, seien sie nun genauso oder weniger sexistisch eingestellt wie Männer.

Die Unklarheit bezüglich der geschlechtsspezifischen Betroffenheit vom sozialen Wandel hatte zur Folge, dass weder der herrschaftstheoretische noch der modernisierungstheoretische Ansatz überzeugend erklären konnte, warum beide Geschlechter beim Wahlverhalten zugunsten rechtsextremer Parteien (damals der Republikaner) so unterschiedlich reagieren. Als die männlich dominierte Wahlforschung in Vorlage trat, erntete sie teilweise bissige Kritik aus den Reihen der Frauenforschung. Roth (1989: 11 f.) hatte den Gender Gap zunächst mit dem vergleichsweise geringen politischen Interesse von Frauen erklärt ${ }^{26}$ und damit, dass Frauen "zurückhaltender und abwartender als Männer" auf neue Entwicklungen reagierten und sich, wie das Beispiel der Grünen gezeigt habe, erst mit zeitlicher Verzögerung veränderten Gegebenheiten anpassten. Später präzisierte er:

"Höheres Interesse an Politik bei Männern bedeutet nicht, dass die Wähler der Republikaner politisch stärker interessiert sind als andere Wähler, sondern lediglich, dass Männer qua höherem Interesse neue politische Bewegungen früher wahrnehmen als Frauen und deshalb auch neuen Parteien gegenüber aufgeschlossener sind als Frauen. Die sich daraus ergebende Hypothese, dass nach eine Phase der Zurückhaltung sich Frauen dem Verhalten der Männer angleichen, stimmt in jüngster Vergangenheit für die GRÜNEN, kann dort möglicherweise aber auch anders erklärt werden; die These stimmt historisch auch

26 Hentges (1993: 42) glaubte beispielsweise, dass das politische Interesse schon deshalb als Wahlmotivation ausschied, weil die Republikaner in ihren Wahlkämpfen "weniger explizit politisch Interessierte angesprochen, als vielmehr dumpfe Affekte bedient" hätten. 
für die NSDAP. Für die NPD oder die Republikaner konnte dieser Satz empirisch nie überprüft werden, weil beide Parteien als relevante Größen im Parteiensystem zu schnell wieder verschwunden waren." (Roth 1990: 30 ff.)

Roth räumte zudem ein, dass das (patriarchale und aggressive) Erscheinungsbild der rechtsextremen Parteien offensichtlich von größerer Erklärungskraft für das Wahlverhalten von Frauen sei als ihr politisches Interesse. Dass er dieses in Beziehung zum weiblichen Wahlverhalten gesetzt hatte, löste in der Frauenforschung heftige Reaktionen aus. So behauptete beispielsweise Hentges, dass sich das politische Interesse von berufstätigen Frauen und berufstätigen Männern nicht unterscheide. Diese - übrigens nicht durch Zahlen belegte ${ }^{27}$ - Behauptung verband sie mit folgender Schlussfolgerung:

"Daran wird deutlich, dass nicht etwa die Geschlechtszugehörigkeit ein politisches Interesse determiniert, sondern dieses vor allem durch die realen - über die Erwerbstätigkeit vermittelten - Lebenserfahrungen bestimmt wird. Die von Roth zur Erklärung geschlechtsspezifischen Wahlverhaltens herangezogene ... Umfrage könnte in dem Sinne missverstanden werden, dass Frauen - qua Geschlechtszugehörigkeit unpolitischer seien." (Hentges 1993: 41 f.)

Auch Meyer (1991: 609 f.) verwies das "angebliche politische Desinteresse von Frauen" in den Bereich "oberflächlicher Uralterklärungen" zumeist männlicher Wahlforscher, denen ein "traditioneller, enger Politikbegriff" zugrunde läge, der sich an "institutionalisierter Partei- oder Regierungspolitik" orientiere "oder an dem, was die männlich dominierten Redaktionen unserer Medien darunter verstehen".

"Mit dem Slogan 'Das Private ist politisch!' (Hv. i.O.) erweiterte die Frauenbewegung die gesellschaftliche Diskussion um bislang von der Privatsphäre verdeckt gehaltene Probleme, die aber politischgesellschaftlich brisant sind: Themen wie Liebe, Sexualität, Hausarbeit, Beziehungsmuster u.ä. galten bislang als naturhaft-fixiert oder privat-unberechenbar. Erst die Frauenbewegung hat sie öffentlich zum politischen Thema gemacht. Die größere Distanz zu den männlichen Ritualen des uns täglich als Politik präsentierten Schaulaufens darf keinesfalls mit politischer Apathie verwechselt werden." (Meyer 1991: 610)

Damit wurde unterstellt, dass mit der Frage nach dem politischen Interesse ein institutionelles Politikverständnis gemessen wird. Und weil institutionelle Politik von der Frauenbewegung als männliche Veranstaltung erkannt und kritisch bewertet werde, ließe sich mit diesem Messinstrument das tatsächliche politische Interesse von Frauen nicht abbilden. Dieses habe sich beispielsweise in den außerparlamentarischen Bewegungen der achtziger Jahre manifestiert, in denen Frauen die Mehrheit ausgemacht hätten (ausführlich Meyer 1992).

Selbst wenn die Kritik berechtigt gewesen wäre, dass Roth fahrlässigerweise einen Subgruppenvergleich (berufstätige Männer und berufstätige Frauen) in Bezug auf das politische Interesse nicht durchgeführt hat, so ändert dies doch nichts an der Tatsache, dass Frauen im Durchschnitt gerin-

27 Offenbar bezog sich Hentges auf Hofmann-Göttig (1989b: 30), der unter Berufung auf eine Umfrage im Saarland die These vom geringeren politischen Interesse der Frauen "differenziert" wissen wollte, denn die voll berufstätigen Frauen hätten in dieser Umfrage "fast die Durchschnittswerte aller Beteiligten" erreicht. 
ger politisch interessiert sind als Männer (Westle/Schoen 2002: 220). Weiterhin gilt, dass "Frauen in der Einschätzung ihrer politischen Fähigkeiten erheblich selbstkritischer sind als Männer, und dies deutlich mit ihrem im Durchschnitt geringeren politischen Interesse korrespondiert" (ebda: 238). Bei der konventionellen Partizipation schneiden Männer ebenfalls besser ab als Frauen, bei der unkonventionellen Beteiligung schrumpft der Gender Gap etwas, von Gleichstand kann allerdings keine Rede sein (Hoecker 1995: 163 ff.; siehe auch Molitor 1993). Der besteht lediglich bei der unkonventionellen Partizipation von berufstätigen Frauen (Molitor 1992: 163). Keine Beachtung fand die Frage, ob rechtsextreme Frauen politisch weniger interessiert sind als rechtsextreme Männer.

Wenn die Angebotsseite in den Blick genommen wird, dann wiederholen sich die Argumente, die im Zusammenhang mit der Attraktivität des völkisch-nationalistischen Frauenbildes für die Ausprägung von rechtsextremen Einstellungen vorgetragen wurden. Da bekannt ist, dass die Anhängerschaft der rechtsextremen Parteien nur zu etwa einem Drittel aus Frauen besteht, sind die Vertreter der These, dass Sexismus dabei keine (oder nur eine sehr geringe) Rolle spielt, einem erhöhten Begründungszwang ausgesetzt.

Däubler-Gmelin/Kießler (1990) analysierten die Programme rechtsextremer Parteien bezüglich ihrer Aussagen über die Rolle der Frauen in der Gesellschaft und entdeckten dabei den "letzten politischen Hort für ein überlebtes patriarchalisches Weltbild" (ebda: 127), das insbesondere "Männer, bei denen Emanzipation und Quotenregelungen Ängste und Identitätsprobleme auslösen" (ebda: 129) anspräche ${ }^{28}$. Ebenso Jansen (1989: 84): Die Frauenpolitik der Republikaner sei "durch und durch eine Politik der Männer". Die Partei dürfte es daher schwer haben, bei Frauen nennenswerte Zustimmung zu finden. "Die heutigen Lebensrealitäten stehen dieser Programmatik entgegen."

Hofmann-Göttig (1989), der die Republikaner für "die Männerparteien schlechthin" hielt (ebda: 28) und die These vertrat, dass sich der Gender Gap (anders als bei der NSDAP und den Grünen) auch nicht auf mittlere Sicht schließen werde, sah die Ursachen für die männlich geprägte Wählerschaft weniger in der Statusverunsicherung der Männer infolge der allmählichen Durchsetzung weiblicher Emanzipationsinteressen, sondern in der für "männliche Ellenbogenpolitik" typischen "Ausrufezeichen-Botschaft" "Ausländer raus!". Dem häufig genannten Bedrohungsgefühl von Männern angesichts der Emanzipationstendenzen maß er allenfalls eine geringe Bedeutung bei, da "für breite Schichten der Bevölkerung der Gleichstellungsanspruch zur demokratischen Selbst-

28 '"Republikaner' stellen mit ihrer Fremdenfeindlichkeit und ihrer Repressions-Propaganda Themen in den Vordergrund, die für Frauen nicht die zentralen Fragen der modernen Gesellschaft sind. Für Frauen sind Fragen der Umwelt, der Ressourcenschonung, die großen Probleme von Frieden und Abrüstung, aber auch konkrete Ansätze in der Bildungspolitik und in den Fragen der Gleichstellung von Mann und Frau wichtig. Ihnen geht es um eine humane, um eine lebens- und liebenswerte Umwelt." (DäublerGmelin/Kießler 1990: 132). 
verständlichkeit geworden ist" (ebda: 31). Da sich mit einem anachronistischen Frauenbild kaum mehr eine "moderne Frau" an die Wahlurne locken lasse, so die vielfach geäußerte Beobachtung in der Literatur, seien die rechtsextremen Parteien auch bestrebt, ihre Frauen- und Familienprogrammatik zu modernisieren. Dass gleichwohl immerhin ein Drittel des REP-Elektorats aus Frauen bestand, wurde damit erklärt, dass das Programm der Republikaner durchaus Anziehungskraft auf spezifische weibliche Mentalitäten ausübte:

"Eine Ursache könnte die Auflösung von traditionellen Rollenmustern sein, die gerade Mädchen und junge Frauen in einer Phase, wo sie ihre Identität ausbilden und auf der Suche nach Orientierungen sind, verunsichert. Durch die Vermittlung von traditionellen Männlichkeits- und Weiblichkeitsidealen erhalten Mädchen wie Jungen klare Orientierungen. Die ideologische Erhöhung der Mutterrolle bietet verunsicherten Mädchen und jungen Frauen die Kompensation eines erlebten Selbstwertverlustes an." (Oltmanns 1990: 44)

Hentges (1993) widersprach dieser These vehement. Zunächst wendete sie sich gegen die Charakterisierung der Republikaner als "Männerparteien", weil damit die "Wählerinnen und Sympathisantinnen aus der Verantwortung" (ebda: 39) genommen würden. Sie glaubte auch nicht, dass sich bei den Anhängerinnen der Republikaner "eine überdurchschnittlich starke Affinität zu Rollenklischees" (ebda: 44) nachweisen ließe. Es seien erwiesenermaßen nicht nur unterprivilegierte Frauen mit niedriger Schulbildung, die sich der Schönhuber-Partei zuwendeten, sondern eben auch gesellschaftlich privilegierte Frauen:

\begin{abstract}
"An dieser Stelle werden ... die Grenzen einer Argumentation spürbar, die vor allem den Gewinn an Orientierungssicherheit in den Mittelpunkt stellt und die Attraktivität des Rechtsextremismus für Frauen und Mädchen auf die Wiederbelebung des traditionellen Geschlechterverhältnisses zurückführt. Wenn die sozialstrukturelle Zusammensetzung der WählerInnenbasis der 'Republikaner' darüber Aufschluss gibt, dass nicht nur unterprivilegierte Frauen mit niedriger Schulbildung, sondern auch privilegierte, hoch qualifizierte Frauen dieser Partei ihre Stimme gegeben haben, ist es offensichtlich, dass die Wahlentscheidung für die 'Republikaner' als Ausdruck einer Privilegiensicherung der Ersten gegenüber der Dritten Welt gewertet werden muss. Die Programmatik und Propaganda der Extremen rechten diskreditiert Flüchtlinge und MigrantInnen und erteilt nicht nur innen, sondern der Dritten Welt eine Kampfansage." (Ebda )
\end{abstract}

Dass Frauen deutlich weniger zu Gewalt neigen als Männer, bestritt eigentlich nur Lohmeier (1991: 34). Sie führte als Beleg dafür die (aus der geschlechtsspezifischen Zusammensetzung der RAF und der "Bewegung 2. Juni" gewonnene) Beobachtung an, "dass die Beteiligung von jungen Frauen an gewaltbereiten Gruppen des linken Spektrums nahezu viermal so hoch war wie die an rechten Gruppen". Konsequenz: "Es scheint offenbar nicht die Variable 'Extremismus' für Erklärungen tauglich ohne die Betrachtung der speziellen Botschaften, die die jeweiligen Gruppen transportieren."

Die vergleichsweise geringe Gewaltbereitschaft von Frauen beruht nach Siller darauf, dass die weiblichen Lebenserfahrungen durch Gewalt von Männern gegenüber Frauen geprägt seien ${ }^{29}$. Frauen erlebten Gewalt als Opfer. "Sowohl öffentliche als auch private Gewaltausübung bleibt fast

29 Zur Verbindung von Sexismus, Rassismus und Gewalt vgl. Wobbe 1994; zum Forschungsstand über Gewalt gegen Frauen: Dobash/Dobash 2001; Hagemann-White 2001. 
ausschließlich den Männern vorbehalten" (Siller 1991: 29). Der Frauenrolle werde nach wie vor Emotionalität, Fürsorglichkeit, Nachgiebigkeit und Anpassungsfähigkeit zugeschrieben. Frauen verfügten deshalb aber nicht notwendigerweise über weniger Aggressionspotential als Männer, ihnen stünden allerdings weniger Möglichkeiten zur Verfügung, Konflikte und Probleme durch aggressives oder gewalttätiges Handeln zu bearbeiten. Sie äußerten Aggressivität "eher auf Umwegen, in indirekter Form" (ebda: 30$)^{30}$, beispielsweise durch die Delegation von Gewalt gegen Ausländer an Männer, oder, so Birsl (1992: 26), durch die Befürwortung staatlicher Repressionsmaßnahmen. Überhaupt vermittele die frauenspezifische Sozialisation einen anderen Umgang mit Konflikten. Frauen kämpften nicht selbst, sie "lassen kämpfen" (Meyer 1993: 215). Mehr noch: "Wer die Benachteiligungen durch Ungleichbehandlungen als deren Konsequenz zu tragen hat, wird stärker für eine Wertschätzung von Gleichheit und Gleichbehandlung sensibilisiert sein." (Möller 1991b: 37) Differenzierter argumentieren Holzkamp/Rommelspacher (1991a: 19): Frauen gäben als Diskriminierte "nicht nur die Unterdrückung weiter, sondern sie können sich in die Unterdrückung auch eher einfühlen und die Unmenschlichkeit mitempfinden."

"Dass es vor allem Jugendliche sind, die sich dazu [zur Gewalt] berufen fühlen, ist klar: weil die Jugendzeit die Phase ist, in der die Gesellschaft Regelverletzungen in einem gewissen Rahmen zugesteht, und das selbstredend in erster Linie den Männern. Insofern sind männliche Jugendliche die geeigneten Projektionsfiguren für unbewusste gesellschaftliche Aggressionen. Sie leben die gewalttätigen, menschenverachtenden Phantasien aus, mit dem Resultat, dass sich alle anderen von ihrer eigenen Beteiligung freisprechen können. Sie können sich projektiv entlasten und haben selbst nichts mehr damit zu tun." (Rommelspacher 1993c: 76)

Welche Schlussfolgerungen ergeben sich nun für die Entwicklung von operationalisierbaren Konzepten für Survey-Studien aus dem heterogenen, weithin widersprüchlichen Diskussions- und Forschungsstand? Im Wesentlichen geht es um zwei offene Fragen: Zunächst ist strittig, ob Männer wegen ihres ins Wanken geratenen Selbstbildnisses oder Frauen wegen der Belastungen aus ihrer doppelten Vergesellschaftung anfälliger für Rechtsextremismus sind. Angenommen, beide Geschlechter entwickelten - wenn auch aus unterschiedlichen Gründen - in demselben Umfang rechtsextreme Einstellungen, dann ist immer noch ungeklärt, ob sich Frauen dem Rechtsextremismus trotz oder gerade wegen seines sexistischen Frauenbildes zuwenden. Diese Frage wird allerdings nicht für Männer gestellt. Dass diese sich von Rechtsextremismus auch die Bewahrung des Patriarchats versprechen, gilt offenbar als ausgemacht. Daraus folgt, dass im Bewusstsein der Männer eine enge Beziehung zwischen Sexismus und Rassismus bestehen muss.

30 "Offensichtlich drückt sich Fremdenfeindlichkeit von Frauen weniger in aggressiven Parolen gegen ausländische Arbeitnehmer aus. Vielmehr könnte sie sich zeigen in der alltäglichen Sorge um ihre Familie, z.B. bei Schulklassen mit hohem Ausländeranteil, in der Angst vor Überfremdung, wenn es um die eigenen Kinder geht. Oder sie drückt sich aus in Angst vor Fremden bzw. in einem Gefühl physischer Bedrohung durch ausländische Männer. (...) In der Aggressionsforschung wird angenommen, dass Frauen eher in indirekter Form aggressiv sind, z.B. durch Ignorieren, Vermeiden, Ausschließen, Zurückweisen, Anstacheln etc." (Siller 1992: 63 f.) 
Während der herrschaftstheoretische Ansatz eine derartige Verbindung auch für Frauen nahe legt, hebt der modernisierungstheoretische Ansatz den qualitativen Unterschied zwischen sexistischer und rassistischer Diskriminierung hervor und bescheinigt auch rechtsextremen Frauen in einem gewissen Umfang Emanzipationsbestrebungen. Daher folgten sie rechtsextremen Verheißungen trotz des traditionalistischen Frauenbildes. In der Konsequenz bedeutete dies, dass zwischen einem männlichen, sexistischen Rechtsextremismus und einem weiblichen, nicht-sexistischen Rechtsextremismus zu unterscheiden wäre. Wenn Frauen aber Rechtsextremismus wegen seiner rassistischen, nationalistischen und autoritären Vorstellungen gutheißen, warum sind sie dann so zurückhaltend bei der Wahl rechtsextremer Parteien? Als Erklärung kann der modernisierungstheoretische Ansatz nicht gut deren Frauenprogramme ins Feld führen. Das gilt erst recht für den herrschaftskritischen Ansatz: Wenn die patriarchale Dominanzkultur für Frauen funktional sein kann, dann haben diese Frauen keinen Grund, sich den rechtsextremen Parteien wegen ihres Frauenbildes zu verweigern. Auch hinsichtlich der Gewaltbereitschaft von Frauen bestehen widersprüchliche Positionen: Während der herrschaftstheoretische Ansatz behauptet, Freuen seien keineswegs das friedfertige Geschlecht, sie lehnten lediglich "männlich-chauvinistisches Gebaren" $a b$, betont der modernisierungstheoretische Ansatz wegen der Diskriminierungserfahrungen der Frauen eher ihre sanften, humanen, fürsorglichen und rücksichtsvollen Eigenschaften. Welchem Ansatz man auch immer folgt, irgendwann landet man in einer Sackgasse!

Die Erklärungen der Wahlforschung für den Gender Gap wurden von der Frauenforschung übrigens mit schwachen Argumenten zurückgewiesen. Selbstverständlich sind die Ursachen auch in geschlechtsspezifischen Orientierungen gegenüber der eigenen politischen Rolle (politisches Interesse, politisches Selbstbewusstsein) oder in geschlechtsspezifischen Wertorientierungen zu suchen. Allerdings wurde bislang nicht vergleichend analysiert, wie es um das politische Interesse und um die Wertorientierungen von rechtsextremen Frauen und Männern bestellt ist.

Als Schlussfolgerung für die Analysestrategie ergibt sich ein exploratives Vorgehen, wobei es die zur Verfügung stehenden Daten nicht gestatten, alle angesprochenen Probleme und Forschungsdefizite zu bearbeiten. Im 5. Abschnitt werde ich mich mit dem latenten Rechtsextremismus befassen, vor allem mit der Geschlechterdifferenz bei rechtsextremen Einstellungen und mit den Beziehungen zwischen Rechtsextremismus und Sexismus. Im 6. Abschnitt geht es um den manifesten Rechtsextremismus, also um Verhalten bzw. Verhaltensdispositionen bei Männern und Frauen. Untersuchungsgegenstand sind zunächst die NPD-Wähler bei der Bundestagswahl 2005, sodann die Ursachen für eine positive Beurteilung der NPD und schließlich die Gewaltbereitschaft von Rechtsextremisten. Dabei werde ich mich bei der Analyse und Interpretation auf zwei Probleme konzentrieren: auf den Gender Gap im Rechtsextremismus und auf die Bedeutung des Sexismus für Rechtsextremismus. Dahinter verbirgt sich die Leitfrage, ob ein Zusammenhang zwischen Sexismus und dem Gender Gap besteht. Die präsentierten Daten weisen gelegentlich über diesen 
(engen) Rahmen hinaus, ohne dass ich diese zusätzlichen Informationen immer in meine Betrachtungen einbeziehe. Für eilige Leserinnen und Leser werden die empirischen Analysen jeweils zu einem Fazit verdichtet, und der 7. Abschnitt enthält eine Zusammenfassung der Untersuchungsergebnisse.

\section{Datenbasis und Analyseinstrumente}

Die folgenden Analysen beruhen zumeist auf den Daten der Deutschen Bundestagswahlstudie 2005 ("Bürger und Parteien in einer veränderten Welt"). Es werden hilfsweise aber auch andere Erhebungen herangezogen. Dies ist dann im Text bzw. in den Tabellen ausdrücklich vermerkt. Eine Übersicht über die Datenquellen findet sich in Anhang 1.

Da ich mich bezüglich der Definition von Rechtsextremismus und der Messung von rechtsextremen Einstellungen anderweitig hinreichend geäußert habe (Stöss/Fichter,Kreis/Zeuner 2004: Kap. A u. B; Stöss 2007: Kap. 1 u. 4), teile ich hier nur das Nötigste mit: Beim Rechtsextremismus handelt es sich um völkischen Nationalismus. In der Regel wird zwischen Einstellungen (auch latenter Rechtsextremismus) und Verhalten (auch manifester Rechtsextremismus) unterschieden. Zu den Verhaltensweisen zählen Wahlverhalten, Organisationsmitgliedschaft, politische Aktivität und Gewalt. Rechtsextreme Einstellungen bilden ein mehrdimensionales Syndrom, das sich aus folgenden Bestandteilen zusammensetzt: Befürwortung einer rechtsautoritären Diktatur, Chauvinismus (i.e. übersteigerter Nationalismus), Ausländerfeindlichkeit, Antisemitismus, Sozialdarwinismus und Verharmlosung des Nationalsozialismus. Dieser Katalog wurde von einer Expertenkonferenz entwickelt (Kreis 2007: 9 ff., 17 ff.), die zudem für jede der sechs Dimensionen fünf Statements ausarbeitete. In der Langfassung besteht die Rechtsextremismus-Skala also aus 30 Items. Weiterhin wurde eine Kurzskala mit je einem Statement pro Dimension vorgeschlagen (Kreis 2007: 25), die auch in der Deutschen Bundestagswahlstudie 2005 abgefragt wurden. Die Statements sind in Anhang 2 aufgeführt. Die Antwortvorgaben lauten: 1 "lehne völlig ab", 2 "lehne eher ab", 3 "stimme eher zu", 4 "stimme völlig zu". Statistisch wurde die Skala REX nach dem Likert-Verfahren (Technik der summierten Einschätzungen) konstruiert: Jede Befragungsperson entscheidet selbst über das Ausmaß an Zustimmung zu den einzelnen Skalensätzen. Pro Statement erhält jeder Befragte also einen Wert zwischen 1 und 4. Die sechs Werte werden für jede Person summiert. Maximal können 24 Punkte $(6 \times 4)$ erreicht werden, mindestens jedoch sechs $(6 \times 1)$. Die Skalenwerte reichen mithin von 6 bis 24 (Item-Statistiken in Anhang 2a). Der Schwellenwert (cutting point) für die Bestimmung des rechtsextremen Einstellungspotenzials (REXPOT), für die Identifizierung der Befragten also, die als Rechtsextremisten zu bezeichnen sind, wurde auf das arithmetische Mittel 
(15) festgesetzt. Personen mit mehr als 15 Punkten (also mit Werten zwischen 16 und 24) gelten mithin als rechtsextrem eingestellte Personen (oder auch als Rechtsextremisten).

Da dieses Verfahren gelegentlich als willkürlich und daher als wissenschaftlich unzulässig bezeichnet wird, sei darauf hingewiesen, dass jedes Maß, jedes Messinstrument, jede DIN-Norm willkürlich ist, da es sich dabei stets um eine Übereinkunft handelt. So wurde beispielsweise das Meter Ende des 18. Jahrhunderts als der zehnmillionste Teil des Erdquadranten auf dem Meridian von Paris festgelegt. Heute ist es als die Strecke definiert, die das Licht in einer bestimmten Zeit in einem Vakuum zurücklegt. Ein anderes Beispiel ist die Bestimmung von Windstärken (Zug, Brise, Wind, Sturm, Orkan). Sie folgt zumeist einer (auf der Geschwindigkeit des Windes basierenden) Skala, die Anfang des 19. Jahrhunderts von Sir Francis Beaufort entwickelt wurde. Danach wird aus einem stürmischen Wind ein Sturm, wenn der Beaufort-Wert von acht auf neun steigt (ab 21 Meter pro Sekunde bzw. ab 75,6 Kilometer pro Stunde). Ebenso bedarf es eines Grenzwerts, bei dessen Überschreitung ein rechtsextremes Weltbild vorliegt. Im Unterschied zum Meter oder zur Beaufort-Skala existiert derzeit keine allgemein anerkannte Konvention zur Bestimmung dieses Schwellenwerts. Daraus kann jedoch nicht abgeleitet werden, dass die Fixierung eines derartigen Schwellenwerts unzulässig ist. Das arithmetische Mittel einer Skala (der Skalenwerte, nicht der Messwerte!) erscheint mir als Schnittstelle besonders geeignet, da es in der Statistik als herausragender Parameter ständig Verwendung findet, leicht interpretierbar und gut kommunizierbar ist. Potenzialbestimmungen auf der Basis von Prozentangaben sind unverzichtbar und auch nicht durch Mittelwertvergleiche ersetzbar. Denn im Unterschied zu Mittelwerten sind Prozentangaben eindeutig und nachvollziehbar normiert und daher allgemein verständlich.

Als Prozentuierungsbasis der Potenzialbestimmung werden die gültigen Werte herangezogen, die fehlenden Werte ("missings", nonresponses, Ausfälle) bleiben unberücksichtigt. Dadurch wird das Rechtsextremismuspotenzial keineswegs überschätzt. Die Tabelle im Anhang $2 f$ zeigt, dass die "Antwortverweigerer" (die Männer etwas mehr als die Frauen) stärker rechtsextrem eingestellt sind als die "Antwortgeber". Das bedeutet, dass auch mit diesem Vorgehen das Rechtsextremismuspotenzial unterschätzt wird. Würden die Ausfälle in die Prozentuierungsbasis aufgenommen, fiele die Unterschätzung noch größer aus. So gelangen wir zu dem Befund, dass 200512 Prozent der Befragten (Männer 15\%, Frauen 9\%) rechtsextrem eingestellt waren (Anhang 2c).

Bei kumulierten Skalen wird die Anzahl der Statements gezählt, die die Befragten positiv beantwortet haben. Bei sechs Skalensätzen reichen die Skalenwerte von null (keinem Statement zugestimmt) bis sechs (allen sechs Statements zugestimmt). Für die kumulierte RechtsextremismusSkala verwende ich das Kürzel REXKUM. 
Bezüglich der Definition von Sexismus orientiere ich mich am "Lexikon zur Soziologie". Danach ist Sexismus

"ein analog zum Terminus Rassismus gebildeter Begriff zur Bezeichnung von Vorurteilen und Diskriminierungen aufgrund der Geschlechtszugehörigkeit. Wegen der in den meisten Gesellschaften vorherrschenden patriarchalischen Strukturen wird S. fast ausschließlich zur Kennzeichnung von diskriminierenden Einstellungen und Handlungen gegenüber Frauen verwendet, bzw. zur Kennzeichnung von Bevorzugung und Verherrlichung des männlichen Geschlechts." (Fuchs-Heinritz u.a. 1994: 599)

Bei der Messung von sexistischen Einstellungen greife ich im Prinzip auf das Konzept der Geschlechtsrollenorientierung (Krampen 2007) zurück:

"Geschlechtsrollenorientierungen werden als die normativen Konzeptionen eines Individuums über angemessenes Verhalten von Frauen und Männern definiert. Mit Geschlechtsrollenorientierung werden also normative Einstellungsaspekte bezeichnet, die moralische Wertungen darüber beinhalten, wie sich Männer und Frauen verhalten sollten und wie sie sein sollten." (Glöckner-Rist 2007)

Die in der Bundestagswahlstudie 2005 zur Verfügung stehenden Statements (Anhang 4) entstammen zwar nicht der Batterie von Krampen, entsprechen aber in etwa dem Konzept der Geschlechtsrollenorientierung. Die Bildung des Index Sexismus (SEX) erfolgte analog zur Konstruktion der Rechtsextremismus-Skala (Details in Anhang 4). Der Anteil der sexistisch eingestellten Personen (SEXPOT) betrug 200516 Prozent (Männer 21\%, Frauen 11\%) (Anhang 4e).

Weitere bedeutsame Variablen werden im Anhang vorgestellt. Bei der Bildung von Indizes folge ich zumeist der Likert-Technik. Auf Abweichungen und Besonderheiten wird ausdrücklich hingewiesen.

\section{Latenter Rechtsextremismus}

\section{a) Geschlechtsspezifische Aspekte der Potenzialbestimmung}

In der Literatur wird ein enger Zusammenhang hergestellt zwischen der Verbreitung von rechtsextremen Einstellungen und der Sozialisation, der Lage und der Beziehung der Geschlechter in der durch raschen sozialen Wandel gekennzeichneten postindustriellen Gesellschaft. Dass von dieser Entwicklung beide Geschlechter betroffen sind und Anlass haben, ihre (wen auch unterschiedlichen) sozialen Erfahrungen und problematischen Lagen im Sinne des Rechtsextremismus zu deuten und zu verarbeiten, ist unstrittig. Diskutiert wird die Frage, ob die mit dem Kontinuitätsbruch verbundenen Belastungen und Herausforderungen asymmetrisch verteilt sind, ob Männer oder Frauen besonders bedroht, benachteiligt oder verunsichert und daher besonders empfänglich für rechtsextreme Angebote sind. Die geschlechtsspezifische Verbreitung von rechtsextremen Einstellungen ist daher in diesem Kontext von großer Bedeutung. 
Zunächst einmal ist festzustellen, dass die empirische Forschung hinsichtlich der Anfälligkeit von Frauen und Männern für rechtsextreme Einstellungen zu sehr unterschiedlichen Befunden gelangt. Mal sind die Männer anfälliger, mal die Frauen. Tabelle 1 vergleicht die Messergebnisse von neun verschiedenen Skalen aus drei Studien, die ihre Statements aus demselben Fundus beziehen. Selbst die "Norm"-Kurzskalen mit sechs identischen Statements (Nrn. e, f, h in Tab. 1) differieren bei der Bestimmung der geschlechtsspezifischen Potenziale (auch für West und Ost) ${ }^{31}$. Die genauen Ursachen lassen sich empirisch nicht exakt ermitteln, weil wir es mit drei verschiedenen Datensätzen zu tun haben. Mit hoher Wahrscheinlichkeit hängen die widersprüchlichen Resultate nicht zuletzt davon ab, ob die Antwortvorgaben über eine Mitte verfügen. Die auch hier zugrunde liegende Skala Nr. f, die Männer beträchtlich rechtsextremer erscheinen lässt als Frauen, unterscheidet nur nach starker und schwacher Zustimmung bzw. Ablehnung, eine neutrale Antwortmöglichkeit (teils-teils o.ä.) fehlt. Das führt dazu, dass diese Skala den bei weitem größten Teil an Ausfällen aufweist (22,6\%). Diese fehlenden Antworten verteilen sich geschlechtsspezifisch asymmetrisch, wie Anhang 2d ausweist: Frauen verweigern die Antwort häufiger als Männer. Der Verzicht auf eine Mitte hat auch den Effekt, dass die mit der summierten und mit der kumulierten Skala (Nrn. f u. g) gemessenen Potenziale übereinstimmen. Die Skala Nr. h verfügt mit dem Wert 3 über einen explizit benannten Mittelpunkt ("stimme teils zu, teils nicht zu"), was allerdings bewirkt, dass der Anteil der Befragten, der sich bei den einzelnen Statements für die Mitte entscheidet, sehr groß ist, wobei davon mehr Frauen als Männer Gebrauch machen. Diese zentrale Tendenz wirkt sich bei den meisten Statements zu Lasten der Zustimmungswerte 4 und 5 aus.

Dafür ist der Anteil der Ausfälle mit 2,1 Prozent allerdings verschwindend gering. Auffällig ist, dass alle Skalen mit einer siebenstufigen Antwortvorgabe (Nrn. a bis e) mehr rechtsextreme Frauen als Männer identifizieren, während es sich bei den Skalen mit vier- oder fünfstufigen Antwortvorgaben (Nrn. f bis i) umgekehrt verhält. Bei den siebenstufigen Antwortvorgaben werden nur die Extrempositionen mit einem Label versehen: 1 "stimme überhaupt nicht zu" und 7 "stimme voll und ganz zu". Sie haben zwar auch eine Mitte (4), aber sie wird nicht explizit benannt. Die Befragten mit mittiger Tendenz schwanken daher zwischen den Werten 3, 4 und 5, wobei der Wert 5 über dem arithmetischen Mittel liegt und damit zum Potenzialbereich zählt. Bei siebenstufigen Antwortvorgaben verteilen sich die Befragten mithin gleichmäßiger über den gesamten Wertebereich als bei vier- oder fünfstufigen Antwortvorgaben. Die Ausfälle bei der "Norm"-Skala Nr. e machen 7,4 Prozent aus (4,2\% bei den Männern und 10,5\% bei den Frauen).

31 Dies zeigt sich auch, wenn der Vergleich mit den arithmetischen Mitteln durchgeführt wird. Aus Platzgründen wird auf den Nachweis verzichtet. 


\begin{tabular}{|c|c|c|c|c|c|c|c|}
\hline \multicolumn{2}{|c|}{ Tabelle 1: } & \multicolumn{6}{|c|}{$\begin{array}{l}\text { Rechtsextremismus in den Gebieten nach Geschlecht (\%) - Messungen mit } \\
\text { verschiedenen Skalen }\end{array}$} \\
\hline \multirow{2}{*}{\multicolumn{2}{|c|}{ Skalen }} & \multicolumn{2}{|c|}{ BRD } & \multicolumn{2}{|c|}{ West } & \multicolumn{2}{|c|}{ Ost } \\
\hline & & Männer & Frauen & Männer & Frauen & Männer & Frauen \\
\hline \multirow[t]{5}{*}{ Stö } & $\mathrm{REXL}^{\mathrm{a})}$ & 17 & 23 & 15 & 21 & 26 & 28 \\
\hline & $\mathrm{REXKUM}^{\mathrm{b})}$ & 13 & 16 & 11 & 14 & 19 & 20 \\
\hline & $\mathrm{REXH} \mathrm{H}^{\mathrm{c})}$ & 7 & 10 & 6 & 9 & 12 & 15 \\
\hline & $R E X W^{d)}$ & 27 & 33 & 25 & 32 & 36 & 36 \\
\hline & $\mathrm{REXN}^{\mathrm{e}}$ & 15 & 17 & 13 & 15 & 21 & 27 \\
\hline \multirow[t]{2}{*}{ Küh } & $R E X^{f)}$ & 15 & 9 & 14 & 9 & 18 & 10 \\
\hline & REXKUM ${ }^{g)}$ & 15 & 9 & 14 & 9 & 17 & 9 \\
\hline \multirow[t]{2}{*}{ Bräh } & REX ${ }^{h)}$ & 19 & 14 & 19 & 13 & 17 & 14 \\
\hline & REXKUM') & 7 & 5 & 8 & 5 & 5 & 4 \\
\hline
\end{tabular}

Die Befunde sind repräsentativ für die wahlberechtigte Bevölkerung.

a) Stöss u.a. 2003; Langfassung, 30 Statements, summiert, Antwortvorgaben: 7er Skalen von 1 ("stimme überhaupt nicht zu") bis 7 ("stimme voll und ganz zu"); nicht im Block, sondern mit anderen Statements gemischt abgefragt.

b) Stöss u.a. 2003; Langfassung, 30 Statements, kumuliert, Antwortvorgaben: 7er Skalen von 1 ("stimme überhaupt nicht zu") bis 7 ("stimme voll und ganz zu"); Zustimmung: Werte 5 bis 7; nicht im Block, sondern mit anderen Statements gemischt abgefragt.

c) Stöss u.a. 2003; "harte" Version, 12 Statements der Langfassung (besonders schwierig, also mit geringem Mittelwert bzw. geringer Zustimmung und ggf. mit vielen fehlenden Antworten), summiert, Antwortvorgaben: 7er Skalen von 1 ("stimme überhaupt nicht zu") bis 7 ("stimme voll und ganz zu"); nicht im Block, sondern mit anderen Statements gemischt abgefragt.

d) Stöss u.a. 2003; "weiche" Version, 12 Statements der Langfassung (mittlere Schwierigkeit), summiert, Antwortvorgaben: 7er Skalen von 1 ("stimme überhaupt nicht zu") bis 7 ("stimme voll und ganz zu"); nicht im Block, sondern mit anderen Statements gemischt abgefragt.

e) Stöss u.a. 2003; "Norm"-Kurzskala, 6 ausgewählte Statements der Langfassung (Kreis 2007; Statements hier im Anhang Nr. 2 aufgeführt), summiert, Antwortvorgaben: 7er Skalen von 1 ("stimme überhaupt nicht zu") bis 7 ("stimme voll und ganz zu"); nicht im Block, sondern mit anderen Statements gemischt abgefragt; fehlende Antworten: 7,4 Prozent.

f) Kühnel u.a. 2005; "Norm"-Kurzskala, 6 Statements (s.o. Nr. e) summiert, Antwortvorgaben: 1 ("lehne völlig ab"), 2 ("lehne eher ab"), 3 ("stimme eher zu"), 4 ("stimme völlig zu"); im Block abgefragt; fehlende Antworten: 22,6 Prozent.

g) Kühnel u.a. 2005; "Norm"-Kurzskala, 6 Statements (s.o. Nr. e) kumuliert, Antwortvorgaben: 1 ("lehne völlig ab"), 2 ("lehne eher ab"), 3 ("stimme eher zu"), 4 ("stimme völlig zu"); Zustimmung: Werte 4 bis 6; im Block abgefragt.

h) Brähler u.a. 2006; "Norm"-Kurzskala, 6 Statements (s.o. Nr. e) summiert, Antwortvorgaben: 1 ("lehne völlig ab"), 2 ("lehne überwiegend ab"), 3 ("stimme teils zu, teils nicht zu"), 4 ("stimme überwiegend zu"), 5 ("stimme voll und ganz zu"); im Block abgefragt; fehlende Antworten: 2,1 Prozent.

i) Brähler u.a. 2006; "Norm"-Kurzskala, 6 Statements (s.o. Nr. e) kumuliert, Antwortvorgaben: 1 ("lehne völlig $a b "), 2$ ("lehne überwiegend ab"), 3 ("stimme teils zu, teils nicht zu"), 4 ("stimme überwiegend zu"), 5 ("stimme voll und ganz zu"); Zustimmung: Werte 4 bis 6; im Block abgefragt.

Siehe auch Anhang 1. 
Da sich die genannten messtechnischen Ursachen für einen möglichen Gender Gap im Bereich des latenten Rechtsextremismus nicht direkt miteinander in Beziehung setzen lassen, kann die Frage also nicht zuverlässig beantwortet werden, ob Männer oder Frauen stärker zu rechtsextremen Einstellungen neigen. Allerdings lassen die bisherigen Analysen vermuten, dass die Ausprägung derartiger Einstellungen durchaus auch von geschlechtsspezifischen Merkmalen im Antwortverhalten gesteuert wird. Darüber sollen nun am Beispiel der hier zugrunde liegenden Rechtsextremismus-Skala REX (Nr. f) einige Vermutungen angestellt werden, die allerdings nicht auf andere Skalen bzw. Untersuchungen übertragbar sind. So verfügen Frauen in unserer Studie häufiger als Männer über ein geringes politisches Selbstbewusstsein (60\% zu 42\%) und sind stärker politisch desinteressiert als diese (25\% zu 13\%). Das dürfte eine Ursache dafür sein, dass sich Frauen öfter als Männer mit der Bewertung der Rechtsextremismus-Statements schwer tun und dass folglich wesentlich mehr weibliche als männliche Antwortverweigerer bei der Potenzialbestimmung unberücksichtigt bleiben (Anhang 2d). Zudem ist das Weltbild der rechtsextremen Männer konsistenter als das der rechtsextremen Frauen, wie aus Anhang 2e hervorgeht. Dies könnte eine weitere Ursache dafür sein, dass Männer häufiger Werte über dem "cutting point" erreichen als Frauen. Auffällig ist, dass Männer den einzelnen Statements nur wenig stärker zustimmen als Frauen, die Unterschiede sind bis auf das NS-Item gering (Anhang 2c). Würde man die geschlechtsspezifische Ausprägung von rechtsextremen Einstellungen nur anhand der Zustimmung zu den Statements beurteilen, käme man zu dem Ergebnis, dass Männer und Frauen nur unwesentlich voneinander abweichen. Erst bei der Potenzialbestimmung mittels der Skala REX offenbart sich der beträchtliche Unterschied.

Es lassen sich also einige Gründe dafür anführen, dass wir in der Bundestagswahlstudie deutlich mehr rechtsextreme Männer als Frauen vorfinden, mehr noch als in der Untersuchung von Brähler u.a. Das "forced choice"-Konzept (der Verzicht auf eine neutrale Mitte bei den Antwortvorgaben) verdrängt augenscheinlich rechtsextreme Frauen stärker als rechtsextreme Männer entweder in die Gruppe der "Nonrespondents" oder in den Wertebereich unterhalb des arithmetischen Mittels.

Fazit: Selbst bei identischen Frageformulierungen haben die Antwortvorgaben geschlechtsspezifische Auswirkungen auf die Bewertung der Statements. Um Ausfälle (insbesondere bei Frauen) gering zu halten, sollten Antwortskalen über eine neutrale Mitte verfügen. In dem hier verwendeten Datensatz wird das Ausmaß von rechtsextremen Einstellungen bei Frauen offenbar unterschätzt. Beim gegenwärtigen Forschungsstand lässt sich die Frage jedenfalls nicht eindeutig beantworten, ob Frauen oder Männer stärker zur Entwicklung von rechtsextremen Orientierungen neigen. Vermutlich besteht kein gravierender Unterschied. Bei der Gewichtung der Argumente, die in der Literatur aus modernisierungstheoretischer und aus herrschaftstheoretischer Perspektive vorgetragen werden, gelange ich persönlich übrigens zu dem Ergebnis, dass Männer und Frauen vom sozialen Wandel zwar unterschiedlich, aber nicht ungleichgewichtig betroffen sind. 


\section{b) Der Index Rechtsextremismus-Sexismus}

Anders als Wahlverhalten, Organisationsmitgliedschaft, politische Aktivität und Gewalt lassen sich rechtsextreme Einstellungen nicht unmittelbar beobachten. Ihre Messung erfolgt durch entsprechende Indikatoren. Das Messergebnis hängt mithin auch von der Auswahl der Indikatoren ab. Bei den bisherigen Messungen könnte es sich um eine systematische Fehleinschätzung des weiblichen Einstellungspotenzials handeln, weil die Indikatorenbildung in der Regel geschlechtsspezifische Faktoren außer Acht lässt.

Bei der Erforschung von rechtsextremen Einstellungen spielten geschlechtsspezifische Aspekte bislang kaum eine tragende Rolle. Ausnahmen bilden einige Jugendstudien, die allerdings keine Verallgemeinerungen für die Bevölkerung insgesamt (oft nicht einmal für Jugendliche bzw. junge Erwachsene) zulassen (z.B. Birsl 1994; Held u.a. 1996; Horn-Metzger/Riegel 1995; UtzmannKrombholz 1994). Und die geläufigen Rechtsextremismus-Skalen enthalten in der Regel auch keine geschlechtsspezifische Dimension. Allerdings sind zwei Sonderfälle zu erwähnen: Das Konzept "Gruppenbezogene Menschenfeindlichkeit" (GMF) von Heitmeyer (2006) enthält neben Fremdenfeindlichkeit, Etabliertenvorrechte, Islamophobie, Heterophobie, Antisemitismus und Rassismus auch eine Dimension "klassischer Sexismus" ${ }^{32}$. GMF kommt dem hier zugrunde liegenden Rechtsextremismusbegriff sehr nahe und zeigt, dass es sich beim Sexismus um einen integralen Bestandteil von Ungleichwertigkeitsvorstellungen handelt. Birsl (1994: 178 ff.) arbeitete mit zwei geschlechtsspezifischen Rechtsextremismus-Skalen, eine für weibliche und eine für männliche Jugendliche. Die Skalen wurden für jedes Geschlecht auf der Grundlage der vorhandenen Indikatoren nach statistischen Gesichtspunkten konstruiert, also auf die männlichen und weiblichen Befragten zugeschnitten. Als Begründung für dieses unkonventionelle Vorgehen ${ }^{33}$ führt die Verfasserin an, dass sich das Geschlecht "als die entscheidende unabhängige Variable" (S. 178) erwiesen habe. Damit wird gegen das Gebot der Inhaltsvalidität verstoßen. Denn bei der durchaus plausiblen theoretischen Herleitung der Dimensionalität des Messinstruments wurde beispielsweise das Merkmal "natürlicher Wesensunterschied zwischen den Geschlechtern" als Bestandteil des rechtsextremen Einstellungsmusters festgelegt und auch mit sieben Statements erhoben ${ }^{34}$. Bei der

32 Diese Dimension wird mit zwei Statements gemessen: "Frauen sollten sich wieder mehr auf die Rolle der Ehefrau und Mutter besinnen" und "Für eine Frau sollte es wichtiger sein, ihrem Mann bei seiner Karriere zu helfen, als selbst Karriere zu machen" (Heitmeyer 2006: 29).

33 In diesem Fall sind Vergleiche allenfalls zulässig, wenn die funktionale Äquivalenz beider Messinstrumente nachgewiesen wird.

34 "Frauen sind genauso wie Männer geeignet, Meisterin, Abteilungsleiterin, Managerin oder Firmenchefin zu werden"; "Eine Frau kann nicht allein im Beruf ihr Glück finden. Kinderbekommen und für die Familie da sein gehört dazu"; "Hausarbeit und Kindererziehung wird nach wie vor zu wenig gesellschaftlich anerkannt. Die Gleichberechtigung der Frau kann deshalb nur durch eine höhere Bewertung dieser Tätigkeiten erreicht werden"; "Nur Frauen sind von Natur aus in der Lage, durch Wärme und Hingabe ein Klima der Geborgenheit in der Familie zu schaffen"; "Frauen können besser Kinder erziehen als Männer"; "Ein Mann kann sich gegenüber anderen besser durchsetzen als eine Frau" und "Es ist verständlich, dass Männer weniger gern unter einer Frau als Chefin arbeiten" (Birsl 1994: 159). 
Konstruktion der beiden Rechtsextremismus-Skalen wurde dann aber keines dieser Statements berücksichtigt, um "eine etwas höhere Eindimensionalität" (S. 185) zu erreichen.

In diesem Abschnitt geht es um die Beziehung zwischen Sexismus und Rassismus. Da in der einschlägigen Literatur nicht exakt zwischen Rassismus und Rechtsextremismus unterschieden wird und weil völkisches Denken mit ganz seltenen Ausnahmen übersteigerten Nationalismus und hierarchische Ordnungsvorstellungen impliziert, wird im Folgenden das Verhältnis von Sexismus und Rechtsextremismus untersucht. Zunächst ist zu fragen, ob es sich überhaupt um zwei Dimensionen von Diskriminierung und Unterordnung handelt, ob eine inhaltliche Verbindung zwischen beiden Orientierungen besteht.

\begin{tabular}{|c|c|c|}
\hline \multirow{2}{*}{$\begin{array}{l}\text { Tabelle 2: } \\
\text { Alle Befragten }\end{array}$} & \multicolumn{2}{|c|}{$\begin{array}{l}\text { Korrelate }(r) \text { der Rechtsextremismus } \\
\text { Skala und des Index Sexismus für } \\
\text { ausgewählte Untersuchungsgruppen } \\
2005\end{array}$} \\
\hline & & ,424 \\
\hline West & & ,452 \\
\hline Ost & & ,341 \\
\hline Männer & & ,457 \\
\hline Frauen & & ,354 \\
\hline \multirow[t]{5}{*}{ Altersgruppen } & $18-24$ & ,276 \\
\hline & $25-34$ & ,453 \\
\hline & $35-44$ & ,418 \\
\hline & $45-59$ & ,419 \\
\hline & $60-$ & ,401 \\
\hline \multirow[t]{3}{*}{ Bildung } & niedrig & ,325 \\
\hline & mittel & ,439 \\
\hline & hoch & ,412 \\
\hline \multirow[t]{3}{*}{ Schicht } & Unterschicht & ,343 \\
\hline & Mittelschicht & ,478 \\
\hline & Oberschicht & ,365 \\
\hline
\end{tabular}

Alle Korrelationen sind auf dem Niveau von 0,01 signifikant.

Das Ergebnis der Prüfung fällt positiv aus: Alle sechs Rechtsextremismus-Statements korrelieren gleichsinnig mit dem Sexismus-Index (Anhang 2b), die Zusammenhänge mit Antisemitismus, Ausländerfeindlichkeit und Chauvinismus fallen ziemlich stark aus, die mit Darwinismus, Verharmlosung des Nationalsozialismus und Befürwortung einer rechtsautoritären Diktatur sind schwach 
ausgeprägt ${ }^{35}$. Sexismus korrespondiert also nicht nur mit rassistischen Orientierungen sondern mit allen Dimensionen des rechtsextremen Einstellungsmusters. Die Intensität der Verbindungen variiert nur geringfügig und sollte daher nicht überinterpretiert werden. Entscheidend ist, dass dies für beide Geschlechter gilt, wenn auch die Zusammenhänge bei Männern stärker ausfallen als bei Frauen. Ebenso sind die sechs Statements des Sexismus-Index SEX (schwach) positiv mit der Rechtsextremismus-Skala REX assoziiert (Anhang 4d).

Die Skala REX und der Index SEX korrelieren stark positiv miteinander. Gleichgerichtete, allerdings unterschiedlich enge Zusammenhänge finden sich bei allen Untersuchungsgruppen (Auswahl in Tab. 2). Sie fallen im Westen dichter aus als im Osten und sind bei Männern intensiver als bei Frauen. Es existiert also ein gegenseitiges Abhängigkeitsverhältnis zwischen Rechtsextremismus und Sexismus, und wir können mit gutem Grund Diskriminierung und Unterordnung als gemeinsame Hintergrundvariable annehmen.

Die These, dass es sich bei Sexismus und Rassismus/Rechtsextremismus um zwei Seiten einer Medaille handelt, wird - mit unseren Daten - bestätigt. Damit steht die Behauptung, es könne "als relativ gesichert gelten ... dass das traditionelle Frauenbild des Rechtsextremismus kein zentrales Attraktionsmoment für Frauen darstellt" (Amesberger/Halbmayr 2002b: 46), auf schwachen Füßen - jedenfalls mit Blick auf rechtsextreme Einstellungen. Ob es sich um ein "zentrales" Attraktionsmoment handelt, wird im folgenden Abschnitt untersucht. Hier ist zunächst nur festzuhalten, dass die Annahmen des herrschaftstheoretischen Ansatzes - anders als Amesberger und Halbmayr vermuten (ebda: 45) - sehr wohl "nachweisbar" sind. Richtig ist allerdings auch, dass der statistische Zusammenhang zwischen Rechtsextremismus und Sexismus bei Frauen geringer ist als bei Männern. Das können sich die Vertreterinnen des modernisierungstheoretischen Ansatzes zugute halten.

Da Rechtsextremismus und Sexismus stark positiv miteinander variieren, bietet sich die Bildung eines Instruments an, das beide Orientierungen miteinander verbindet. Damit wird keine Identität unterstellt sondern lediglich getestet, ob beide Orientierungen im Bewusstsein der Befragten zu einem homogenen Syndrom verschmelzen und welche Wechselwirkungen dabei stattfinden. In die gewählte Konstruktion (Details in Anhang 5) gehen Rechtsextremismus und Sexismus gleichgewichtig ein, damit der Effekt von Sexismus besonders deutlich zutage treten kann. Denn letztlich geht es um die Frage, ob sich die gängigen Rechtsextremismus-Skalen um die Dimension Sexismus erweitern lassen. Selbst wenn statistisch nichts dagegen spräche und sich auf diese Weise Erkenntnisfortschritte erzielen ließen, müsste immer auch noch theoretisch entschieden werden, ob die Bildung eines derartigen Index notwendig und sinnvoll ist. 
Die Prüfstatistik des Index Rechtsextremismus-Sexismus (REXSEX) fällt nur mäßig aus, die Koeffizienten sind zwar gerade noch tolerierbar, die interne Konsistenz ist aber unbefriedigend ${ }^{36}$. Die entsprechenden Einstellungspotenziale berichtet Tabelle 3.

\begin{tabular}{|l|c|c|r|r|r|r|r|r|r|}
\hline Tabelle 3: & \multicolumn{3}{c|}{$\begin{array}{l}\text { Rechtsextremismus (REX), Sexismus (SEX) und Rechtsextremismus- } \\
\text { Sexismus (REXSEX) nach Gebiet und Geschlecht 2005 (\%) }\end{array}$} \\
\hline & \multicolumn{3}{|c|}{ BRD } & \multicolumn{3}{c|}{ West } & \multicolumn{4}{c|}{ Ost } \\
\hline & Alle & M & F & Alle & M & F & Alle & M & F \\
\hline REX & 12 & 15 & 9 & 12 & 14 & 9 & 14 & 18 & 10 \\
SEX & 16 & 21 & 11 & 17 & 22 & 12 & 12 & 19 & 6 \\
REXSEX & 10 & 14 & 6 & 11 & 15 & 7 & 8 & 12 & 4 \\
\hline
\end{tabular}

Die Verbindung von Rechtsextremismus um Sexismus wirkt sich bei der Potenzialbestimmung auf die Geschlechter unterschiedlich aus: Bei Männern ist das rechtsextreme und das rechtsextremsexistische Einstellungspotenzial bundesweit (12\% zu 10\%) und im Westen (12\% zu 11\%) nahezu identisch. Im Osten ist der Anteil der Rechtsextremisten allerdings anderthalbmal so groß wie der Anteil der Rechtsextremisten/Sexisten (18\% zu 12\%). Bei den Frauen vermindern sich die Anteile durchgängig: Republikweit verfügen neun Prozent über rechtsextreme, aber nur sechs Prozent über rechtsextrem-sexistische Einstellungen. Im Westen beträgt das Verhältnis neun Prozent zu sieben Prozent, im Osten zehn Prozent zu vier Prozent. Die Erweiterung von Rechtsextremismus um Sexismus bewirkt im Ost-West-Vergleich zudem eine Gewichtsverlagerung: Die Ostdeutschen neigen mehr als die Westdeutschen zu rechtsextremen Einstellungen (14\% zu 12\%), rechtsextrem-sexistische Orientierungen finden sich dagegen häufiger im Westen als im Osten (11\% zu 8\%). Die Kombination von Rechtsextremismus und Sexismus hat also erhebliche Auswirkungen auf das Geschlechterverhältnis und auf die West-Ost-Relation, weil Frauen seltener als Männer, Westdeutsche häufiger als Ostdeutsche sexistischen Vorstellungen folgen. Dieser Effekt dürfte auch dann (allerdings vermindert) eintreten, wenn Sexismus mit einem geringeren Gewicht in den Index Rechtsextremismus-Sexismus eingeht.

Im Vergleich zum nach herkömmlicher Art gemessenen Rechtsextremismus verändert sich beim neuartigen Index REXSEX die Geschlechterdifferenz deutlich zugunsten der Frauen. Auf nationaler Ebene übersteigt die Anfälligkeit der Männer die der Frauen um das 2,3-fache, im Osten sogar um das dreifache. Wenn aus grundsätzlichen Erwägungen das rechtsextreme Einstellungsmuster um die Dimension Sexismus erweitert würde, vergrößerte sich der Abstand zwischen den Ge- 
schlechtern also erheblich, und die Wissenschaft wäre um eine Erklärung für den Gender Gap beim manifesten Rechtsextremismus reicher.

Hinsichtlich der Wechselwirkungen zwischen Rechtsextremismus und Sexismus im Rahmen des Konstrukts REXSEX findet offenbar keine gegenseitige Verstärkung sondern eine Überlagerung, genauer: eine gegenseitige Begrenzung, statt. Da REXSEX durch Summierung der Messwerte der Rechtsextremismus-Skala und des Sexismus-Index gebildet wurde und da die Verteilung der Messwerte der Rechtsextremismus-Skala extrem rechtsschief ist (Schiefe: 0,9), beträgt der Überschneidungsbereich beider Potenziale, also der Anteil der Befragten, die den Schwellenwert für die Potenzialbestimmung sowohl bei der Rechtsextremismus-Skala als auch beim Sexismus-Index überwinden, bundesweit ganze vier Prozent, also weniger als die Hälfte des REXSEX-Potenzials von zehn Prozent (Tab. 3).

Um herauszufinden, welche zusätzlichen Einsichten mit dem Index Rechtsextremismus-Sexismus möglich sind, wird abschließend noch ein Vergleich der drei Instrumente REX, SEX und REXSEX vorgenommen. Korrelate mit einigen Erklärungsfaktoren finden sich in Anhang 13c. Diese Variablen sind - wie zu erwarten war - durchweg gleichsinnig mit Rechtsextremismus und Sexismus assoziiert, denn beide stehen auch untereinander in enger Beziehung. Allerdings variieren sie zumeist (wesentlich) stärker mit Rechtsextremismus als mit Sexismus ${ }^{37}$. Derselbe Effekt zeigt sich, wenn mit den Erklärungsfaktoren nach Anhang 13c lineare Regressionen auf die Rechtsextremismus-Skala und auf den Index Sexismus gerechnet werden: Für Sexismus wird eine Varianzaufklärung von mageren 18 Prozent erreicht, für Rechtsextremismus immerhin 34 Prozent. Das bedeutet, dass Sexismus - jedenfalls teilweise - durch andere Variablen erklärt wird als Rechtsextremismus. Über mitteilenswerte Erklärungskraft für Sexismus verfügen (nach Einfluss geordnet) Orientierungslosigkeit (Anomie), die Präferenz für autoritäre gegenüber libertären Ordnungsvorstellungen, die Präferenz für neoliberale gegenüber staatsinterventionistischen Ordnungsvorstellungen, Schichtzugehörigkeit (negativ) und politische Unzufriedenheit. Für Rechtsextremismus gelten entsprechend die Präferenz für autoritäre gegenüber libertären Ordnungsvorstellungen, Unzufriedenheit mit der Demokratie, Orientierungslosigkeit (Anomie) und die Links-Rechts-Selbsteinstufung. Rechtsextremismus und Sexismus sind also gemeinsam durch autoritäre und anomische Haltungen geprägt. Während Rechtsextremismus weiterhin durch Unzufriedenheit mit der Demokratie und durch ein rechtsgerichtetes ideologisches Selbstverständnis begünstigt wird, profitiert Sexismus von neoliberalen Zielvorstellungen, von einem geringen sozialen Status und von politischer Unzufriedenheit.

37 Über die Rechtsextremismus-Skala und den Sexismus-Index hinausreichende Erklärungskraft für den Index Rechtsextremismus-Sexismus verfügen nur Bildung, Schicht und Anomie (Anhang 13c). 
Auch wenn die Bundestagswahlstudie keine Variablen mit hoher Erklärungskraft für Sexismus (vermutlich aus dem Bereich der geschlechtsspezifischen Sozialisation) bereithält, steht für mich außer Zweifel, dass trotz der starken statistischen Beziehung zwischen Rechtsextremismus und Sexismus erhebliche Unterschiede hinsichtlich der Ursachen beider Orientierungen bestehen.

Fazit: Erstens bewegt sich die Verbreitung von sexistischen Einstellungen in der Bevölkerung in engen Grenzen (16\%). Männer sind zwar doppelt so häufig sexistisch eingestellt wie Frauen (21\% zu 11\%), aber das Bedrohungsgefühl angesichts des (vermeintlichen) allmählichen Untergangs des Patriarchats ist bei innen eher gering ausgeprägt. Vermutlich erwarten viele Männer diesen Untergang überhaupt nicht. Zweitens widersprechen sich die Befunde des herrschaftstheoretischen und des modernisierungstheoretischen Ansatzes nicht, sie ergänzen sich eher: Es besteht zwar eine starke Korrelation zwischen Rechtsextremismus und Sexismus. Daraus folgt, dass Sexismus bei der Entwicklung von rechtsextremen Einstellungen durchaus von Bedeutung ist. Das betrifft allerdings Männer wesentlich stärker als Frauen. Dennoch gilt: Frauen wenden sich dem Rechtsextremismus also nicht trotz, sondern wegen seines althergebrachten Frauen- und Familienbilds zu. Drittens erscheint mir die Bildung eines Messinstruments, das Rechtsextremismus und Sexismus miteinander kombiniert, trotz der starken Korrelation beider Orientierungen nicht empfehlenswert. Dagegen spricht zunächst die mäßige interne Konsistenz dieses Konstrukts, woraus die Schlussfolgerung zu ziehen ist, dass sich Rechtsextremismus und Sexismus nicht zu einem homogenen Einstellungssyndrom verbinden. Ferner verfügen beide Orientierungen über teilweise sehr verschiedene Ursachen. Und schließlich kommt dem vor allem von afro-amerikanischen Frauen vorgetragenen Einwand erhebliches Gewicht zu, dass es sich bei Sexismus und Rassismus/Rechtsextremismus um zwei unterschiedliche Qualitäten von Diskriminierung handelt. Die Parole "Ausländer raus!" findet im Sexismus keine Entsprechung. Bei den folgenden Analysen verwende ich Sexismus daher als Prädiktor für Rechtsextremismus.

\section{c) Sexismus als Erklärungsfaktor für Rechtsextremismus}

Nachdem der Nachweis erbracht wurde, dass sexistische Einstellungen sehr wohl die Hinwendung zum Rechtsextremismus begünstigen, soll nun ermittelt werden, über welche Erklärungskraft Sexismus im Kontext weiterer Prädiktoren für die geschlechtsspezifische Ausprägung von rechtsextremen Einstellungen verfügt, ob es sich bei dem reaktionären Frauenbild des Rechtsextremismus um ein "zentrales Attraktionsmoment" für Frauen und/oder Männer handelt.

Tabelle 4 berichtet, dass die fünf Variablen, die am stärksten mit Rechtsextremismus korrelieren, bei Männern und Frauen identisch sind, dass sogar die Reihenfolge übereinstimmt. Mit einer Ausnahme allerdings: Die Plätze 1 und 2 sind spiegelbildlich angeordnet. Während bei Männern Sexismus am intensivsten (positiv) mit Rechtsextremismus variiert, stehen bei Frauen die politischen 
Ordnungsvorstellungen "Autoritarismus vs. Libertarismus" (negativ) an erster Stelle. Es folgen auf Platz 3 für beide Geschlechter Anomie (positiv), sodann Demokratiezufriedenheit (negativ) und schließlich Bildung (negativ). Die Zusammenhänge fallen in diesen fünf Fällen bei Männern enger aus als bei Frauen, vor allem Sexismus beeinflusst den männlichen Rechtsextremismus stark, den weiblichen nur ziemlich stark ${ }^{38}$.

\begin{tabular}{|c|c|c|}
\hline \multirow[t]{2}{*}{ Tabelle 4: } & \multicolumn{2}{|c|}{$\begin{array}{l}\text { Korrelate (r) von Rechtsextremismus } \\
\text { (REX) mit ausgewählten Variablen nach } \\
\text { Geschlecht } 2005\end{array}$} \\
\hline & Männer & Frauen \\
\hline ALTER & $\star \star *, 160$ & $\star \star \star 205$ \\
\hline BILDUNG & $\star^{* *_{-}, 269}$ & $*^{* *_{-}, 245}$ \\
\hline SCHICHT & $*^{*}-, 203$ & $\star^{*}-, 170$ \\
\hline ANOMIA & $\star \star * \star 390$ & $\star \star *, 297$ \\
\hline EFFIINT & $*^{*},, 138$ & $\star^{*}-, 181$ \\
\hline LIRE & $\star \star, 217$ & **,155 \\
\hline POLINT & $\star^{* *_{-}, 179}$ & $\star^{*}-, 185$ \\
\hline DEMOZU & $*_{-}, 310$ & $*^{* *_{-}, 282}$ \\
\hline POLUNZU & $\star \star *, 171$ & **,180 \\
\hline STANEO & ${ }^{\star}, 068$ & ,043 \\
\hline AUTOLIB & $*^{*}, 423$ & $\star^{*}-, 404$ \\
\hline SEX & $* *, 457$ & $* \star, 354$ \\
\hline
\end{tabular}

** Die Korrelation ist auf dem Niveau von 0,01 signifikant.

* Die Korrelation ist auf dem Niveau von 0,05 signifikant.

$\begin{array}{ll}\text { ALTER } & \text { Alter in Jahren } \\ \text { ANOMIA } & \text { Orientierungslosigkeit, Macht- und Hilflosigkeit } \\ \text { AUTOLIB } & \text { Politische Ordnungsvorstellungen: Autoritarismus } \\ & \text { vs. Libertarismus } \\ \text { BILDUNG } & \text { Schulabschluss } \\ \text { DEMOZU } & \text { Demokratiezufriedenheit } \\ \text { EFFIINT } & \text { Politisches Selbstbewusstsein } \\ \text { LIRE } & \text { Links-Rechts-Selbsteinstufung } \\ \text { POLINT } & \text { Politisches Interesse } \\ \text { POLUNZU } & \text { Politische Unzufriedenheit } \\ \text { SCHICHT } & \text { Objektive Schichteinstufung } \\ \text { SEX } & \text { Sexismus } \\ \text { STANEO } & \text { Politische Ordnungsvorstellungen: Staatsinter- } \\ & \text { ventionismus vs. Neoliberalismus }\end{array}$

Die Koeffizienten für folgende Variablen sind bei den Frauen größer als bei den Männern: Alter (positiv), politisches Selbstbewusstsein (negativ), politisches Interesse (negativ) und politische 
Unzufriedenheit (positiv) ${ }^{39}$. Orientierungen, die sich auf die eigene politische Rolle oder auf das politische Geschehen beziehen, begünstigen bei Frauen die Entwicklung von rechtsextremen Einstellungen etwas intensiver als bei Männern. Die Koeffizienten bewegen sich allerdings auf einem sehr geringen Niveau. Rechnet man Regressionen der Rechtsextremismus-Skala auf die hier als unabhängig betrachteten Variablen, dann ergeben sich die in Tabelle 5 aufgeführten BetaKoeffizienten.

\begin{tabular}{|lllr|}
\hline Tabelle 5: & Signifikante standardisierte Regressions- \\
koeffizienten (Beta) der Prädiktoren für die \\
Rechtsextremismus-Skala REX nach \\
Geschlecht 2005
\end{tabular}

Signifikanzniveau der Beta-Werte 0,05.

(Schrittweise) eingeführte Variablen:

$\begin{array}{ll}\text { ALTER } & \begin{array}{l}\text { Alter in Jahren } \\ \text { ANOMIA }\end{array} \\ \text { Orientierungslosigkeit, Macht- und Hilflosigkeit } \\ \text { AUTOLIB } & \begin{array}{l}\text { Politische Ordnungsvorstellungen: Autoritarismus vs. } \\ \text { Libertarismus }\end{array} \\ \text { BILDUNG } & \text { Schulabschluss } \\ \text { DEMOZU } & \text { Demokratiezufriedenheit } \\ \text { EFFIINT } & \text { Politisches Selbstbewusstsein } \\ \text { LIRE } & \text { Links-Rechts-Selbsteinstufung } \\ \text { POLINT } & \text { Politisches Interesse } \\ \text { POLUNZU } & \text { Politische Unzufriedenheit } \\ \text { REX } & \text { Rechtsextremismus } \\ \text { SCHICHT } & \text { Objektive Schichteinstufung } \\ \text { SEX } & \text { Sexismus } \\ \text { STANEO } & \text { Politische Ordnungsvorstellungen: Staatsinterventionis- } \\ & \text { mus vs. Neoliberalismus }\end{array}$

Als bester Prädiktor für Rechtsextremismus erweist sich für beide Geschlechter die Präferenz für autoritäre politische Ordnungsvorstellungen. Über die zweitbeste Erklärungskraft bei Männern und Frauen verfügt die Unzufriedenheit mit der Demokratie. Dass Sexismus jeweils erst an dritter Stelle steht, liegt daran, dass ein Teil der Varianz dieser Variable von der Präferenz für autoritäre Ord-

39 Alter korreliert übrigens nicht mit politischem Selbstbewusstsein, politischem Interesse oder mit politischer Unzufriedenheit, auch nicht bei Frauen. 
nungsvorstellungen abgedeckt wird, die Elemente von Diskriminierung und Unterordnung enthält (Anhang 10). Egal, ob man sich an den Korrelaten oder an den Beta-Werten orientiert: Sexismus spielt bei der Ausprägung von rechtsextremen Einstellungen eine maßgebliche Rolle, und zwar bei Männern und Frauen.

Einschränkend gilt, dass die Bundestagswahlstudie kaum einschlägige Variablen über den sozioökonomischen Status und seine mentale Verarbeitung enthält. Die aufgeklärte Varianz der REXSkala beträgt bei den Männern nur 42 Prozent und bei den Frauen sogar nur 33 Prozent. Denkbar wäre also, dass die Erklärungskraft von Sexismus im Reigen weiterer relevanter Prädiktoren geringer ausfällt. Nach meinen persönlichen Forschungserfahrungen ist dies allerdings wenig wahrscheinlich, da ich auch mit einem breiteren Set an Einflussvariablen keine wesentlich besseren Koeffizienten erzielt habe. Zumeist haben sich sozioökonomische Faktoren bei der Erklärung von Rechtsextremismus sogar als schwächer erwiesen als soziopolitische Orientierungen (Stöss/Fichter/Kreis/Zeuner 2004: 383 ff.). Würde der Datensatz Variablen zur geschlechtsspezifischen Sozialisation bereithalten, dann dürfte sich der Einfluss von Sexismus auf Rechtsextremismus eher noch verstärken.

Mit Blick auf die zur Verfügung stehenden Erklärungsfaktoren für rechtsextreme Einstellungen unterscheiden sich Männer und Frauen also nicht grundsätzlich. Daher besteht auch kein Anlass, die Existenz eines geschlechtsspezifischen Rechtsextremismus anzunehmen. Jedenfalls spricht nichts für die Unterscheidung zwischen einem männlichen, sexistischen und einem weiblichen, nicht sexistischen Rechtsextremismus. Etwas differenziertere Einsichten ergeben sich, wenn nicht statistische Zusammenhänge sondern Größenordnungen betrachtet werden.

Dass ein völkisch-biologistisches Frauenbild mit rechtsextremen Einstellungen korrespondiert, illustrieren folgende Prozentangaben: Sexistisch eingestellte Frauen tendieren häufiger zum Rechtsextremismus als nicht sexistisch eingestellte Frauen: So weisen durchschnittlich neun Prozent aller Frauen, aber 17 Prozent der sexistischen Frauen rechtsextreme Einstellungen auf. Das gilt entsprechend für Männer. Bei innen betragen die entsprechenden Anteile 15 Prozent und 35 Prozent (Anhang 13a). Umgekehrt tendieren rechtsextrem eingestellte Frauen häufiger zu Sexismus als nicht rechtsextrem eingestellte Frauen. So weisen durchschnittlich 11 Prozent aller Frauen, aber 21 Prozent aller rechtsextremen Frauen sexistische Einstellungen auf. Das gilt wiederum entsprechend für Männer. Die entsprechenden Anteile betragen 21 Prozent und 46 Prozent (Anhang $4 e, 13 b)$. Diese Befunde informieren zugleich auch darüber, dass sexistische Männer doppelt so häufig rechtsextrem denken wie sexistische Frauen, und dass rechtsextreme Männer doppelt so häufig sexistische Vorstellungen äußern wie rechtsextreme Frauen. Es sind also in erster Linie Männer, die sich vom Rechtsextremismus die Sicherung des Patriarchats versprechen. Unsere Befunde widersprechen mithin nicht der These, dass auch rechtsextreme Frauen in gewissem Um- 
fang nach Gleichberechtigung streben. Sie darf aber nicht für alle rechtsextrem orientierten Frauen verallgemeinert werden.

Bei den Korrelationsanalysen (Tab. 4) hatten wir festgestellt, dass Alter, politisches Selbstbewusstsein, politisches Interesse und politische Unzufriedenheit bei Frauen etwas stärker mit Rechtsextremismus assoziiert ist als bei Männern. Das schlägt sich bei den Einstellungspotenzialen wie folgt nieder: Männliche Rechtsextremisten sind im Durchschnitt 52, weibliche 57 Jahre alt. Von den rechtsextremen Frauen sind 51 Prozent 60 Jahre und älter, bei den rechtsextremen Männern sind es 38 Prozent. Über ein geringes politisches Selbstbewusstsein verfügen 66 Prozent der rechtsextremen Frauen, aber nur 45 Prozent der rechtsextremen Männer, und politisches Desinteresse zeigen 35 Prozent der rechtsextremen Frauen, aber nur 20 Prozent der rechtsextremen Männer. Kein Unterschied besteht aus dieser Perspektive hinsichtlich der politischen Unzufriedenheit. Auffällig ist, dass bei Männern die Links-Rechts-Selbsteinstufung (positiv) und die Demokratiezufriedenheit (negativ) stärker mit Rechtsextremismus korrelieren als bei Frauen. Das macht sich bei der Potenzialbestimmung vor allem bei der Unzufriedenheit mit der Demokratie bemerkbar: 40 Prozent der männlichen, aber nur 26 Prozent der weiblichen Rechtsextremisten teilen diese Unzufriedenheit ${ }^{40}$.

Daraus ziehe ich die Schlussfolgerung, dass rechtsextreme Männer der demokratischen Ordnung feindseliger begegnen und damit dem Kernanliegen des Rechtsextremismus eher folgen als Frauen. Der weibliche Rechtsextremismus ist offenbar eher durch Distanz gegenüber der Politik geprägt, der männliche eher durch Distanz gegenüber der Demokratie. Rechtsextreme Männer sind offenbar auch ideologischer strukturiert als rechtsextreme Frauen. Dass ihr Weltbild konsistenter ist, als das der rechtsextremen Frauen, hatten wir bereits in Abschnitt 5 a festgestellt.

Fazit: Hinsichtlich der Ursachen für die Entwicklung von rechtsextremen Einstellungen bestehen (in den hier benutzten Daten) keine gravierenden geschlechtsspezifischen Unterschiede. Dabei spielt Sexismus eine maßgebliche Rolle und kann daher durchaus als "zentrales Attraktionsmoment" bezeichnet werden, mehr noch bei Männern als bei Frauen. Anzeichen für einen geschlechtsspezifischen Rechtsextremismus haben sich freilich nicht offenbart. Mit Blick auf das Ausmaß von rechtsextremen Einstellungen treten die Unterschiede zwischen Männern und Frauen deutlicher hervor: Es sind vor allem rechtsextreme Männer, die ein sexistisches Frauenbild vertreten. Sie sind auch stärker ideologisch geprägt und zeichnen sich besonders durch antidemokratische Orientierungen aus, während sich rechtsextreme Frauen eher für politisch inkompetent halten und sich auch weniger für das politische Geschehen interessieren. 


\section{Manifester Rechtsextremismus}

\section{a) Die NPD-Wähler bei der Bundestagswahl 2005}

Die Analysen dieses Abschnitts beruhen auf der Wahltagsbefragung von Infratest dimap für die ARD-Wahlberichterstattung. Der Vorteil dieser Datenquelle besteht in den großen Fallzahlen, die auch die detaillierte Betrachtung kleiner Parteien ermöglichen. Nachteilig für den Zweck unserer Untersuchung wirkt sich aus, dass sie keine Informationen über rechtsextreme und sexistische Einstellungen enthält.

Dass sich Männer häufiger für rechtsextreme Parteien entscheiden als Frauen, ist bekannt und bestätigte sich auch bei der Bundestagswahl 2005 (Tab. 6): Bei den Republikanern war der Anteil der Zweitstimmen bei den Männern fast doppelt so groß wie den Frauen. Und die NPD wurde sogar über zweieinhalb Mal so häufig von Männern gewählt wie von Frauen. Dabei fiel der Gender Gap - vor allem bei den Republikanern - im Osten größer aus als im Westen. Männer wählten die NPD häufiger als Frauen aus Überzeugung, bei den Frauen überwog dafür die Enttäuschung über die etablierten Parteien. Die weiblichen NPD-Wähler fühlten sich auch nicht so oft an die NPD gebunden wie die männlichen NPD-Wähler. Kennzeichnend für Frauen ist zudem, dass sie ihre Wahlmotive öfter als Männer nicht genau angeben konnten. Diese Unsicherheit kam auch darin zum Ausdruck, dass sie ihre Wahlentscheidung eher spontan trafen, während die der Männer zumeist seit längerem fest stand (Tab. 7). Überspitzt formuliert handelte es sich bei den männlichen NPD-Wählern eher um Überzeugungstäter, bei den weiblichen NPD-Anhängern eher um Protestwähler.

\begin{tabular}{|c|c|c|c|}
\hline \multirow[t]{2}{*}{ Tabelle 6: } & \multicolumn{3}{|c|}{$\begin{array}{l}\text { Zweitstimme für NPD und Republikaner in den } \\
\text { Gebieten und bei den Geschlechtern bei der } \\
\text { Bundestagswahl } 2005(\%)\end{array}$} \\
\hline & BRD & West & Ost \\
\hline Republikaner & 0,6 & 0,6 & 0,4 \\
\hline Männer & 0,7 & 0,7 & 0,6 \\
\hline Frauen & 0,4 & 0,5 & 0,1 \\
\hline NPD & 1,6 & 1,1 & 3,6 \\
\hline Männer & 2,3 & 1,6 & 5,2 \\
\hline Frauen & 0,9 & 0,7 & 1,9 \\
\hline
\end{tabular}

Daten: Wahltagsbefragung Infratest dimap (ARD-Wahlberichterstattung). $\mathrm{N}=16.365$.

Obwohl sich Männer und Frauen gleichermaßen (jeweils zu zwei Dritteln) bei den Wahlmotiven an Sachfragen orientierten, machten sich bei den wahlentscheidenden Themen (Tab. 8) durchaus 
geschlechtsspezifische Besonderheiten bemerkbar. Zunächst fällt auf, dass Frauen bei allen Themen mehr Nennungen aufweisen als Männer. Allerdings mit einer Ausnahme: Männer optierten wesentlich häufiger wegen der Ausländerpolitik für die NPD als Frauen. Diese legten dafür deutlich mehr Gewicht auf die Schul- und Bildungspolitik, auf die Wirtschaftspolitik und auf soziale Gerechtigkeit. Damit dürften sich allerdings kaum Kompetenzzuschreibungen für die NPD verbunden haben. Vermutlich signalisierten die Frauen mit diesen Präferenzen, dass sie mit dem konkreten, auf ihre Alltagsbedürfnisse bezogenen Politikoutput der etablierten Parteien unzufrieden waren.

\begin{tabular}{|c|c|c|c|c|}
\hline \multirow[t]{2}{*}{ Tabelle 7: } & \multicolumn{4}{|c|}{$\begin{array}{l}\text { Die Wähler der NPD (Zweitstimme) nach Geschlecht sowie nach } \\
\text { Wahlmotiven und Zeitpunkt der Wahlentscheidung bei der } \\
\text { Bundestagswahl } 2005(\%)\end{array}$} \\
\hline & & Alle & Männer & Frauen \\
\hline \multicolumn{5}{|c|}{ Wahlmotive 1} \\
\hline Überzeugung & & 41 & 47 & 27 \\
\hline Protest & & 49 & 44 & 59 \\
\hline Rest & & 10 & 9 & 14 \\
\hline \multicolumn{5}{|c|}{ Wahlmotive 2} \\
\hline Kandidaten & & 8 & 7 & 8 \\
\hline Sachfragen & & 65 & 67 & 63 \\
\hline Parteibindun & & 16 & 18 & 12 \\
\hline Mix & & 11 & 8 & 17 \\
\hline \multicolumn{5}{|c|}{ Zeitpunkt der Wahlentscheidung } \\
\hline Heute & & 21 & 13 & 43 \\
\hline Während der & letzten Tage & 12 & 13 & 10 \\
\hline In den letzter & Wochen & 15 & 16 & 10 \\
\hline Schon vor lä & gerer Zeit & 42 & 48 & 29 \\
\hline Wähle imme & dieselbe Partei & 9 & 10 & 7 \\
\hline Rest & & 1 & 0 & 1 \\
\hline
\end{tabular}

Daten: Wahltagsbefragung Infratest dimap (ARD-Wahlberichterstattung). $\mathrm{N}=16.365$.

Noch eine Bemerkung zur Sozialstruktur: Während rechtsextreme Einstellungen mit wachsendem Alter zunehmen (bei Frauen noch stärker als bei Männern ${ }^{41}$ ), sinken die Wähleranteile der NPD mit steigendem Alter. Bei den 18-24jährigen erreichen die Männer mit 6,4 Prozent (bei einem Durchschnittsergebnis von 2,3\%) einen Spitzenwert (Anhang 13d). Übereinstimmende Befunde für beide Geschlechter ergeben sich für die Erwerbs- und Berufsgruppen: Hier stellen die Arbeitslo- 
sen, die einfachen und die Facharbeiter die fleißigsten NPD-Wähler, und auch rechtsextreme Einstellungen gedeihen überdurchschnittlich in der Unterschicht.

\begin{tabular}{|l|c|c|c|}
\hline \multicolumn{4}{|c|}{$\begin{array}{c}\text { Die wahlentscheidenden Themen der Wähler der NPD (Zweitstimme) nach } \\
\text { Geschlecht bei der Bundestagswahl 2005 (\%) }\end{array}$} \\
\hline & Alle & Männer & Frauen \\
\hline Wirtschaftspolitik & 20 & 17 & 30 \\
Ausländerpolitik & 54 & 59 & 44 \\
Arbeitsmarktpolitik & 41 & 38 & 47 \\
Innere Sicherheit, Kriminalität & 22 & 20 & 24 \\
Umweltpolitik & 3 & 2 & 4 \\
Steuerpolitik & 13 & 13 & 15 \\
Soziale Gerechtigkeit & 24 & 21 & 32 \\
Schul-, Bildungspolitik & 9 & 4 & 19 \\
Außenpolitik & 7 & 6 & 7 \\
\hline
\end{tabular}

Daten: Wahltagsbefragung Infratest dimap (ARD-Wahlberichterstattung). $\mathrm{N}=16.365$.

Fazit: Dass sich Frauen für die NPD eher aus Unzufriedenheit mit den etablierten Parteien entscheiden, während sie von den Männern eher aus Überzeugung gewählt werden, fügt sich in unseren früheren Befund ein, dass der weibliche Rechtsextremismus eher durch Distanz gegenüber der Politik, der männliche eher durch Distanz gegenüber der Demokratie geprägt ist. Dies gilt entsprechend für die Annahme, dass Männer ideologischer strukturiert sind und über ein konsistenteres Weltbild verfügen als Frauen. Diese sind sich ihrer Parteipräferenz längst nicht so sicher wie das andere Geschlecht und bewerten mit ihrer Wahlentscheidung offenbar primär die Auswirkungen der etablierten Politik auf ihre Lebensumstände. Damit bestätigen sich auch Vermutungen, dass sich Frauen eher von humanistischen und prosozialen Erwägungen leiten lassen und mehr Gewicht auf Fragen der Umwelt- oder der Bildungspolitik legen als Männer.

\section{b) Die Beurteilung der NPD}

Da die Wahltagsbefragung von Infratest dimap keine Informationen über rechtsextreme und sexistische Einstellungen enthält, führen wir die folgenden Analysen mit den Daten der Bundestagswahlstudie 2005 fort. Da sich unter den Befragten dieser Studie nur wenige bekennende NPDWähler befinden, verwenden wir als abhängige Variable hilfsweise die Beurteilung der NPD. "Generelle evaluative Orientierungen" (Niedermayer 2005: 83) gegenüber politischen Parteien werden mittels einer elfstufigen Skala erhoben (Anhang 3). Sie indizieren selbstverständlich nicht Wahl- 
verhalten sondern ausschließlich die allgemeine Bewertung einer Partei. Jedoch kann angenommen werden, dass Personen, die die NPD positiv beurteilen, auch Gefallen an ihr finden und sie eher wählen werden, als Personen, die ihr ablehnend gegenüber stehen. Dies dürfte insbesondere für rechtsextrem eingestellte Personen gelten.

\begin{tabular}{|c|c|c|c|c|}
\hline \multicolumn{2}{|c|}{ Tabelle 9: } & \multicolumn{3}{|c|}{$\begin{array}{l}\text { Die Beurteilung der NPD durch alle Befragten und durch } \\
\text { Rechtsextremisten in den Gebieten nach Geschlecht } \\
2005(\%)\end{array}$} \\
\hline & & Negativ & Wohlwollend & Positiv \\
\hline \multirow[t]{3}{*}{ BRD } & Alle & 76 & 12 & 12 \\
\hline & Männer & 74 & 13 & 13 \\
\hline & Frauen & 77 & 11 & 12 \\
\hline \multirow[t]{3}{*}{ West } & Alle & 76 & 12 & 12 \\
\hline & Männer & 74 & 13 & 13 \\
\hline & Frauen & 77 & 11 & 12 \\
\hline \multirow[t]{3}{*}{ Ost } & Alle & 77 & 10 & 12 \\
\hline & Männer & 76 & 11 & 14 \\
\hline & Frauen & 79 & 10 & 11 \\
\hline \multicolumn{5}{|c|}{ Nur Rechtsextremisten } \\
\hline \multirow[t]{3}{*}{ BRD } & Alle & 51 & 21 & 28 \\
\hline & Männer & 47 & 20 & 33 \\
\hline & Frauen & 56 & 23 & 21 \\
\hline \multirow[t]{3}{*}{ West } & Alle & 52 & 23 & 25 \\
\hline & Männer & 49 & 24 & 27 \\
\hline & Frauen & 56 & 23 & 21 \\
\hline \multirow[t]{3}{*}{ Ost } & Alle & 48 & 14 & 38 \\
\hline & Männer & 43 & 10 & 47 \\
\hline & Frauen & 59 & 22 & 19 \\
\hline
\end{tabular}

Aus Tabelle 9 geht hervor, dass nur drei Viertel der Befragten die NPD negativ einschätzen. Von einer allgemeinen Ächtung oder gar Ausgrenzung der neonazistischen Partei (Stöss 2007: 133) kann daher keine Rede sein. Jeweils 12 Prozent der (wahlberechtigten) Bürger betrachten sie wohlwollend oder positiv. Dabei besteht überraschenderweise kein Unterschied zwischen den Geschlechtern und auch kaum ein Ost-West-Unterschied. Die Ost-Frauen empfinden für die NPD nur geringfügig seltener Zuneigung als die Ost-Männer. Positiv beurteilt werden die Nationaldemokraten vor allem von (eher männlichen) unteren Jahrgängen, von (eher männlichen) Arbeitslosen, von (eher weiblichen) einfachen Arbeitern und von männlichen Facharbeitern sowie von gering gebil- 
deten Personen, mithin von der Unterschicht (Anhang 13e). Ähnlichkeiten mit der Sozialstruktur der NPD-Wähler sind unübersehbar.

Personen mit rechtsextremen Einstellungen begutachten die NPD erwartungsgemäß wesentlich besser als der Durchschnitt der Befragten (Tab. 9). Hier besteht allerdings ein geschlechtsspezifischer Unterschied: Rechtsextreme Männer stellen der NPD ein besseres Zeugnis aus als rechtsextreme Frauen. Dass diese die NPD zurückhaltender evaluieren als rechtsextreme Männer, ist überraschend und daher erklärungsbedürftig. Und für den nun zutage tretenden Ost-WestUnterschied sind auch nicht die rechtsextremen Frauen sondern ausschließlich die rechtsextremen Männer verantwortlich: Während in West und Ost gleichermaßen rund ein Fünftel der weiblichen Rechtsextremisten der NPD gegenüber positiv eingestellt sind, fällen 27 Prozent der männlichen Rechtsextremisten im Westen, aber 47 Prozent von innen im Osten ein gutes Urteil über die Nationaldemokraten.

Die Wertschätzung der der NPD durch rechtsextreme Männer fällt dann besonders häufig gut aus, wenn sie mit der Demokratie unzufrieden sind, wenn sie sexistisch eingestellt sind oder wenn sie über ein geringes politisches Selbstbewusstsein verfügen. Rechtsextreme Frauen attestieren der NPD besonders oft eine gute Performanz, wenn sie politisch uninteressiert, mit der Demokratie oder der Politik unzufrieden oder anomisch eingestellt sind (Tab. 10).

\section{Tabelle 10: Die positive Beurteilung der NPD durch alle Befragten und durch Rechtsextremisten nach Geschlecht in Gruppen mit ausgewählten politischen Orientierungen 2005 (\%)}

\begin{tabular}{|l|cc|cc|}
\hline \multirow{2}{*}{ Orientierungsgruppen } & \multicolumn{3}{|c|}{ Alle } & \multicolumn{2}{c|}{ Nur Rechtsextremisten } \\
\cline { 2 - 5 } & Männer & Frauen & Männer & Frauen \\
\hline Sexismus & 23 & 15 & 38 & $\star 12$ \\
Autoritäre Dispositionen & 18 & 14 & 32 & 16 \\
Anomie & 16 & 13 & 33 & 23 \\
Geringes politisches Selbstbewusstsein & 19 & 14 & 35 & 22 \\
Politisches Desinteresse & 24 & 21 & 30 & 32 \\
Unzufriedenheit mit der Demokratie & 33 & 19 & 41 & 26 \\
Politische Unzufriedenheit & 21 & 18 & 32 & 23 \\
\hline Insgesamt & $\mathbf{1 3}$ & $\mathbf{1 2}$ & $\mathbf{3 3}$ & $\mathbf{2 1}$ \\
\hline
\end{tabular}

* Geringe Fallzahlen.

Lesebeispiel: 23 Prozent aller befragten Männer mit sexistischen Orientierungen bewerteten die NPD 2005 positiv. Insgesamt urteilten aber nur 13 Prozent der Männer positiv über die NPD. Von den rechtsextremen Männern mit sexistischen Orientierungen bewerteten die NPD sogar 38 Prozent positiv. Damit lagen sie fünf Prozentpunkte über dem Durchschnittswert. Denn nur 33 Prozent der männlichen Rechtsextremisten beurteilten die NPD positiv. 
Welche geschlechtsspezifischen Auswirkungen hat Rechtsextremismus auf die Zuneigung zur NPD? Die Differenz bei der positiven Beurteilung der NPD zwischen allen Männern und rechtsextremen Männern ist insgesamt doppelt so groß wie die zwischen allen Frauen und rechtsextremen Frauen (sie beträgt 20 Prozentpunkte zu neun Prozentpunkten). Die Werte streuen allerdings beträchtlich, wie aus Tabelle 10 hervorgeht. Erhebliche Steigerungen sind vor allem bei Männern zu verzeichnen, wenn sich Rechtsextremismus mit Anomie (+17 Prozentpunkte), mit geringem politischem Selbstbewusstsein (+16 PP), mit autoritären Dispositionen (+14 PP) oder mit politischer Unzufriedenheit (+11 PP) verbindet. Frauen erreichen zweistellige Zuwächse nur bei der Kombination von Rechtsextremismus mit politischem Desinteresse (+11 PP) und mit Anomie (+10 PP). Gerade bei Frauen können sich diese Veränderungen auch nur geringfügig auswirken, so bei der Verbindung von Rechtsextremismus mit autoritären Dispositionen (+2 PP) oder mit politischer Unzufriedenheit (+5 PP).

Rechtsextreme Einstellungen bewirken also nicht durchgängig, dass die NPD wesentlich häufiger besser evaluiert wird. Sogar das Gegenteil ist möglich. Beispiel Sexismus: 23 Prozent aller Männer mit sexistischen Einstellungen, aber 38 Prozent aller rechtsextremen Männer mit sexistischen Einstellungen bewerten die NPD positiv. Nun zu den Frauen: Gefallen finden an der NPD 15 Prozent der sexistischen, aber nur (etwa) 12 Prozent der zugleich rechtsextremen und sexistischen Frauen.

Bei rechtsextremen Männern verursachen sexistische Einstellungen also eine deutliche Verbesserung der Benotung der NPD, während sie bei rechtsextremen Frauen zu einer Verschlechterung des Urteils führen. Zur Erinnerung: In Abschnitt $5 c$ hatten wir festgestellt, dass Sexismus bei der Ausprägung von rechtsextremen Einstellungen bei beiden Geschlechtern eine maßgebliche Rolle spielt und dass es vor allem Männer sind, die ein sexistisches Frauenbild vertreten. Nun stellt sich heraus, dass rechtsextreme Männer mit sexistischen Orientierungen die NPD noch häufiger positiv bewerten als ihre Geschlechtsgenossen ohne Sexismus. Sie erwarten sich also gerade auch von der NPD die Absicherung patriarchaler Verhältnisse. Dieser Effekt ist bei den rechtsextremen Frauen vergleichsweise seltenen zu beobachten. Leider ist es mit unseren Daten nicht möglich, den Einfluss von Sexismus auf das Wahlverhalten abzuschätzen. Die These, dass sich rechtsextreme Frauen der NPD trotz ihres reaktionären Frauenbildes zuwenden, ist allerdings nicht von der Hand zu weisen.

So viel zum Vergleich von Einstellungspotenzialen. Nun widmen wir uns der Analyse von Zusammenhängen. Dabei beziehen wir als unabhängige Variablen auch die Beurteilung der Bundestagsparteien mit ein (Tab. 11). Zunächst werden Männer und Frauen miteinander verglichen, im nächsten Schritt dann rechtsextreme Männer und rechtsextreme Frauen. 


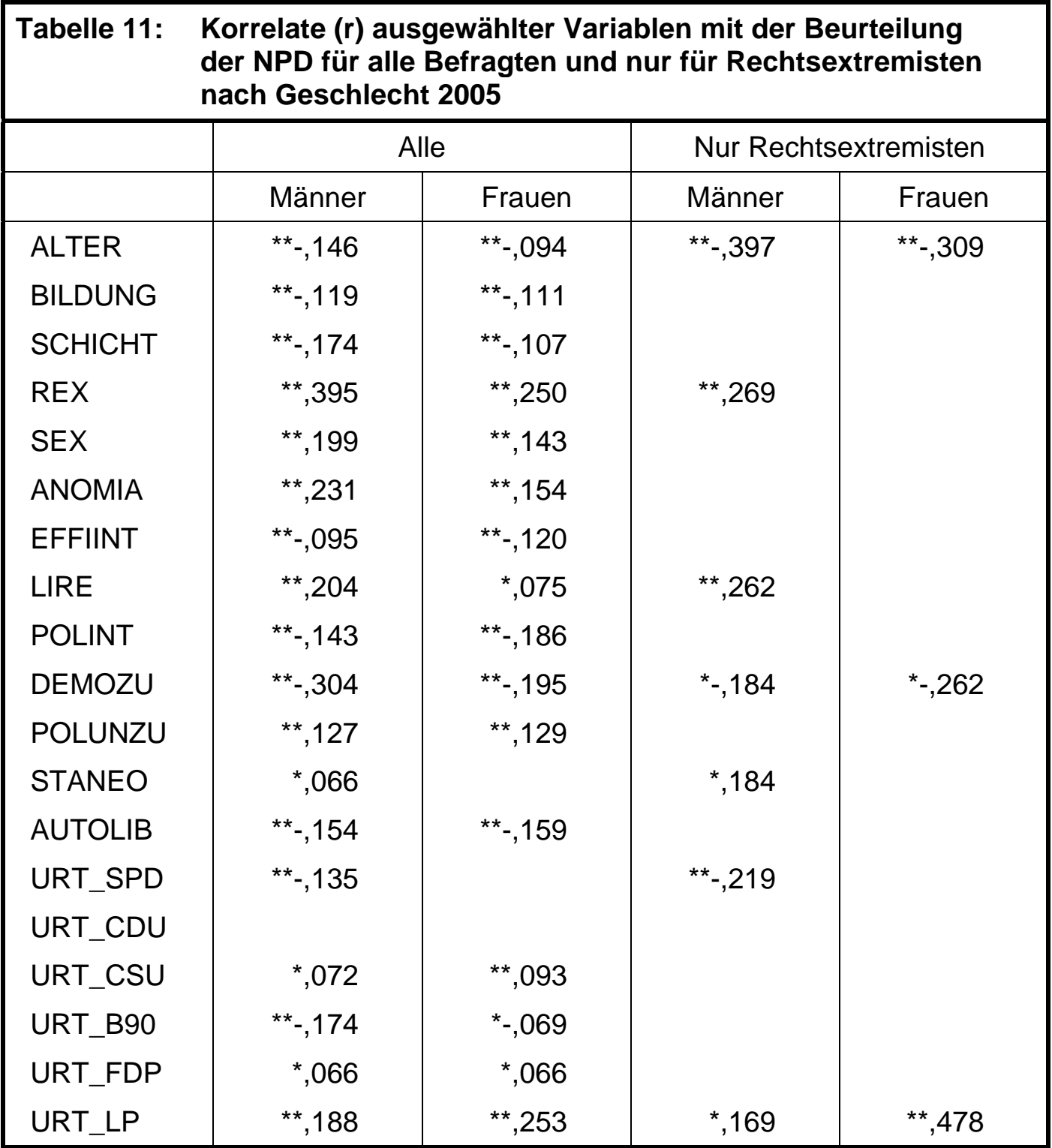

** Die Korrelation ist auf dem Niveau von 0,01 signifikant.

* Die Korrelation ist auf dem Niveau von 0,05 signifikant.

Nicht besetzte Felder: nicht signifikant.

\begin{tabular}{|c|c|}
\hline ALTER & Alter in Jahren \\
\hline ANOMIA & $\begin{array}{l}\text { Orientierungslosigkeit, Macht- und } \\
\text { Hilflosigkeit }\end{array}$ \\
\hline AUTOLIB & $\begin{array}{l}\text { Politische Ordnungsvorstellungen: } \\
\text { Autoritarismus vs. Libertarismus }\end{array}$ \\
\hline & Schulabschluss \\
\hline EMOZU & Demokratiezufriedenheit \\
\hline EFFIINT & Politisches Selbstbewusstsein \\
\hline IRE & Links-Rechts-Selbsteinstufung \\
\hline
\end{tabular}

ALTER Orientierungslosigkeit, Macht- und Politische Ordnungsvorstellungen: Autoritarismus vs. Libertarismus Demokratiezufriedenheit Links-Rechts-Selbsteinstufung
POLINT Politisches Interesse POLUNZU Politische Unzufriedenheit REX Rechtsextremismus (summiert)

SCHICHT Objektive Schichteinstufung SEX Sexismus

STANEO Politische Ordnungsvorstellungen: Staatsinterventionismus vs. Neoliberalismus

URT_XY Beurteilung der Partei XY 
Wie schon bei den Korrelationen mit rechtsextremen Einstellungen (Tab. 4) erzielen auch die Männer bei den Korrelationen mit der Begutachtung der NPD zumeist höhere Koeffizienten als die Frauen. Männer evaluieren die neonazistische Partei zwar genauso häufig positiv wie Frauen, die Ursachen für die Beurteilung der Partei treten bei innen aber etwas deutlicher zutage als bei Frauen. Ihre Wertschätzung wird ziemlich stark durch rechtsextreme Einstellungen (positiv) und durch Demokratiezufriedenheit (negativ) sowie schwach durch Anomie (positiv) und die Links-RechtsSkala (positiv) beeinflusst. Eindeutig dominant ist dabei Rechtsextremismus, und zwar mit einem Koeffizienten, der nahezu einen starken Zusammenhang signalisiert ${ }^{42}$. Für die Frauen messen wir höchstens schwache Assoziationen, nämlich mit der Evaluierung der Linkspartei (positiv) und mit Rechtsextremismus (positiv).

Sexismus spielt bei der Einschätzung der NPD durch beide Geschlechter nur eine sehr geringe Rolle, wobei der Koeffizient bei Männern über dem von Frauen liegt. Sexistisch eingestellte Personen benoten die NPD zwar überdurchschnittlich häufig positiv (Männer noch öfter als Frauen), aber Sexismus beeinflusst die Zuneigung nur mäßig. Bei der Entwicklung von rechtsextremen Einstellungen kommt dem Sexismus dagegen ein wesentlich größeres Gewicht zu: Seine Wirkung ist bei Männern stark, bei Frauen immerhin noch ziemlich stark (Tab. 4). Ein gegen Emanzipation gerichtetes Frauenbild stell zwar ein "zentrales Attraktionsmoment" bei der Hinwendung zum latenten Rechtsextremismus dar, für die Taxierung der NPD ist es allerdings von nachgeordneter Bedeutung. Besonders wichtig ist hier die Ideologie im Allgemeinen, die bei der Urteilsbildung der Männer eine deutlich größere Wirkung ausübt als bei der von Frauen.

Charakteristisch für die Urteilsbildung der Männer sind also rechtsextreme Einstellungen, eine rechtsgerichtete ideologische Selbstidentifikation und die Unzufriedenheit mit der Demokratie, Faktoren, die unsere These bestätigen, dass die rechtsextremen Neigungen von Männern stark ideologisch fundiert und durch eine feindselige Haltung gegenüber der Demokratie geprägt sind.

Charakteristisch für die Urteilsbildung der Frauen sind neben den beiden bereits genannten und bei innen vergleichsweise einflussreichen Prädiktoren folgende unabhängige Variablen, die allerdings nur etwas stärker als bei Männern mit der Bewertung der NPD korrelieren: politisches Selbstbewusstsein (negativ), politisches Interesse (negativ) und politische Unzufriedenheit (positiv). Die Zusammenhänge sind sehr schwach und sollten daher - auch mit Blick auf die geringen Differenzen zu den Männern - nicht überbewertet werden, aber die Parallelen zu den Korrelaten mit rechtsextremen Einstellungen (Tab. 4) sind unübersehbar: Die Affinität der Frauen zur NPD wächst mit zunehmender Distanz gegenüber dem politischen Geschehen und den Leistungen der etablierten Politik. Bei Männern ist die Unzufriedenheit mit der demokratischen Ordnung viel wichtiger für die Zuneigung zur NPD als bei Frauen. 
Da in den neunziger Jahren intensiv über die Bedeutung des politischen Interesses für das Wahlverhalten von Frauen diskutiert wurde (s. oben Abschn. 3), erfolgen dazu noch einige Hinweise auf der Grundlage unserer Daten. Männer sind politisch interessierter als Frauen: Sehr starkes politisches Interesse bekunden 17 Prozent der Männer, aber nur neun Prozent der Frauen. Völlig desinteressiert zeigen sich 13 Prozent der Männer und 25 Prozent der Frauen. Rechtsextremisten sind noch weniger politisch interessiert als der Durchschnitt der Befragten. Aber auch dann gilt, dass rechtsextreme Männer seltener politisch desinteressiert sind als rechtsextreme Frauen (20\% zu 35\%; Anhang 13b). Aus der Tatsache, dass sich (insbesondere rechtsextreme) Frauen weniger für Politik interessieren als (rechtextreme) Männer, sollten aber keine voreiligen Schlüsse gezogen werden. Denn das politische Interesse übt nur einen sehr geringen Einfluss auf die Entwicklung von rechtsextremen Einstellungen (Tab. 4) und auf die Evaluierung der NPD (Tab. 11) aus. Dies dürfte im Großen und Ganzen auch für das Wahlverhalten gelten. Dazu sind hier keine Angaben möglich, aber auch in der erwähnten Literatur werden nur Potenziale, aber keine Zusammenhänge genannt.

Ursächlich für das politische Desinteresse scheint mir das damit eng verbundene politische Selbstbewusstsein ${ }^{43}$ zu sein, das Gefühl also, kompetent und aussichtsreich auf politische Prozesse einwirken zu können (Vetter 2000). Ein geringes politisches Kompetenzgefühl weisen in unserer Befragung 42 Prozent der Männer und 60 Prozent der Frauen auf. Bei den rechtsextrem eingestellten Personen finden sich fast identische Größenordnungen: Männer 45 Prozent, Frauen 66 Prozent (Anhang 13b). Daher bewegen sich die Korrelationskoeffizienten auch auf einem sehr niedrigen Niveau, wobei das politische Selbstbewusstsein bei der Benotung der NPD noch eine geringere Rolle spielt als bei der Ausprägung von rechtsextremen Einstellungen (Tab. 4, 11). Dass Frauen dabei etwas bessere Messwerte aufweisen als Männer, ist kaum von Bedeutung. Wichtiger scheint mir die Tatsache zu sein, dass Frauen ihre Interventionschancen geringer einschätzen als Männer, und zwar unabhängig davon, ob sie rechtsextrem eingestellt sind oder nicht. Dies dürfte das Ergebnis von Erfahrungen mit ihrer doppelten Vergesellschaftung und/oder mit der patriarchalen Dominanzkultur sein. Ob sich die Frauen den bestehenden Verhältnissen unterwerfen, ob sie sich mit ihnen nur abfinden oder sie sogar kritisch betrachten, lässt sich mit unseren Daten nicht beantworten.

Bei der Regressionsanalyse (Tab. 12) bestätigt sich für Männer der dominante Einfluss von rechtsextremen Einstellungen auf die Zuneigung zur NPD. An zweiter Stelle folgt die Evaluierung der Linkspartei. Dass zwischen den Einschätzungen beider Parteien ein positiver Zusammenhang besteht, hatte sich schon bei den Korrelaten gezeigt (Tab. 11). Offenbar kommt damit die im 


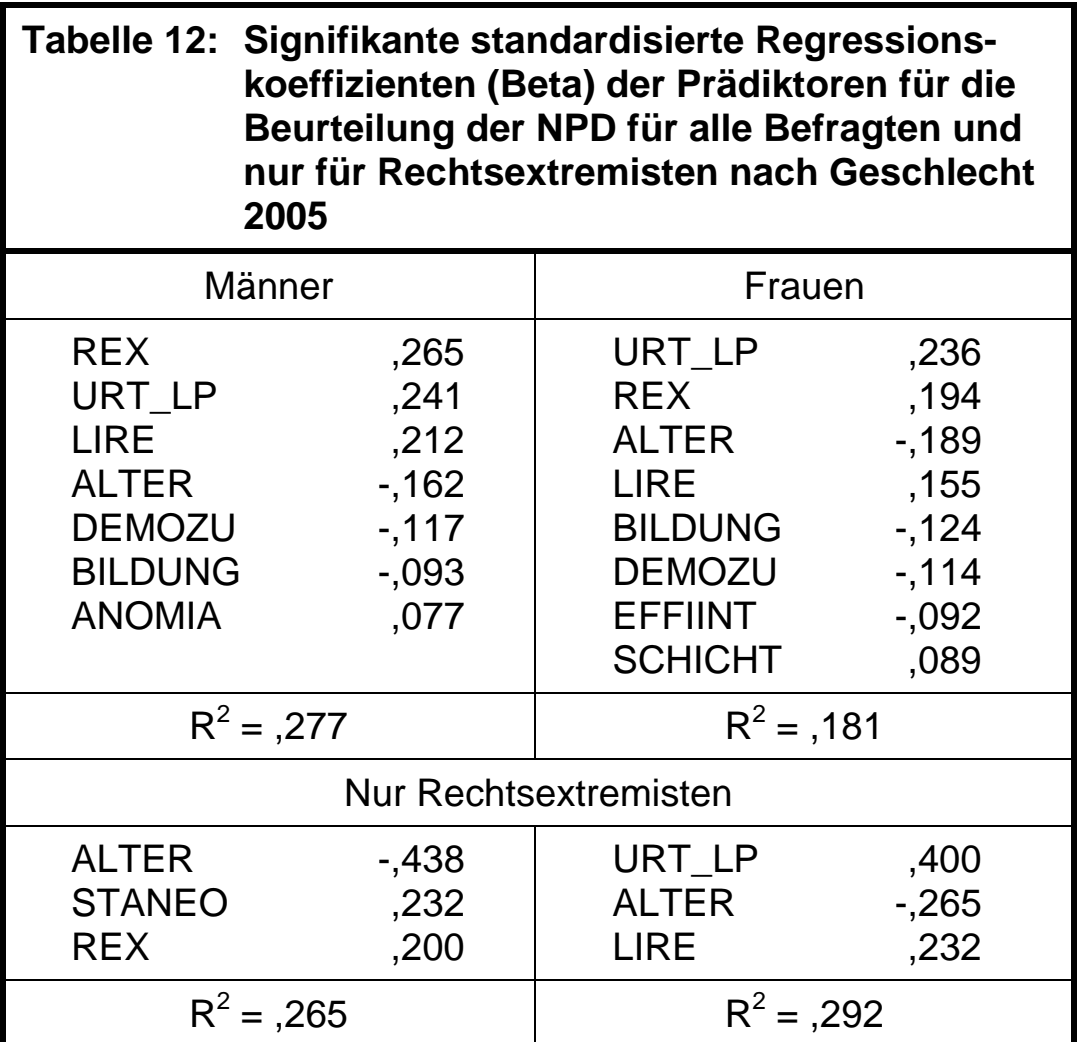

Signifikanzniveau der Beta-Werte 0,05.

(Schrittweise) eingeführte Variablen:

ALTER

Alter in Jahren

ANOMIA Orientierungslosigkeit, Macht- und Hilflosigkeit

AUTOLIB Politische Ordnungsvorstellungen: Autoritarismus vs.

Libertarismus

BILDUNG Schulabschluss

DEMOZU Demokratiezufriedenheit

EFFIINT Politisches Selbstbewusstsein

LIRE Links-Rechts-Selbsteinstufung

POLINT Politisches Interesse

POLUNZU Politische Unzufriedenheit

REX Rechtsextremismus

SCHICHT Objektive Schichteinstufung

SEX Sexismus

STANEO Politische Ordnungsvorstellungen: Staatsinterventionismus vs. Neoliberalismus

URT_CDU Beurteilung der CDU

URT_CSU Beurteilung der CSU

URT B90 Beurteilung der Bündnisgrünen

URT_FDP Beurteilung der FDP

URT_LP Beurteilung der Linkspartei

URT_NPD Beurteilung der NPD (abhängige Variable) 
Rechtsextremismus weit verbreitete Kapitalismuskritik zum Ausdruck (Stöss 2008), als deren Repräsentanten im Parteiensystem nicht nur die NPD sondern auch die Linkspartei angesehen wird. Bei den Frauen bildet die Begutachtung der Linkspartei sogar den stärksten Prädiktor für ihre Affinität zur NPD, gefolgt vom Rechtsextremismus. Dass Sexismus bei der Regressionsrechnung für beide Geschlechter unter den Tisch fällt, dürfte daran liegen, dass schon die Korrelationskoeffizienten gering ausfallen und ein Teil der Varianz im Prädiktor Rechtsextremismus "eingepreist" sein dürfte.

Beim Vergleich von rechtsextremen Männern und rechtsextremen Frauen ist zu bedenken, dass nur die Varianz der wenigen Messwerte oberhalb des "cutting points" der RechtsextremismusSkala zur Disposition steht. Nennenswerte (signifikante) Kovarianzen mit anderen Variablen dürften selten sein und erhalten dadurch eine besondere Bedeutung. Wenn beispielsweise rechtsextreme Einstellungen bei rechtsextremen Männern (wenn auch nur schwach) positiv mit der Wertschätzung der NPD korrelieren (Tab. 11), dann lernen wir daraus, dass sich selbst innerhalb des rechtsextremen Einstellungspotenzials die Taxierung der NPD mit steigenden Skalenwerten verbessert. Für Frauen gilt das nicht. Bemerkenswert ist vor allem, dass bei innen nun die Beurteilung der Linkspartei mit der der NPD mit einem Wert von $r=, 478$ korreliert. Dabei handelt es sich um den stärksten Koeffizienten, den wir im Laufe dieser Untersuchung gemessen haben. Beim weiblichen Rechtsextremismus hängt die Bewertung der NPD also in exorbitanter Weise von der Einschätzung der Linkspartei ab. Dies schlägt sich entsprechend bei den Regressionskoeffizienten nieder (Tab. 12).

Bemerkenswert ist weiterhin, dass bei Rechtsextremisten die Benotung der NPD stark (negativ) vom Alter abhängt, mehr noch bei Männern als bei Frauen. Bei den rechtsextremen Männern folgen als Einflussfaktoren die ideologische Selbstidentifikation, die (negative) Evaluierung der SPD, die Unzufriedenheit mit der Demokratie, die Präferenz für staatsinterventionistische Ordnungsvorstellungen und schließlich - wie erwähnt - die positive Beurteilung der Linkspartei (Tab. 11). Bei der Regressionsanalyse für rechtsextreme Männer verbleiben nur noch das Alter, der Staatsinterventionismus und der Rechtsextremismus, bei rechtsextremen Frauen die Wertschätzung für die Linkspartei, das Alter und die Links-Rechts-Selbsteinstufung (Tab. 12).

Damit dürfte auch klar sein, warum rechtsextreme Frauen weniger Gefallen an der NPD finden als rechtsextreme Männer: Dass ihre Zuneigung zur NPD stark mit der Wertschätzung der Linkspartei korrespondiert, deutet darauf hin, dass diese Zuneigung vor allem auf ihrer prosozialen Orientierung bzw. auf ihrer Kritik an der Wirtschafts- und Sozialordnung der Bundesrepublik basiert und dass rechtsextreme Frauen auch in der Linkspartei eine mögliche Alternative im Parteiensystem sehen. Sie sind also nicht so stark auf die NPD fixiert wie rechtsextreme Männer, die von der NPD vorrangig aus ideologischen, systemfeindlichen Erwägungen angetan sind. Übrigens findet die 
gelegentlich vorgetragene These, dass Frauen eine "Abneigung gegenüber den Extremen" (Hofmann-Göttig 1989b: 30) hätten, in unseren Daten keine Bestätigung.

Das Alter stellt eine wichtige Variable dar, die den Unterschied zwischen latentem und manifestem Rechtsextremismus markiert. Rechtsextremen Einstellungen nehmen bei beiden Geschlechtern (bei Frauen mehr als bei Männern) mit wachsendem Alter zu. Beim Wahlverhalten zugunsten von rechtsextremen Parteien und bei der Evaluierung der NPD verhält es sich umgekehrt. Insbesondere bei Rechtsextremisten steigt die Wertschätzung der NPD mit abnehmendem Alter (bei Männern mehr als bei Frauen).

Rechtsextreme Einstellungen und die Beurteilung der NPD unterscheiden sich auch hinsichtlich der Varianzaufklärung durch die zur Verfügung stehenden unabhängigen Variablen. Zunächst einmal korrelieren diese mit Rechtsextremismus (Tab. 4) zumeist stärker als mit der Einschätzung der NPD (Tab. 11). Vor allem aber erklären sie bei Männern 42 Prozent und bei Frauen immerhin noch 33 Prozent der Varianz der Rechtsextremismus-Skala (Tab. 5), während die entsprechenden Anteile für die Bewertung der NPD nur 28 Prozent bzw. 18 Prozent betragen (Tab. 12), und dies, obwohl dabei noch zusätzliche Variablen berücksichtigt wurden. Dass die Aufklärungsquote bezüglich des Rechtsextremismus so gering ausfällt, haben wir oben mit dem Mangel an sozioökonomischen Variablen begründet, die gemeinhin als wichtige Ursachen für Rechtsextremismus gelten. Dass die diesbezügliche Aufklärungsquote für Frauen noch geringer ist als für Männer, haben wir zusätzlich auf das Fehlen von Variablen zur geschlechtsspezifischen Sozialisation zurückgeführt. All dies erklärt wohl kaum die dürftige Varianzaufklärung bei der Evaluierung der NPD. Ich vermute, dass dabei auch das Erscheinungsbild der Partei und tagespolitische Stimmungen eine Rolle spielen.

Fazit: Die Befunde lassen sich wie folgt kondensieren:

- Frauen finden genauso häufig Gefallen an der NPD wie Männer.

- Personen mit rechtsextremen Einstellungen bewerten die NPD wesentlich besser als der Durchschnitt der Befragten. Dabei besteht allerdings ein Unterschied zwischen den Geschlechtern: Rechtsextreme Männer stellen der NPD noch häufiger ein gutes Zeugnis aus als rechtsextreme Frauen.

- Wenn sich bei Männern zu rechtsextremen auch noch sexistische Einstellungen gesellen, wächst der Anteil der positiven Evaluierungen. Das Gegenteil ist bei rechtsextremen Frauen der Fall: Wenn sie über sexistische Orientierungen verfügen, fällt der Anteil der positiven Urteile (bezogen auf alle rechtsextremen Frauen) deutlich unterdurchschnittlich aus. Allerdings ist der Einfluss von Sexismus auf die Wertschätzung der NPD gering, bei Frauen noch geringer als bei Männern. 
- Die Bedeutung des politischen Interesses für die Entwicklung von rechtsextremen Neigungen wird zumeist überschätzt. Es wirkt sich nur in sehr geringem Umfang auf die Verbreitung von rechtsextremen Einstellungen und auf die Beurteilung der NPD aus, bei Frauen allerdings etwas stärker als bei Männern.

- Maßgeblich für die Bewertung der NPD durch Männer sind rechtsextreme Einstellungen. Es folgen Unzufriedenheit mit der Demokratie, Anomie und eine rechtsgerichtete ideologische Selbstverortung. Bei Frauen sind diesbezüglich die Zuneigung zur Linkspartei und rechtsextreme Einstellungen vorrangig.

- Wenn nur die Affinität der Rechtsextremisten zur NPD betrachtet wird, dann erweisen sich bei Männern das Ausmaß an rechtsextremen Einstellungen und das Alter als herausragende Einflussfaktoren, bei Frauen die Wertschätzung für die Linkspartei und ebenfalls das Alter.

\section{c) Gewaltbereitschaft}

Gewalt wurde in der Bundestagswahlstudie nicht abgefragt. Ich hatte allerdings die Möglichkeit, mit den Daten einer Untersuchung zu arbeiten, die Fragen sowohl zur Gewaltbereitschaft als auch zu Sexismus und Rechtsextremismus enthält. Es handelt sich um die Studie "Rechtsextreme Einstellungen und ihre Einflussfaktoren in Deutschland" von Prof. Dr. Elmar Brähler (Universität Leipzig) aus dem Jahr 2006 (Anhang 1). Brähler hat mir die Daten freundlicherweise zur Verfügung gestellt, wofür ich mich an dieser Stelle nochmals herzlich bedanke. Die Erhebungsinstrumente werden in Anhang 14 beschrieben.

Sturzbecher, Landua und Shahla (2001: 261) unterscheiden bei Gewalt zwischen der Akzeptanzebene, der Ebene der Verhaltensintentionen und der Handlungsebene ${ }^{44}$. Die sechs Statements der Brähler-Studie (Anhang 14) beziehen sich auf Akzeptanz und Verhaltensintentionen. Wir sprechen daher von Gewaltbereitschaft, wobei Gewaltbereitschaft nicht mit Gewalttätigkeit gleichgesetzt werden darf. Faktorenanalysen legen es nahe, zwischen aktiver und passiver Gewaltbereitschaft zu unterscheiden. Aktive Bereitschaft liegt vor, wenn eine Person ihre Bereitschaft erklärt, selbst unmittelbar Gewalt anzuwenden (z.B. "Ich bin in bestimmten Situationen durchaus bereit, auch körperliche Gewalt anzuwenden, um meine Interessen durchzusetzen"). Um passive Gewaltbereitschaft handelt es sich, wenn eine Person für sich selbst Gewalttätigkeit ausschließt, aber das Gewalthandeln anderer begrüßt (z.B. "Ich würde selbst nie körperliche Gewalt anwenden, finde es aber gut, wenn es Leute gibt, die auf diese Weise für Ordnung sorgen"). Die Formulierung der Sta- 
tements haben bis auf eine Ausnahme ${ }^{45}$ keine inhaltliche Beziehung zum Rechtsextremismus. Wir untersuchen also nicht rechtsextreme Gewalt sondern Gewaltbereitschaft bei (nicht) rechtsextrem eingestellten Männern und Frauen.

Bei der Zustimmung zu den Statements zur Gewaltbereitschaft (Anhang 14a) fällt auf, dass passive Gewaltbereitschaft weiter verbreitet ist als aktive Gewaltbereitschaft und dass sich die Geschlechter nur hinsichtlich der aktiven Gewaltbereitschaft unterscheiden. Dies zeigt sich auch bei den Indizes (Tab. 13): Jeweils 16 Prozent der Männer und der Frauen weisen passive Gewaltbereitschaft auf, zu aktiver Gewaltbereitschaft bekennen sich zehn Prozent der Männer, aber nur vier Prozent der Frauen. Diese Befunde sprechen kaum dafür, dass es sich bei den Frauen schlechthin um das friedfertige Geschlecht handelt. Sie neigen zwar weniger als Männer zu selbsttätiger Gewalt, begrüßen aber genauso häufig wie diese das aggressive Verhalten von Dritten. Insofern hat die These eine gewisse Berechtigung, dass Frauen nicht selbst kämpfen, sondern kämpfen lassen. Damit ist allerdings die Behauptung widerlegt, dass Frauen auf Distanz zu Männern gingen, wenn sich rassistisches Verhalten mit "männlich-chauvinistischem Gebaren amalgamiert".

\begin{tabular}{|c|c|c|c|c|c|c|c|c|c|}
\hline \multirow[t]{3}{*}{ Tabelle 13: } & \multicolumn{9}{|c|}{$\begin{array}{l}\text { Aktive (GEWAKT) und passive (GEWPAS) Gewaltbereitschaft bei allen } \\
\text { Befragten und nur bei Rechtsextremisten nach Gebiet und Geschlecht } \\
2006(\%)\end{array}$} \\
\hline & \multicolumn{3}{|c|}{ BRD } & \multicolumn{3}{|c|}{ West } & \multicolumn{3}{|c|}{ Ost } \\
\hline & Alle & M & $\mathrm{F}$ & Alle & M & $\mathrm{F}$ & Alle & M & $\mathrm{F}$ \\
\hline GEWAKT & 7 & 10 & 4 & 7 & 10 & 5 & 6 & 11 & 3 \\
\hline GEWPAS & 16 & 16 & 16 & 16 & 15 & 17 & 15 & 18 & 13 \\
\hline \multicolumn{10}{|c|}{ Nur Rechtsextremisten } \\
\hline GEWAKT & 17 & 24 & 9 & 17 & 22 & 10 & 19 & 30 & 8 \\
\hline GEWPAS & 28 & 26 & 30 & 29 & 25 & 34 & 24 & 31 & 14 \\
\hline
\end{tabular}

Daten: Brähler, N=4872.

Der Gender Gap beim Gewalthandeln ist aus der Jugendforschung bekannt und wird auch auf biologische Faktoren zurückgeführt:

"Die Körperkraft beeinflusst insbesondere die Bereitschaft zu physischen Aggressionen und ist nicht zuletzt eine Ursache für die existierenden Geschlechtsunterschiede bei aggressivem Handeln. So bevorzugen Mädchen aufgrund ihrer physischen Unterlegenheit und ihres Vorsprungs bei der Entwicklung kommunikativer Fähigkeiten spätestens ab dem fünften Lebensjahr subtile bzw. verbale Formen der Aggressivität. Betrachtet man Reputationsschädigung und soziale Ausgrenzung als Formen von Aggressivität, so sind Mädchen bzw. Frauen auf jeder Altersstufe aggressiver als Jungen bzw. Männer." (Sturzbecher/Hess/Them 2002: 183 f.) 
Die Ostdeutschen unterscheiden sich von den Westdeutschen weder in Bezug auf aktive noch auf passive Gewaltbereitschaft. Die Männer im Osten neigen jedoch etwas mehr zu passiver Gewaltbereitschaft als die im Westen, die ostdeutschen Frauen dafür etwas weniger als ihre westlichen Geschlechtsgenossinnen. Bemerkenswert ist zudem, dass sich westdeutsche Frauen geringfügig öfter zu passiver Gewaltbereitschaft bekennen als westdeutsche Männer. Rechtsextremisten sind deutlich gewaltbereiter als der Durchschnitt der Befragten. Das gilt insbesondere für die Ostdeutschen. Knapp ein Drittel der männlichen Rechtsextremisten im Beitrittsgebiet verfügt über aktive Gewaltbereitschaft! Und wiederum begrüßen die rechtsextremen westdeutschen Frauen passive Gewaltbereitschaft häufiger als die männlichen Rechtsextremisten in der alten Bundesrepublik, diesmal sogar wesentlich häufiger.

Gewaltbereitschaft findet sich überdurchschnittlich bei gering Gebildeten, bei Arbeitslosen und einfachen Arbeitern, bei der Unterschicht. Befragte, die sich ideologisch eher rechts verorten und die über rechtsextreme oder sexistische Einstellungen verfügen, lassen ebenfalls erhebliche Gewaltbereitschaft erkennen, wobei Frauen bei der passiven Gewaltbereitschaft teilweise größere Anteile aufweisen als Männer. Die unteren Jahrgänge, vor allem die 14-17jährigen, zeichnen sich durch deutlich stärkere aktive Gewaltbereitschaft aus, als die mittleren und oberen Jahrgänge. Dies gilt jedoch nicht für passive Gewaltbereitschaft (Anhang 14b).

\begin{tabular}{|l|c|c|c|c|}
\hline \multirow{2}{*}{ Tabelle 14: } & \multicolumn{3}{c|}{ Korrelate (r) von aktiver und passiver Gewaltbereitschaft } \\
mit ausgewählten Variablen nach Geschlecht 2006
\end{tabular}

Daten: Brähler, N=4872.

** Die Korrelation ist auf dem Niveau von 0,01 signifikant.

* Die Korrelation ist auf dem Niveau von 0,05 signifikant.

$\begin{array}{ll}\text { ALTER } & \text { Alter in Jahren } \\ \text { BILDUNG } & \text { Schulabschluss } \\ \text { LIRE } & \text { Links-Rechts-Selbsteinstufung } \\ \text { REX_B } & \text { Rechtsextremismus (Brähler) } \\ \text { SCHICHT } & \text { Objektive Schichteinstufung } \\ \text { SEX_B } & \text { Sexismus (Brähler) }\end{array}$


Die statistischen Zusammenhänge berichtet Tabelle 14: Die Links-Rechts-Skala korreliert bei beiden Geschlechtern - wenn auch nur sehr schwach - positiv mit aktiver und passiver Gewaltbereitschaft. Gewaltbereitschaft wächst also mit einer rechten ideologischen Selbstverortung. Besonders eng fallen die Zusammenhänge mit rechtsextremen Einstellungen aus. Beim Rechtsextremismus handelt es sich mithin um eine tendenziell gewaltförmige Weltanschauung ${ }^{46}$. Ein Geschlechterunterschied macht sich nur bei der aktiven Gewaltbereitschaft bemerkbar: Sie wird bei Männern stärker durch Rechtsextremismus beeinflusst als bei Frauen. Derselbe Effekt zeigt sich - auf niedrigerem Niveau - beim Sexismus. Auch Sexismus stellt eine tendenziell gewaltförmige Überzeugung dar. Und auch dabei gilt, dass aktive Gewaltbereitschaft bei Männern stärker durch Sexismus geprägt ist als bei Frauen.

Fazit: Frauen sind offenbar nicht weniger aggressiv als Männer, aber ihre Bereitschaft zu gewalttätigem Handeln ist geringer. Einen Geschlechterunterschied konnten wir nur bei der aktiven Gewaltbereitschaft ermitteln. Tatsächlich neigen Frauen dazu, Gewalt zu delegieren. Daher sind sie wohl eher passive als aktive Mittäterinnen bei der Reproduktion der Dominanzkultur. Gewaltbereitschaft wird durch rechtsextreme Einstellungen begünstigt, im Weiteren dann auch durch Sexismus. Das gilt eher für Männer als für Frauen, eher für aktive als für passive Gewaltbereitschaft. Nachgerade besorgniserregend ist der Befund, dass knapp ein Drittel der ostdeutschen Männer bereit ist, Gewalt auszuüben.

\section{Zusammenfassung der Untersuchungsergebnisse}

Die Untersuchung befasst sich vorrangig mit folgenden Fragen: Warum wählen Frauen seltener rechtsextreme Parteien, warum begehen sie weniger rechtsextreme Straftaten als Männer, obwohl sie - so jedenfalls die herrschende Meinung - genauso häufig rechtsextreme Meinungen vertreten wie diese? Bezieht sich dieser Gender Gap tatsächlich nur auf Verhalten (manifester Rechtsextremismus) oder auch auf Einstellungen (latenter Rechtsextremismus)? Sind Männer oder Frauen vom sozialen Wandel, von den Individualisierungs- und Desintegrationsvorgängen besonders betroffen? Welches der beiden Geschlechter hat mehr Anlass, seine problematische soziale Lage unter Zuhilfenahme von rechtsextremen Deutungsangeboten zu verarbeiten? Wenden sich Frauen dem Rechtsextremismus trotz oder gerade wegen seines sexistischen - oder eben auch völkischbiologistischen, auf einer vermeintlich naturgegebenen Rollenzuweisung beruhenden - Frauen-

46 "Besonders gefährlich jedoch, und dies kann wohl nicht oft genug betont werden, ist der Zusammenhang zwischen Rechtsextremismus und Gewalt. Wir können davon ausgehen, dass zwar längst nicht jeder Gewaltbereite rechtsextreme Meinungen vertritt. Umgekehrt ist jedoch nahezu jeder rechtsextreme Jugendliche bereit, Gewalt auszuüben." (Sturzbecher/Hess/Them 2002: 208) 
und Familienbilds zu? Und wie ist das bei Männern? Besteht überhaupt ein Zusammenhang zwischen Rechtsextremismus und Sexismus? Handelt es sich beim Sexismus womöglich sogar um einen Bestandteil des rechtsextremen Einstellungsmusters?

Datenbasis der Untersuchung ist die Bundestagswahlstudie 2005. Gelegentlich werden aber auch andere Umfragen herangezogen.

\section{a) Zum Gender Gap bei rechtsextremen Einstellungen}

Der Gender Gap besteht nicht nur beim manifesten Rechtsextremismus, er zeigt sich ebenfalls beim latenten Rechtsextremismus. Er ist gewissermaßen omnipräsent. Frauen sind eben grundsätzlich anders als Männer (und umgekehrt). In der Literatur finden sich viele Thesen, die in ihrer Pauschalität nicht zu halten sind, weil sie nicht zwischen rechtsextremen Einstellungen und rechtsextremem Verhalten und auch nicht zwischen Rechtsextremisten und Personen ohne rechtsextreme Einstellungen unterscheiden. Und oft stellen sich die Unterschiede zwischen den Geschlechtern auch diffiziler dar, als es der schlichte Vergleich von Einstellungspotenzialen nahe legt. Das betrifft insbesondere die Anfälligkeit von Männern und Frauen für Rechtsextremismus. Die Forschung hat diesbezüglich verschiedene Befunde zutage gefördert, sodass sich als herrschende Lehre die Auffassung durchgesetzt hat, dass im Großen und Ganzen keine geschlechtsspezifische Resistenz gegenüber rechtsextremen Einstellungen besteht. Dem soll hier auch nicht widersprochen werden, obwohl in unserer Umfrage Männer wesentlich häufiger zum Rechtsextremismus neigen als Frauen. Viel interessanter scheint mir die Frage zu sein, worauf sich die widersprüchlichen Resultate gründen. Unsere Untersuchungen zeigen, dass die Messergebnisse auch von der formalen Gestaltung der Messinstrumente, insbesondere der Antwortvorgaben, abhängen. So tendieren Frauen häufiger als Männer dazu, sich auf den Antwortskalen mittig einzustufen. Wenn eine erkennbare Mitte fehlt (wie bei unserer Befragung), weichen sie oft in die Antwortverweigerung oder in untere Skalenwerte aus. So finden sich in unseren Daten wesentlich mehr weibliche als männliche "Nonrespondents". Wenn eine Antwortskala eine explizit benannte neutrale Mitte enthält (z.B. "teils-teils"), ist die Anzahl der Ausfälle verschwindend gering. Männer scheuen sich seltener als Frauen, auch hohe Punktwerte bei einzelnen Statements zu vergeben. Im Ergebnis verfügen sie, wie Analysen mit der kumulierten Rechtsextremismus-Skala zeigen, über ein konsistenteres rechtsextremes Weltbild als Frauen. Dass geschlechtsspezifische Faktoren bei der Bewertung von Rechtsextremismus-Statements eine Rolle spielen, zeigt sich auch daran, dass sich Frauen der Auseinandersetzung mit "schwierigen" Statements häufiger verweigern als Männer. Dies führe ich darauf zurück, dass sie sich weniger für Politik interessieren und sich weniger politische Kompetenz zubilligen als Männer und daher eher vor der Beantwortung von heiklen politischen Fragen zurückweichen. 


\section{b) Rechtsextreme und sexistische Einstellungen}

Der herrschaftstheoretische und der modernisierungstheoretische Ansatz nähern sich der Geschlechterproblematik im Rechtsextremismus aus verschiedenen Perspektiven. Beide schließen sich gegenseitig jedoch nicht aus sondern ergänzen sich. Das Verdienst des herrschaftstheoretischen Ansatzes besteht darin, dass er auf den engen Zusammenhang zwischen rassistischen, völkisch-nationalistischen und sexistischen Bestrebungen als zwei Formen von Diskriminierung, Hierarchisierung und Unterwerfung hingewiesen und begründet hat, warum auch Frauen von einer patriarchalen Dominanzkultur profitieren können. Dass dieser Zusammenhang tatsächlich besteht, und zwar bei Männern und Frauen, konnten wir zweifelsfrei nachweisen. Damit war auch eine erste Antwort auf die Frage gegeben, ob sich Frauen dem Rechtsextremismus trotz oder gerade wegen seines antiemanzipatorischen Weiblichkeitsideals zuwenden: Die Ausprägung von rechtsextremen Einstellungen wird stark durch sexistische Orientierungen begünstigt. Beide Geschlechter erwarten sich vom Rechtsextremismus also - wenn auch aus unterschiedlichen Motiven - die Sicherung des (angeblich bedrohten) Patriarchats durch ein traditionalistisches Frauen- und Familienkonzept. Den Frauen geht es letztlich um Anerkennung, Aufwertung und Orientierungssicherheit, den Männern um die Bewahrung bzw. Stärkung ihrer dominanten gesellschaftlichen Stellung.

Der enge Zusammenhang zwischen Sexismus und Rechtsextremismus legte die Bildung eines Index nahe, der beide Orientierungen miteinander verbindet. Detaillierte Analysen ergaben freilich, dass er kaum die Anforderungen an ein konsistentes und zuverlässiges Messinstrument erfüllt. Theoretisch steht diese Kombination auch auf schwachen Füßen. Denn in der Literatur wurde insbesondere von afro-amerikanischen Frauen darauf hingewiesen, dass es sich bei Rassismus/Rechtsextremismus und Sexismus um zwei sehr unterschiedliche Qualitäten von Diskriminierung handelt. Daher wurde Sexismus als Prädiktor für Rechtsextremismus herangezogen.

Die Leistungen des modernisierungstheoretischen Ansatzes bestehen darin, dass er den Blick dafür geschärft hat, dass aus den besonderen Sozialisationserfahrungen und gesellschaftlichen Existenzbedingungen von Männern und Frauen unterschiedliche Motive und Intensitäten bei der Hinwendung zum Rechtsextremismus resultieren. Das macht sich schon beim Verhältnis von Rechtsextremismus und Sexismus bemerkbar: Bei Männern fällt der statistische Zusammenhang stärker aus als bei Frauen, innen ist die Gewährleistung der patriarchalen Dominanzkultur durch den Rechtsextremismus also wichtiger als den Frauen. Auch im Kontext weiterer Erklärungsfaktoren für rechtsextreme Einstellungen spielt Sexismus bei beiden Geschlechtern eine maßgebliche Rolle und kann daher durchaus als zentrales Attraktionsmoment des Rechtsextremismus bezeichnet werden. Dies trifft wiederum eher auf Männer als auf Frauen zu. Hinsichtlich der zur Verfügung stehenden Erklärungsfaktoren für rechtsextreme Einstellungen unterscheiden sich Männer und Frauen nicht grundsätzlich. Allerdings enthält unser Datensatz keine Variablen zur geschlechts- 
spezifischen Sozialisation. Wenn allerdings die Größe der Einstellungspotenziale verglichen werden, machen sich durchaus Besonderheiten bemerkbar: So weisen durchschnittlich 11 Prozent aller Frauen, aber 21 Prozent aller rechtsextremen Frauen sexistische Einstellungen auf, während 21 Prozent aller Männer und sogar 46 Prozent aller rechtsextremen Männer über sexistische Orientierungen verfügen. Es ist also nicht auszuschließen, dass sich rechtsextreme Frauen (und Männer) auch für die Gleichberechtigung der Geschlechter einsetzen. An der positiven Assoziation von Rechtsextremismus und Sexismus ändert das freilich nichts. Männer zeichnen sich überdies nicht nur durch ein konsistenteres rechtsextremes Weltbild aus, sie sind auch ideologischer ausgerichtet und folgen dem antidemokratischen Kernanliegen des Rechtsextremismus häufiger als Frauen. Diese unterscheiden sich von den Männern vor allem durch ein geringeres Interesse am politischen Geschehen und halten sich diesbezüglich auch öfter für inkompetent als Männer. Kurz: Der weibliche Rechtsextremismus ist eher durch Distanz gegenüber der Politik geprägt, der männliche eher durch Distanz gegenüber der Demokratie.

\section{c) Zum Gender Gap bei Wahlen}

Männer wählen nach wie vor häufiger rechtsextreme Parteien als Frauen. Aber nicht nur darin besteht der Geschlechterunterschied. Am Beispiel der NPD konnte gezeigt werden, dass sie mit ihrer Stimmabgabe auch unterschiedliche Ziele verfolgen. Männer wählen die NPD eher aus Überzeugung, Frauen eher aus Protest. Diese sind sich ihrer Parteipräferenz auch nicht so sicher wie Männer und entscheiden sich zumeist erst kurz vor der Wahl, während Männer häufiger über eine Bindung an die NPD verfügen und sich daher zumeist schon vor längerer Zeit auf die Partei festgelegt haben. Bei den wahlentscheidenden Themen sticht bei Männern die Ausländerpolitik hervor, also das klassische, mit einer "Ausrufezeichen-Botschaft" (z.B. "Ausländer raus!") versehene Thema des Rechtsextremismus, das sich nahtlos in seine völkisch-nationalistische Ideologie einfügt. Frauen nennen dagegen eher "weiche" Themen, wie Schul- und Bildungspolitik, Wirtschaftspolitik und soziale Gerechtigkeit. Das spricht dafür, dass sie sich bei ihrer Wahlentscheidung vor allem von der Enttäuschung über die etablierten Parteien, von ihrer Unzufriedenheit mit dem auf ihre Alltagsbedürfnisse bezogenen Politikoutput leiten lassen. Es geht ihnen offenbar tatsächlich um die Verbesserung ihrer Lage als Hausfrauen und Mütter.

Unsere Untersuchungen über die Beurteilung der NPD deuten darauf hin, dass der Gender Gap seine Existenz nicht den Frauen schlechthin, sondern nur den rechtsextremen Frauen verdankt. Frauen finden nämlich genauso häufig Gefallen an der NPD wie Männer. Der Geschlechterunterschied tritt erst bei Personen mit rechtsextremen Einstellungen zutage. Sie bewerten die NPD zwar insgesamt häufiger positiv als der Durchschnitt der Befragten, das trifft auf rechtsextreme Männer allerdings anderthalb Mal so oft zu wie auf rechtsextreme Frauen. Von der Beurteilung der NPD 
darf zwar nicht auf die Wahl der NPD geschlossen werden. Ich gehe allerdings davon aus, dass die Wahlchancen der Partei mit ihrer positiven Evaluierung - insbesondere durch Personen mit rechtsextremen Einstellungen - wachsen.

Bei der Ursachenanalyse offenbart sich, dass rechtsextreme Einstellungen einen maßgeblichen Prädiktor für die Beurteilung der NPD darstellen. Sie wirken sich bei Männern jedoch nachhaltiger aus als bei Frauen. Dies gilt entsprechend für rechtsextreme Männer. Bei rechtsextremen Frauen steht allerdings die Wertschätzung der Linkspartei mit weitem Abstand an erster Stelle. Sie sind nicht so stark auf die NPD fixiert wie (rechtsextreme) Männer und betrachten auch die Linkspartei als mögliche politische Alternative im Sinne ihrer Alltagsbedürfnisse.

Sexismus hat bei der Hinwendung zur NPD längst nicht die Bedeutung, die ihm in der Literatur zugeschrieben wird. Sexismus korreliert nur sehr schwach mit der Beurteilung der NPD, bei Frauen noch schwächer als bei Männern. Da es sich um einen positiven und hoch signifikanten Zusammenhang handelt, gilt generell, dass das traditionalistische Frauen- und Familienbild der NPD durchaus eine gewisse Anziehungskraft auf Männer und Frauen ausübt. Die Annahme, dass Frauen dadurch eher abgestoßen werden, dass sie kein Interesse an Parteien haben, die vornehmlich Männerbelange vertreten, trifft in dieser Pauschalität also nicht zu. Richtig ist allerdings, dass die Alltagsbedürfnisse der Frauen wesentlich mehr Einfluss auf die Wertschätzung der NPD ausüben als ihre sexistischen Vorstellungen. Das bedeutet im Umkehrschluss aber auch, dass die Frauen der NPD nicht vorrangig wegen ihres patriarchalen Gesellschaftsbildes ein gutes Zeugnis ausstellen. Dies gilt sinngemäß auch für Männer. Deren Zuneigung zur NPD gründet sich primär auf ihr rechtsextremes Weltbild. Männer erwarten sich von der NPD zwar auch die Gewährleistung der patriarchalen Dominanzkultur, aber eben nur als nachgeordnetes Motiv für eine positive Beurteilung der Partei. Wenn der Blick nicht auf statistische Zusammenhänge sondern auf Einstellungspotenziale gerichtet wird, dann ergibt sich, dass sich die sehr geringen Korrelationen in bemerkenswerten Größenordnungen niederschlagen: 23 Prozent aller Männer mit sexistischen Einstellungen, aber 38 Prozent aller rechtsextremen Männer mit sexistischen Einstellungen bewerten die NPD positiv. Dagegen finden 15 Prozent der sexistischen, aber nur (etwa) 12 Prozent der zugleich rechtsextremen und sexistischen Frauen Gefallen an der NPD. Diese Befunde verweisen auf eine beachtliche Anzahl von Männern und erst Recht von Frauen, die sich der NPD trotz ihres reaktionären Weiblichkeitsideals zuwenden.

Noch mehr als Sexismus wird in der Literatur die Bedeutung des politischen Interesses für die positive Evaluierung der NPD überschätzt. Frauen sind zwar politisch desinteressierter als Männer, aber daraus sollten keine weitreichenden Schlussfolgerungen gezogen werden. Politisches Interesse korreliert zwar negativ mit der Rechtsextremismus-Skala und mit der Beurteilung der NPD, aber die Zusammenhänge fallen nur sehr schwach aus. Dass sie bei Männern etwas geringer sind 
als bei Frauen, ist unerheblich. Frauen schätzen ihre politischen Interventionschancen eben schlechter ein als Männer, unabhängig davon, ob sie rechtsextrem eingestellt sind oder nicht. Und damit liegen sie schließlich auch nicht völlig neben der Spur.

Meine These lautet also, dass der Gender Gap beim Wahlverhalten im Wesentlichen auf divergierenden Zielvorstellungen von rechtsextremen Männern und rechtsextremen Frauen beruht. Erstere sind vor allem aus ideologischen Gründen auf rechtsextreme Parteien fixiert, letzteren geht es eher um ihre Alltagsprobleme als Hausfrauen und Mütter. Darum hegen sie auch gewisse Sympathien für Linksaußenparteien. Die Vermutung, dass Frauen aus denselben Gründen wie Männer rechtsextreme Parteien wählen ${ }^{47}$, bestätigt sich mit unseren Daten also nicht.

\section{d) Zur Gewaltbereitschaft von Frauen}

In der Literatur finden sich viele - teilweise auch empirisch belegte - Hinweise darauf, dass sich Frauen gegenüber Männern durch Emotionalität, Fürsorglichkeit, Rücksichtnahme und Einfühlsamkeit auszeichnen und eher humane und soziale Werte vertreten. Gleichzeitig wird innen aber auch genauso viel Aggressivität bescheinigt wie Männern. Nach unseren Untersuchungen unterscheiden sich die Geschlechter nicht hinsichtlich der passiven Gewaltbereitschaft, wohl aber in Bezug auf die aktive Gewaltbereitschaft. Frauen sind kaum das friedfertige Geschlecht, sie kämpfen in der Regel aber nicht selbst, sondern lassen kämpfen. Da Frauen Gewalt delegieren, lässt sich ihre Zurückhaltung bei der Wahl von rechtsextremen Parteien kaum mit dem aggressiven Erscheinungsbild dieser "Männerparteien" erklären ${ }^{48}$. Vielmehr handelte es sich bei einem entsprechenden Votum um einen Akt der Gewaltdelegation. Da wir den Gender Gap im Wahlverhalten auf die Verarbeitung der Alltagsprobleme von rechtsextremen Frauen und Müttern zurückführen, stützen wir in gewissem Umfang auch die These von der Fürsorglichkeit der Frauen. Möglicherweise bezieht sich diese bei rechtsextremen Frauen vor allem auf Mitglieder der "Volksgemeinschaft", während sich ihre Aggressivität hauptsächlich gegen "Volksfeinde" oder Fremde richtet.

Die Bereitschaft zur Ausübung von Gewalt hängt vom Ausmaß der rechtsextremen Einstellungen einer Person ab, bei Männern noch mehr als bei Frauen. Beim Rechtsextremismus handelt es sich mithin unabhängig vom Geschlecht um eine gewaltförmige Ideologie. Dies gilt entsprechend für Sexismus. Auch sexistische Orientierungen fördern die Gewaltbereitschaft, wiederum bei Männern

47 "Aus diesen Ergebnissen kann gefolgert werden, dass Frauen im Wesentlichen aus den gleichen Gründen wie Männer rechtsextreme Parteien wählen. Die ideologischen Motive sind hierfür Autoritarismus, Nationalismus und Rassismus, aber auch Antisemitismus und Antifeminismus." (Amesberger/Halbmayr 2002c: 420)

48 "Bei allen ... Parteien gibt es Hinweise dafür, dass der aggressive politische Stil dieser Parteien oder einiger Persönlichkeiten Frauen auf Distanz hält." (Amesberger/Halbmayr 2002c: 420) 
stärker als bei Frauen. Für die Hinwendung der Frauen zum Rechtsextremismus erweist sich also weder sein traditionelles Frauen- und Familienbild noch sein aggressiver Charakter als hinderlich.

\section{e) Gemeinsamkeiten und Unterschiede von latentem und manifestem Rechtsextremismus bei Männern und Frauen}

Bevor wir uns mit den Unterschieden zwischen latentem und manifestem Rechtsextremismus bei Männern und Frauen befassen, zwei Anmerkungen zu den Gemeinsamkeiten: Erstens dürfte der ideologische Kernbestand des Rechtsextremismus, also völkischer Nationalismus, für Männer und Frauen auf der Einstellungs- und Verhaltensebene identisch sein. Ursprünglich hatte ich die Vermutung, dass zwischen einem maskulinen, sexistisch geprägten und gewalttätigen Rechtsextremismus und einem femininen Rechtsextremismus ohne sexistische Färbung und besondere Aggressivität zu unterscheiden sei und dass sich dieser Unterschied eher beim manifesten als beim latenten Rechtsextremismus offenbart. Das hat sich empirisch jedoch nicht bestätigt. Zweitens scheint Übereinstimmung hinsichtlich der groben sozialstrukturellen Grundlagen des latenten und manifesten Rechtsextremismus bei Männern und Frauen zu bestehen. Beim Rechtsextremismus handelt es sich primär um ein Unterschichtenphänomen, das vor allem bei Arbeitern, Arbeitslosen und Rentnern auftritt. Entscheidend ist - das hat Siller zutreffend angemerkt -, wie die soziale Lage gedeutet wird und welche Handlungsorientierungen daraus abgeleitet werden. Wenn der soziale Status allerdings differenziert erhoben wird (genauer Berufsstatus, Modernität des Arbeitsplatzes, Prekarität des Beschäftigungsverhältnisses etc.), dann macht sich die Omnipräsenz des Gender Gap bemerkbar (Stöss/Fichter/Kreis/Zeuner 2004: 112 ff.) ${ }^{49}$.

Der wohl eklatanteste Unterschied zwischen latentem und manifestem Rechtsextremismus besteht darin, dass ersterer mit wachsendem Alter zunimmt, während letzterer mit wachsendem Alter abnimmt. (Dies verweist einmal mehr auf die Notwendigkeit, deutlich zwischen Einstellungen und Verhalten zu trennen.) Dabei verhalten sich die statistischen Zusammenhänge bei den Geschlechtern spiegelbildlich: Beim latenten Rechtsextremismus sind sie bei Frauen etwas enger, beim manifesten Rechtsextremismus fallen sie dagegen bei Männern etwas stärker aus. Bei der Interpretation dieser Differenzen ist zu beachten, dass es sich durchweg um sehr schwache Korrelationen handelt. Dass es sich vor allem um junge Leute handelt, die zu vom Mainstream abweichendem Verhalten neigen, dürfte an ihrem problematischen, jedenfalls ungefestigten sozialen Status liegen und an eigenständigen Normen, Werten und Gesellungsformen, die mangelnde soziale Integration in die Erwachsenenwelt und zugleich politische Opposition gegen das Establishment zum Ausdruck bringen. Dass es gerade männliche Jugendliche sind, die zu Gewalt neigen, mag zusätzlich

49 Dabei handelt es sich allerdings um einen üblichen Effekt: Je feingliedriger die Subgruppenanalyse, desto differenzierter die Einsichten. 
mit ihrer physischen Konstitution zu tun haben. Passive Gewaltbereitschaft korreliert nämlich nicht mit dem Alter, und aktive Gewaltbereitschaft variiert bei Männern etwas stärker negativ mit dem Alter als bei Frauen.

Latenter und manifester Rechtsextremismus unterscheiden sich auch hinsichtlich ihrer Beziehung zum Sexismus. Beim Sexismus handelt es sich zwar um einen maßgeblichen Prädiktor für rechtsextreme Einstellungen, bei der Hinwendung zu rechtsextremen Parteien und bei der Bereitschaft zu gewalttätigem Handeln spielt er aber nur eine nachgeordnete Rolle. Die rechtsextreme Mentalität schließt zwar antiemanzipatorische, auf Diskriminierung, Hierarchisierung und Unterwerfung gerichtete Elemente ein, steuert aber Verhalten nur partiell. Das zeigt sich nicht zuletzt daran, dass 12 Prozent der Bürger rechtsextrem eingestellt sind, aber nur 2,2 Prozent bei der Bundestagswahl 2005 die NPD oder die Republikaner wählten. Für die Wahlentscheidung sind neben ideologischen Dispositionen eben auch andere Faktoren verantwortlich, wie etwa die Popularität von Personen, die Vordringlichkeit einzelner Sachfragen, die Zuweisung von Kompetenzen, die Wahlkampfführung und die Wahlchancen einzelner Parteien und schließlich tagespolitische Stimmungen. Den Geschlechterunterschied beim Wahlverhalten zugunsten von rechtsextremen Parteien haben wir damit erklärt, dass es sich primär auf rechtsextreme Frauen bezieht: Frauen neigen zwar grosso modo genauso häufig zu rechtsextremem Gedankengut wie Männer, bei Wahlen verhalten sie sich dann jedoch flexibler oder auch "rationaler" als diese, indem sie ihre Entscheidung nicht nur an ideologischen, sondern auch an konkreten Alltagsbedürfnissen ausrichten und daher Sympathien auch für andere Parteien empfinden, die diese Bedürfnisse zu berücksichtigen scheinen. Im Kontext aller Determinanten des Wahlverhaltens verliert Sexismus als eigenständige Einflussgröße an Bedeutung, insoweit er nicht bereits beim Rechtsextremismus mitgedacht wird. Im Übrigen sind sexistische Einstellungen in der Bevölkerung nicht sehr weit verbreitet, und auch im rechtsextremen Lager ufert die Nachfrage nach anachronistischen Frauen- und Familienkonzepten nicht gerade aus: So verfügt nur ein Fünftel der rechtsextremen Frauen und knapp die Hälfte der rechtsextremen Männer über sexistische Orientierungen. Dass die Nachfrage bei (rechtsextremen) Männern größer ist als bei (rechtsextremen) Frauen, bedeutet offenbar, dass sich Männer von den verbreiteten Emanzipations- und Gleichstellungstendenzen stärker bedroht fühlen und sich häufiger nach einem geordneten Patriarchat sehnen als Frauen. 


\section{Literatur}

Amesberger, Helga/Halbmayr, Brigitte (Hrsg.) (2002a): Rechtsextreme Parteien - eine mögliche Heimat für Frauen?, Opladen: Leske + Budrich.

Amesberger, Helga/Halbmayr, Britgitte (2002b): Rechtsextremismus - rechtsextreme Parteien: Begriffsdiskussion, Erklärungsmodelle und Parteienspektrum, in: Dies. (Hrsg.): Rechtsextreme Parteien - eine mögliche Heimat für Frauen?, Opladen: Leske + Budrich, S. 27-60.

Amesberger, Helga/Halbmayr, Britgitte (2002c): Die Parteien im Vergleich, in: Dies. (Hrsg.): Rechtsextreme Parteien - eine mögliche Heimat für Frauen?, Opladen: Leske + Budrich, S. 407-421.

Anthias, Floya/Yuval-Davis, Nira (1993): Racialized Boundaries. Race, Nation, Gender, Colour and Class and the Anti-Racist Struggle, London/New York: Routledge.

Balbach, Sonja (1994): "Wir sind auch die kämpfende Front". Frauen in der rechten Szene, Hamburg: Konkret Literatur Verlag.

Basu, Sanchita (1992): Das Verhältnis zwischen weißem Feminismus und Widerstandsformen von Frauen der Zwei-Drittel-Welt, in: Perspektiven. Zeitschrift für sozialistische Theorie, Nr. 9 (April/Mai), S. 19-21.

Beck, Ulrich (1986): Risikogesellschaft. Auf dem Weg in eine andere Moderne, Frankfurt a. Main: Suhrkamp.

Birsl, Ursula (1992): Frauen und Rechtsextremismus, in: Aus Politik und Zeitgeschichte, B 3-4, S. 22-30.

Birsl, Ursula (1994): Rechtsextremismus: weiblich - männlich? Eine Fallstudie zu geschlechtsspezifischen Lebensverläufen, Handlungsspielräumen und Orientierungsweisen, Opladen: Leske + Budrich.

Birsl, Ursula (1996): Rechtsextremismus und Fremdenfeindlichkeit: Reagieren Frauen anders? Zur theoretischen Verortung der Kategorie Geschlecht in der feministischen Rechtsextremismus-Forschung, in: Falter, Jürgen W./Jaschke, Hans-Gerd/Winkler, Jürgen R. (Hrsg.): Rechtsextremismus. Ergebnisse und Perspektiven der Forschung, Politische Vierteljahresschrift, 37. Jg., Sonderheft 27, Opladen: Westdeutscher Verlag, S. 49-65.

Birsl, Ursula/Bons, Joachim/Busche-Baumann, Maria/Kurzer, Ulrich (1993): Rechtsextremismus ist kein männerspezifisches Phänomen. Fremdenfeindliche Orientierungen im Geschlechtervergleich. Ergebnisse einer Studie, in: Frankfurter Rundschau, Nr. 276 v. 27.11., S. 16.

Birsl, Ursula/Busche-Baumann, Maria/Bons, Joachim/Kurzer, Ulrich (1995): Jugendlicher Rechtsextremismus und Gewerkschaften. Lebensverhältnisse und politische Orientierungen von Auszubildenden, Opladen: Leske + Budrich.

Bitzan, Renate (1997): Variationen des Zweifels - Feminismus und Faschismus. Theoretische Überschneidungen und Widerstände in brüchigen Traditionen, in: Bitzan, Renate (Hrsg.): Rechte Frauen. Skingirls, Walküren und feine Damen, Berlin: Elefanten Press, S. 84-103.

Bitzan, Renate (2000): Selbstbilder rechter Frauen. Zwischen Antisexismus und völkischem Denken, Tübingen: Edition Diskord.

Bitzan, Renate (2002): Frauen in der rechtsextremen Szene, in: Grumke, Thomas/Wagner, Bernd (Hrsg.): Handbuch Rechtsradikalismus, Opladen: Leske + Budrich, S. 87-104.

Bitzan, Renate (2005): Differenz und Gleichheit. Zur Geschlechterideologie rechter Frauen und ihren Anknüpfungspunkten zu feministischen Konzepten, in: Antifaschistisches Frauennetzwerk/Forschungsnetzwerk Frauen und Rechtsextremismus (Hrsg.): Braune Schwestern? Feministische Analysen zu Frauen in der extremen Rechten, Münster: Unrast, S. 75-90.

Brück, Brigitte (2005): Frauen und Rechtsradikalismus in Europa. Eine Studie zu Frauen in Führungspositionen rechtsradikaler Parteien in Deutschland, Frankreich und Italien, Wiesbaden: VS Verlag für Sozialwissenschaften.

Collins, Patricia Hill (1994/94): Malcolm X: Die unbeantwortete Geschlechterfrage, in: Perspektiven. Zeitschrift für sozialistische Theorie, Nr. 10, S. 59-65.

Däubler-Gmelin, Herta/Kießler, Kerstin (1990): Die Rechtsaußen-Parteien und die Frauen. Warum die "Republikaner" eine Männerpartei sind, in: Seeliger, Rolf (Hrsg.): Grauzone zwischen Union und der Neuen Rechten. Personen - Institutionen - Identifikationen, München: Seeliger, S. 122-134.

Davis, Angela (1982): Rassismus und Sexismus. Schwarze Frauen und Klassenkampf in den USA, Berlin: 


\section{Elefanten Press.}

Decker, Oliver; Brähler, Elmar (2006): Vom Rand zur Mitte. Rechtsextreme Einstellungen und ihre Einflussfaktoren in Deutschland, Berlin: Friedrich-Ebert-Stiftung - Forum Berlin.

Dettling, Margarete/Goltz, Jutta (1995): Frauen - Opfer und Täterinnen?, in: Wlecklik, Petra (Hrsg.): Frauen und Rechtsextremismus, Göttingen: Lamuv, S. 33-44.

Döhring, Kirsten/Feldmann, Renate (2005): Akteurinnen und Organisationen. Die Involviertheit von Frauen in der extremen Rechten, in: Antifaschistisches Frauennetzwerk/Forschungsnetzwerk Frauen und Rechtsextremismus (Hrsg.): Braune Schwestern? Feministische Analysen zu Frauen in der extremen Rechten, Münster: Unrast, S. 17-33.

Dörr, Bea (1995): Organisierte Frauen in rechtsextremen Parteien und Gruppierungen, in: Wlecklik, Petra (Hrsg.): Frauen und Rechtsextremismus, Göttingen: Lamuv, S. 45-49.

Dobash, Russell P./Dobash, R. Emerson (2001): Violence Against Women: A Review of Recent AngloAmerivan Research, in: Journal für Konflikt- und Gewaltforschung, 3. Jg., H. 2, S. 5-22.

Eichhorn, Cornelia (1992): "Frauen sind die Neger aller Völker". Überlegungen zu Feminismus, Sexismus und Rassismus, in: Redaktion Diskus (Hrsg.): Die freundliche Zivilgesellschaft. Rassismus und Nationalismus in Deutschland, Berlin - Amsterdam: Edition ID-Archiv, S. 95-104.

Falter, Jürgen W. (1991): Hitlers Wähler, München: Beck.

Falter, Jürgen W. (1993): Die Jungmitglieder der NSDAP zwischen 1925 und 1933. Ein demographisches und soziales Profil, in: Krabbe, Wolfgang R. (Hrsg.): Politische Jugend in der Weimarer Republik, Bochum: Brockmeyer, S. 202-221.

Falter, Jürgen W. (1994): Wer wählt rechts? Die Wähler und Anhänger rechtsextremistischer Parteien im vereinigten Deutschland, München: Beck 1994.

Fantifa Marburg (1996): Kameradinnen, in: Mecklenburg, Jens (Hrsg.): Handbuch deutscher Rechtsextremismus, Berlin: Elefanten Press, S. 743-754.

Fichte, Paula (1997): Politische Aktivistinnen im militanten neofaschistischen Spektrum, in: Bitzan, Renate (Hrsg.): Rechte Frauen. Skingirls, Walküren und feine Damen, Berlin: Elefanten Press, S. 131-146.

Fuchs-Heinritz, Werner/Lautmann, Rüdiger/Rammstedt, Otthein/Wienold, Hanns (Hrsg.) (1994): Lexikon zur Soziologie, 3. Aufl., Opladen: Westdeutscher Verlag.

Geden, Oliver (2006): Diskursstrategien im Rechtspopulismus. Freiheitliche Partei Österreichs und Schweizerische Volkspartei zwischen Opposition und Regierungsbeteiligung, Wiesbaden: VS Verlag für Sozialwissenschaften.

Glöckner-Rist, Angelika (Hrsg.) (2007): Informationen zum Instrument "Geschlechtsrollenorientierung (Krampen)", in: ZUMA-Informationssystem. Elektronisches Handbuch sozialwissenschaftlicher Erhebungsinstrumente, ZIS Version 11.00, Bonn: GESIS.

Gnad, Oliver (2005a): Sozialistische Reichspartei: Mitgliedschaft und Sozialstruktur, in: Handbuch zur Statistik der Parlamente und Parteien in den westlichen Besatzungszonen und in der Bundesrepublik Deutschland. Teilband III: FDP sowie kleinere bürgerliche und rechte Parteien. Mitgliedschaft und Sozialstruktur 1945-1990, bearb. v. Oliver Gnad, Daniela Gniss, Marion Hausmann u. Carl-Wilhelm Reibel, Düsseldorf: Droste, S. 353-473.

Gnad, Oliver (2005b): Nationaldemokratische Partei Deutschlands: Mitgliedschaft und Sozialstruktur, in: Handbuch zur Statistik der Parlamente und Parteien in den westlichen Besatzungszonen und in der Bundesrepublik Deutschland. Teilband III: FDP sowie kleinere bürgerliche und rechte Parteien. Mitgliedschaft und Sozialstruktur 1945-1990, bearb. v. Oliver Gnad, Daniela Gniss, Marion Hausmann u. Carl-Wilhelm Reibel, Düsseldorf: Droste, S. 591-702.

Hagemann-White, Carol (2001): Gewalt gegen Frauen: Ein Überblick deutschsprachiger Forschung, in: Journal für Konflikt- und Gewaltforschung, 3. Jg., H. 2, S. 23-44.

Hartwig, Tanja (1993): Emanzipation in Braun? Die "Attraktivität" neofaschistischer Gruppierungen für Mädchen und Frauen, in: Heil, Hubertus/Perik, Muzaffer/Wendt, Peter-Ulrich (Hrsg.): Jugend und Gewalt. Über den Umgang mit gewaltbereiten Jugendlichen, Marburg: Schüren, S. 70-83.

Heitmeyer, Wilhelm (1987): Rechtsextremistische Orientierungen bei Jugendlichen. Empirische Ergebnisse 
und Erklärungsmuster einer Untersuchung zur politischen Sozialisation, Weinheim/München: Juventa.

Heitmeyer, Wilhelm (2006): Gruppenbezogene Menschenfeindlichkeit. Gesellschaftliche Zustände und Reaktionen in der Bevölkerung aus 2002 bis 2005, in: Heitmeyer, Wilhelm (Hrsg.): Deutsche Zustände. Folge 4, Frankfurt a. Main: Suhrkamp, S. 15-36.

Heitmeyer, Wilhelm/Soeffner, Hans-Georg (Hrsg.) (2004): Gewalt. Entwicklung, Strukturen, Analyseprobleme, Frankfurt a. Main: Suhrkamp.

Held, Josef/Horn, Hans-Werner/Marvakis, Athanasios (1996): Gespaltene Jugend. Politische Orientierungen jugendlicher ArbeitnehmerInnen, Opladen: Leske + Budrich.

Hentges, Gudrun (1993): Immunisiert Weiblichkeit gegenüber Rechtsextremismus? Anmerkungen zur Diskussion über die Attraktivität rechtsextremer Ideologien für Frauen, in: Politologinnen-Rundbrief, 2. Jg., Nr. 4, S. 36-46.

Hentges, Gudrun (1996): Frauen und Rechtsextremismus - Was ist für Frauen an faschistischer Ideologie und Organisierung attraktiv?, in: Fantifa Marburg (Hrsg.): Kameradinnen. Frauen stricken am Braunen Netz, 2. Aufl., Münster: Unrast, S. 9-37.

Heß, Cordelia (2005): Geldjuden, Mädchenhändler, Zeckenschlampen. Zum Verhältnis von Sexismus und Antisemitismus im völkischen Weltbild, in: Antifaschistisches Frauennetzwerk/Forschungsnetzwerk Frauen und Rechtsextremismus (Hrsg.): Braune Schwestern? Feministische Analysen zu Frauen in der extremen Rechten, Münster: Unrast, S. 91-107.

Hewicker, Christine (2001): Die Aussteigerin. Autobiographie einer ehemaligen Rechtsextremistin, Oldenburg: Igel.

Hoecker, Beate (1995): Politische Partizipation von Frauen. Ein einführendes Studienbuch, Opladen: Leske + Budrich.

Hofmann, Ruth (2003): "Weil die ohne Weiber gar nicht können!" Junge Frauen in der rechten Szene, Freiburg: Herder.

Hofmann-Göttig, Joachim (1989a): Die neue Rechte: die Männerparteien. Die Wählerbasis der "Republikaner", DVU und NPD nach Alter und Geschlecht bei der Europawahl vom 18. Juni 1989, Bonn: Demokratische Gemeinde - Vorwärts Verlag (Die Wähler der extremen Rechten II).

Hofmann-Göttig, Joachim (1989b): Die Neue Rechte: Die Männerparteien, in: Aus Politik und Zeitgeschichte, B 41-42, S. 21-31.

Holzkamp, Christine (1994): Wir - nicht nur die andren... Rassismus, Dominanzkultur, Geschlechterverhältnis, in: Tillner, Christiane (Hrsg.): Frauen - Rechtsextremismus, Rassismus, Gewalt. Feministische Beiträge, Münster: Agenda, S. 37-47.

Holzkamp, Christine/Rommelspacher, Birgit (1991a): Frauen und Rechtsextremismus. Wie sind Mädchen und Frauen verstrickt?, in: Sozial extra, Nr. 6 (Juni), S. 17-19.

Holzkamp, Christine/Rommelspacher, Birgit (1991b): Frauen und Rechtsextremismus, in: Päd extra/Demokratische Erziehung, H. 1, S. 33-39.

Hooks, Bell (1990): Schwesterlichkeit: Politische Solidarität unter Frauen, in: Beiträge zur Feministischen Theorie und Praxis, 13. Jg., Nr. 27, S. 77-92.

Horn-Metzger, Traudel/Riegel, Christine (1995): Junge Frauen und politische Orientierungen. Zusammenfassung von Ergebnissen einer Studie mit Auszubildenden, in: Wlecklik, Petra (Hrsg.): Frauen und Rechtsextremismus, Göttingen: Lamuv, S. 91-111.

Hüpping, Sandra (2006): Anomia. Unsicher in der Orientierung, sicher in der Abwertung, in: Heitmeyer, Wilhelm (Hrsg.): Deutsche Zustände. Folge 4, Frankfurt a. Main: Suhrkamp, S. 86-100.

Jäger, Margret (1992): Das Frauen- und Familienbild im Rechtsextremismus, in: Jäger, Margret/Jäger, Siegfried (Hrsg.): Zu den Ursachen von Rechtsextremismus und Rassismus in Europa, Duisburg: Duisburger Institut für Sprach- und Sozialforschung, S. 49-70 (DISS-Texte, Nr. 20).

Jansen, Mechtild (1989): "Zum Wohle des Volkes". Frauenpolitik und Frauenprogrammatik der Republikaner, in: Hellfeld, Matthias von (Hrsg.): Dem Hass keine Chance. Der neue rechte Fundamentalismus, Köln: Pahl-Rugenstein, S. 74-88.

Jung, Anne (1997): Faschistische Feministinnen - ein Widerspruch?, in: Bitzan, Renate (Hrsg.): Rechte 
Frauen. Skingirls, Walküren und feine Damen, Berlin: Elefanten Press, S. 30-42.

Kalinowsky, Harry H./Blath, Richard/Hobe, Konrad/Kothe-Heggemann, Claudia (1985): Rechtsextremismus und Strafrechtspflege. Eine Analyse von Strafverfahren wegen mutmaßlicher rechtsextremistischer Aktivitäten und Erscheinungen, Bonn: Der Bundesminister der Justiz.

King, Deborah K. (1992): Herrschaftsverhältnisse und schwarzer Feminismus, in: Perspektiven. Zeitschrift für sozialistische Theorie, Nr. 9 (April/Mai), S. 5-17.

Köttig, Michaela (1997): "Mädchen sollen am besten die Klappe halten" - Mädchen in rechten Cliquen, in: Bitzan, Renate (Hrsg.): Rechte Frauen. Skingirls, Walküren und feine Damen, Berlin: Elefanten Press, S. 147-156.

Kötting, Michaela (2005): Mädchen und Frauen in der extremen Rechten. Ein Diskussionsbeitrag zu Erklärungskonzepten und Forschungsansätzen, in: Antifaschistisches Frauennetzwerk/Forschungsnetzwerk Frauen und Rechtsextremismus (Hrsg.): Braune Schwestern? Feministische Analysen zu Frauen in der extremen Rechten, Münster: Unrast, S. 57-74.

Krampen, Günter (2007): Geschlechtsrollenorientierung, in: Glöckner-Rist, Angelika (Hrsg.): ZUMAInformationssystem. Elektronisches Handbuch sozialwissenschaftlicher Erhebungsinstrumente, ZIS Version 11.00, Bonn: GESIS.

Kreis, Joachim (2007): Zur Messung von rechtsextremer Einstellung: Probleme und Kontroversen am Beispiel zweier Studien, Arbeitshefte aus dem Otto-Stammer-Zentrum, Nr.12, Berlin, Oktober 2007 (im Internet: http://www.polsoz.fu-berlin.de/polwiss/forschung/systeme/empsoz/schriften/arbeitshefte/ahosz12. pdf).

Kühnl, Reinhard/Rilling, Rainer/Sager, Christine (1969): Die NPD. Struktur, Ideologie und Funktion einer neofaschistischen Partei, Frankfurt a. Main: Suhrkamp.

Lenz, Ilse (1994): Wir wollen sein ein einig Volk von Brüdern. Zur sozialen Konstruktion von Geschlecht und Ethnizität, in: Tillner, Christiane (Hrsg.): Frauen - Rechtsextremismus, Rassismus, Gewalt. Feministische Beiträge, Münster: Agenda, S. 49-64.

Lohmeier, Cornelia (1991): Wie immun sind Mädchen gegen Rechtsextremismus?, in: Deutsche Jugend, 39. Jg., Nr. 1, S. 33-38.

Ludvig, Alice (1999): Black Feminism: Feministische oder Bürgerrechtsbewegung?, in: Österreichische Zeitschrift für Politikwissenschaft, 28. Jg., H. 4, S. 405-418.

Mansfeld, Cornelia (1998): Fremdenfeindlichkeit und Fremdenfreundlichkeit bei Frauen. Eine Studie zur Widersprüchlichkeit weiblicher Biographien, Frankfurt a. Main: Brandes \& Apsel.

Merritt, Anna J./Merritt, Richard L. (Hrsg.) (1970): Public Opinion in Occupied Germany. The OMGUSSurveys 1945-1949, Urbana u.a.: University of Illinois Press.

Merritt, Anna J./Merritt, Richard L. (Hrsg.) (1980): Public Opinion in Semisovereign Germany. The HICOGSurveys 1949-1955, Urbana u.a.: University of Illinois Press.

Meyer, Birgit (1991): Mädchen und Rechtsradikalismus, in: Blätter für deutsche und internationale Politik, 36. Jg., Nr. 5, S. 601-611.

Meyer, Birgit (1992): Die "unpolitische" Frau. Politische Partizipation von Frauen oder: Haben Frauen ein anderes Verständnis von Politik?, in Aus Politik und Zeitgeschichte, B 25-26, S. 3-18.

Meyer, Birgit (1993): Mädchen und Rechtsextremismus. Männliche Dominanzkultur und weibliche Unterordnung, in: Otto, Hans-Uwe/Merten, Roland (Hrsg.): Rechtsradikale Gewalt im vereinigten Deutschland. Jugend im gesellschaftlichen Umbruch, Opladen: Leske + Budrich, S. 211-218.

Mitscherlich, Margarete (1987): Die friedfertige Frau. Eine psychoanalytische Untersuchung zur Aggression der Geschlechter, Frankfurt a. Main: Fischer.

Möller, Kurt (1991a): Mädchen, Frauen und Rechtsextremismus, in: Sozialmagazin, 16. Jg., Nr. 10, S. 30-38.

Möller, Kurt (1991b): Geschlechtsspezifische Aspekte der Anfälligkeit für Rechtsextremismus in der Bundesrepublik Deutschland, in: Frauenforschung. Informationsdienst des Forschungsinstituts Frau und Gesellschaft, 9. Jg., Nr. 3, S. 27-49.

Molitor, Ute (1992): Wählen Frauen anders? Zur Soziologie eines frauenspezifischen politischen Verhaltens in der Bundesrepublik Deutschland, Baden-Baden: Nomos. 
Molitor, Ute (1993): Gibt es ein frauenspezifisches politisches Verhalten? Befunde der empirischen Politikforschung der 80er Jahre, in: Oscar W. Gabriel/Klaus G. Troitzsch (Hrsg.): Wahlen in Zeiten des Umbruchs, Frankfurt a. Main usw.: Lang, S. 131-156.

Müller, Marion (2003): Geschlecht und Ethnie. Historischer Bedeutungswandel, interaktive Konstruktion und Interferenzen, Wiesbaden: Westdeutscher Verlag.

Ng, Roxana (1992): Sexismus, Rassismus und kanadischer Nationalismus, in: Rassismus und Migration in Europa. Beiträge des Kongresses "Migration und Rassismus in Europa", Hamburg: Argument, S. 104-117 (Argument-Sonderband AS 201).

Niedermayer, Oskar (2005): Bürger und Politik. Politische Orientierungen und Verhaltensweisen der Deutschen, 2. Aufl., Wiesbaden: VS Verlag für Sozialwissenschaften.

Ogrzall, Peter (1990): Rechtsextremismus ein Jungen-/Männerproblem?, in: Jugendarbeit gegen Rechtsextremismus, Berlin: Senatsverwaltung für Frauen, Jugend und Familie, S. 22-24.

Oltmanns, Hilke (1990): "Siegen, kämpfen, durchgreifen lassen". Rechtsextremismus bei Mädchen, in: Widersprüche, 10. Jg., Nr. 35, S. 41-45.

Orde, Sabine am (1991): Die neuen alten Frauenbilder der "Neuen Rechten", in: Perspektiven. Zeitschrift für sozialistische Theorie, Nr. 8, S. 27-36.

Ottens, Svenja (1997a): Ausmaß und Formen rechtsextremer Einstellungen bei Frauen. Ein Vergleich verschiedener Repräsentativbefragungen, in: Bitzan, Renate (Hrsg.): Rechte Frauen. Skingirls, Walküren und feine Damen, Berlin: Elefanten Press, S. 178-190.

Ottens, Svenja (1997b): Rechtsextremismus - ein Männerproblem?, in: Bitzan, Renate (Hrsg.): Rechte Frauen. Skingirls, Walküren und feine Damen, Berlin: Elefanten Press, S. 166-177.

Ottens, Svenja (1997c): Eigene Motive - eigene Formen? Erklärungsansätze zu geschlechtsspezifischen Äußerungsformen und Motiven bei der Hinwendung von Frauen zum Rechtsextremismus, in: Bitzan, Renate (Hrsg.): Rechte Frauen. Skingirls, Walküren und feine Damen, Berlin: Elefanten Press, S. 191-214.

Peucker, Christian/Gaßebner, Martina/Wahl, Klaus (2001): Analyse polizeilicher Ermittlungsakten zu fremdenfeindlichen, antisemitischen und rechtsextremistischen Tatverdächtigen, in: Wahl, Klaus (Hrsg.): Fremdenfeindlichkeit, Antisemitismus, Rechtsextremismus. Drei Studien zu Tatverdächtigen und Tätern, Berlin: Bundesministerium des Innern, S. 12-88 (Texte zur Inneren Sicherheit).

Pinn, Irmgard (1990): Das ewig-weibliche... Zum Frauenbild der "alten" und der "neuen" Rechten, in: Beiträge zur Feministischen Theorie und Praxis, 13. Jg., Nr. 27, S. 143-151.

Rademacher, Claudia/Wiechens, Peter (Hrsg.) (2001): Geschlecht - Ethnizität - Klasse. Zur sozialen Konstruktion von Hierarchie und Differenz, Opladen: Leske + Budrich.

Renz, Mariel (1995): "Lebenshüterin im Volkstum, Bewacherin und Spenderin ist die Frau" - Frauenbilder in rechtsextremen Ideologien, in: Wlecklik, Petra (Hrsg.): Frauen und Rechtsextremismus, Göttingen: Lamuv, S. 50-59.

Rippl, Susanne/Boehnke, Klaus/Hefler, Gerd/Hagan, John (1998): Sind Männer eher rechtsextrem und wenn ja, warum? Individualistische Werthaltungen und rechtsextreme Einstellungen, in: Politische Vierteljahresschrift, 39. Jg., Nr. 4, S. 758-774.

Rippl, Susanne/Seipel, Christian (1999): Gender Differences in Right-Wing Extremism: Intergroup Validity of an Second Order Construct, in: Social Psychology Quarterly, 62. Jg., Nr. 4, S. 381-393.

Ritter, Barbara (1997): "Lebensschützerinnen", in: Bitzan, Renate (Hrsg.): Rechte Frauen. Skingirls, Walküren und feine Damen, Berlin: Elefanten Press, S. 72-83.

Rommelspacher, Birgit (1991): Rechtsextreme als Opfer der Risikogesellschaft. Zur Täterentlastung in den Sozialwissenschaften, in: 1999. Zeitschrift für Sozialgeschichte des 20. und 21. Jahrhunderts, 6. Jg., Nr. 2, S. 75-87.

Rommelspacher, Birgit (1993a): Frauen und Rassismus. Im Widerspruch zwischen Diskriminierung und Dominanz, in: Politologinnen-Rundbrief, 2. Jg., Nr. 4, S. 48-50.

Rommelspacher, Birgit (1993b): Männliche Gewalt und gesellschaftliche Dominanz, in: Otto, HansUwe/Merten, Roland (Hrsg.): Rechtsradikale Gewalt im vereinigten Deutschland. Jugend im gesellschaftlichen Umbruch, Opladen: Leske + Budrich, S. 200-210. 
Rommelspacher, Birgit (1993c): Männliche Jugendliche als Projektionsfiguren gesellschaftlicher Gewaltphantasien. Rassismus im Selbstverständnis der Mehrheitskultur, in: Breyvogel, Wilfried (Hrsg.): Lust auf Randale. Jugendliche Gewalt gegen Fremde, Bonn: Dietz, S. 65-82.

Rommelspacher, Birgit (2000): Das Geschlechterverhältnis im Rechtsextremismus, in: Schubarth, Wilfried/Stöss, Richard (Hrsg.): Rechtsextremismus in der Bundesrepublik Deutschland. Eine Bilanz, Bonn: Bundeszentrale für politische Bildung, S. 199-219 (Schriftenreihe der Bundeszentrale für politische Bildung, Bd. 368; Buchhandelsausg.: Leske + Budrich).

Roth, Dieter (1989): Sind die Republikaner die fünfte Partei? Sozial- und Meinungsstruktur der Wähler der Republikaner, in: Aus Politik und Zeitgeschichte, B 41-42, S. 10-20.

Roth, Dieter (1990): Die Republikaner. Schneller Aufstieg und tiefer Fall einer Protestpartei am rechten Rand, in: Aus Politik und Zeitgeschichte, B 37-38, S. 27-39.

Sänger, Fritz/Liepelt, Klaus (1965): Wahlhandbuch 1965. Sammlung von Texten, Daten, Dokumenten zu Wahlrecht, Wahlkampf, Wahlergebnissen, Wahlkreisen, Frankfurt a. Main: Europäische Verlagsanstalt.

Scharenberg, Albert (1992): Rassismus, Sexismus und US-Arbeiterbewegung, in: Perspektiven. Zeitschrift für sozialistische Theorie, Nr. 9 (April/Mai), S. 23-30.

Schnurbein, Stefanie von (1996): Weiblichkeitskonzeptionen im neugermanischen Heidentum und in der feministischen Spiritualität, in: Fantifa Marburg (Hrsg.): Kameradinnen. Frauen stricken am Braunen Netz, 2. Aufl., Münster: Unrast, S. 113-136.

Schultz, Dagmar (1990): Unterschiede zwischen Frauen - ein kritischer Blick auf den Umgang mit "den Anderen" in der feministischen Forschung weißer Frauen, in: Beiträge zur Feministischen Theorie und Praxis, 13. Jg., Nr. 27, S. 45-57.

Schwarzmeier, Antje/Wunderlich, Eike (1996): Politische Aktivistinnen für Volk und Vaterland. Organisierte (Neo-)Faschistinnen in der Deutschen Frauenfront (DFF), in der Skingirlfront Deutschland (SFD) und in Women for Aryan Unity (WAU), in: Fantifa Marburg (Hrsg.): Kameradinnen. Frauen stricken am Braunen Netz, 2. Aufl., Münster: Unrast, S. 39-72.

Siller, Gertrud (1991): Junge Frauen und Rechtsextremismus - Zum Zusammenhang von weiblichen Lebenserfahrungen und rechtsextremistischem Gedankengut, in: Deutsche Jugend, 39. Jg., Nr. 1, S. 23-32.

Siller, Gertrud (1992): Widerstands- und Zugangsformen von Frauen zu rechtsextremistischen Orientierungen, in: Rechtsextremismus, Jugendgewalt und Politikdistanz. In der Mitte der Gesellschaft, Bonn: Vorstand der SPD, S. 53-65 (Schriftenreihe Jugendpolitik).

Siller, Gertrud (1993): Das Verhältnis von Frauen zu Rechtsextremismus und Gewalt. Theoretische Vorüberlegungen für eine weiterführende Analyse, in: Otto, Hans-Uwe/Merten, Roland (Hrsg.): Rechtsradikale Gewalt im vereinigten Deutschland. Jugend im gesellschaftlichen Umbruch, Opladen: Leske + Budrich, S. 219-226.

Siller, Gertrud (1994): Frauen und Rechtsextremismus, in: Kowalsky, Wolfgang/Schroeder, Wolfgang (Hrsg.): Rechtsextremismus. Einführung und Forschungsbilanz, Opladen: Westdeutscher Verlag, S. 143159.

Siller, Gertrud (1997): Rechtsextremismus bei Frauen. Zusammenhänge zwischen geschlechterspezifischen Erfahrungen und politischen Orientierungen, Opladen: Westdeutscher Verlag.

SINUS (1981): 5 Millionen Deutsche: "Wir sollten wieder einen Führer haben..." Die SINUS-Studie über rechtsextremistische Einstellungen bei den Deutschen, Reinbek bei Hamburg: Rowohlt.

Six, Bernd/Wolfradt, Uwe/Zick, Andreas (2001): Autoritarismus und Soziale Dominanzorientierung als generalisierte Einstellungen, in: Zeitschrift für Politische Psychologie, 9. Jg., Nr. 2+3, S. 23-40.

Skrzydlo, Annette/Wohllaib, Nikola (1996): Frauen bei den Republikanern, in: Fantifa Marburg (Hrsg.): Kameradinnen. Frauen stricken am Braunen Netz, 2. Aufl., Münster: Unrast, S. 99-112.

Skrzydlo, Annette/Thiele, Barbara/Wohllaib, Nikola (1992): Frauen in der Partei "Die Republikaner": Zum Verhältnis von Frauen und Rechtsextremismus, in: Beiträge zur Feministischen Theorie und Praxis, 15. Jg., Nr. 33, S. 136-146.

Stöss, Richard (2007): Rechtsextremismus im Wandel, 2. akt. Aufl., Berlin: Friedrich-Ebert-Stiftung.

Stöss, Richard (2008): Rechtsextremismus und Kapitalismuskritik, Arbeitshefte aus dem Otto-Stammer- 
Zentrum, Nr. 9, Berlin, Januar 2008 (im Internet: http://www.polsoz.fu-berlin.de/polwiss/forschung/systeme/empsoz/schriften/arbeitshefte/ahosz9.pdf).

Stöss, Richard/Fichter, Michael/Kreis, Joachim/Zeuner, Bodo (2004): Projekt "Gewerkschaften und Rechtsextremismus". Abschlussbericht, Freie Universität Berlin, Fachbereich Politik- und Sozialwissenschaften, Otto-Suhr-Institut (nur im Internet verfügbar: http://www.polsoz.fu-berlin.de/polwiss/forschung/oekonomie/gewerkschaftspolitik/materialien/GEWREXSCHLUSS/index.html).

Sturhan, Katrin (1997): Zwischen Rechtskonservatismus und Neonazismus - Frauen in rechtsextremen Parteien und Organisationen, in: Bitzan, Renate (Hrsg.): Rechte Frauen. Skingirls, Walküren und feine Damen, Berlin: Elefanten Press, S. 104-130.

Sturzbecher, Dietmar/Hess, Markus/Them, Wiebke (2002): Jugendgewalt und Reaktionen des sozialen Umfelds, in: Sturzbecher, Dietmar (Hrsg.): Jugendtrends in Ostdeutschland: Bildung, Freizeit, Politik, Risiken, Opladen: Leske + Budrich, S. 182-232.

Sturzbecher, Dietmar/Landua, Detlef/Shahla, Hossein (2001): Jugendgewalt unter ostdeutschen Jugendlichen, in: Sturzbecher, Dietmar (Hrsg.): Jugend in Ostdeutschland. Lebenssituationen und Delinquenz, Opladen: Leske + Budrich, S. 249-327.

Tenner, Franziska (1996): Ehre, Blut und Mutterschaft, Berlin: Aufbau Verlag.

Tillner, Christiane (Hrsg.) (1994): Frauen - Rechtsextremismus, Rassismus, Gewalt. Feministische Beiträge, Münster: Agenda.

Utzmann-Krombholz, Hilde (1994): Rechtsextremismus und Gewalt: Affinitäten und Resistenzen von Mädchen und jungen Frauen. Ergebnisse einer Studie, Düsseldorf: Ministerium für die Gleichstellung von Frau und Mann.

Vetter, Angelika (2000): Frischer Wind in einer alten Beziehung? Political Efficacy und die Bundestagswahl 1998, in: Falter, Jürgen/Gabriel, Oscar W./Rattinger, Hans (Hrsg.): Wirklich ein Volk? Die politischen Orientierungen von Ost- und Westdeutschen im Vergleich, Opladen: Leske + Budrich, S. 79-109.

Westle, Bettina/Schoen, Harald (2002): Ein neues Argument in einer alten Diskussion: 'Politikverdrossenheit' als Ursache des gender gap im politischen Interesse?, in: Brettschneider, Frank/Deth, Jan van/Roller, Edeltraud (Hrsg.): Das Ende der politischen Sozialstruktur?, Opladen: Leske + Budrich, S. 215-244.

Willems, Helmut/Eckert, Roland/Würtz, Stefanie/Steinmetz, Linda (1993): Fremdenfeindliche Gewalt. Einstellungen - Täter - Konflikteskalation, Opladen: Leske + Budrich.

Wippermann, Wolfgang (1990): Was ist Rassismus?, in: Materialsammlung: Jugendarbeit gegen Rechtsextremismus, Berlin: Senatsverwaltung für Frauen, Jugend und Familie, S. 12-15.

Wobbe, Theresa (1994): Welten der Gewalt: Sexismus und Rassismus, in: Tillner, Christiane (Hrsg.): Frauen - Rechtsextremismus, Rassismus, Gewalt. Feministische Beiträge, Münster: Agenda, S. 27-36. 


\section{Anhang: Datenquellen, Messinstrumente, Erläuterungen und ergänzende Tabellen}

\section{1) Datenquellen}

Wenn nichts anderes angegeben ist, beruhen die Analysen auf der Studie "Bürger und Parteien in einer veränderten Welt" (Deutsche Bundestagswahlstudie 2005). Primärforscher sind Prof. Dr. Steffen Kühnel (Universität Göttingen), Prof. Dr. Oskar Niedermayer (Freie Universität Berlin) und Prof. Dr. Bettina Westle (Universität Marburg). Die Datenerhebung erfolgte "face to face" im September/Oktober 2005 durch Infratest dimap. Die Grundgesamtheit der Untersuchung ist die in Privathaushalten lebende wahlberechtigte deutsche Bevölkerung ab 18 Jahren in der Bundesrepublik Deutschland. Die Auswahl der Befragungspersonen erfolgte durch eine disproportional geschichtete mehrstufige Zufallsstichprobe per Random-Route-Verfahren auf Basis des ADM-Designs. Die Anzahl der Einheiten beträgt 2.540. Instrumente: Anhang 2 bis 11.

Weiterhin wurde die Wahltagsbefragung von Infratest dimap für die ARD-Berichterstattung zur Bundestagswahl 2005 herangezogen $(N=16.365)$.

Gelegentlich wurde auf zwei weitere Studien zurückgegriffen:

"Gewerkschaften und Rechtsextremismus": Primärforscher sind Prof. Dr. Richard Stöss, Dr. Michael Fichter, Joachim Kreis und Prof. Dr. Bodo Zeuner (alle Berlin). Die Datenerhebung erfolgte im April 2003 durch forsa. Die Grundgesamtheit der Untersuchung ist die in Privathaushalten lebende wahlberechtigte deutsche Bevölkerung ab 16 Jahren in der Bundesrepublik Deutschland. Die Auswahl der Befragungspersonen erfolgte durch vier disproportional geschichtete Stichproben. Die Befragung wurde telefonisch (CATI) durchgeführt. Die Anzahl der Einheiten beträgt $4.008^{50}$.

"Rechtsextreme Einstellungen und ihre Einflussfaktoren in Deutschland": Primärforscher sind Prof. Dr. Elmar Brähler, Oliver Decker und Norman Geißler (alle Universität Leipzig). Die Datenerhebung erfolgte "face to face" (Selbstausfüller) im Mai/Juni 2006 durch USUMA. Die Grundgesamtheit der Untersuchung ist die in Privathaushalten lebende deutsche Bevölkerung ab 14 Jahren in der Bundesrepublik Deutschland. Die Auswahl der Befragungspersonen erfolgte durch eine disproportional geschichtete mehrstufige Zufallsstichprobe per Random-Route-Verfahren auf Basis des ADM-Designs. Die Anzahl der Einheiten beträgt $4.872^{51}$. Instrumente: Anhang 14.

Weitere Angaben oben in Tabelle 1.

\section{2) Die Rechtsextremismus-Skalen REX und REXKUM}

Bei rechtsextremen Einstellungen handelt es sich um ein mehrdimensionales Muster, das folgende Dimensionen aufweist:

- Befürwortung einer rechtsautoritären Diktatur (DIKTA),

- Chauvinismus (CHAU),

- Ausländerfeindlichkeit (AUS),

- Antisemitismus (SEM),

- Sozialdarwinismus (DARW),

- Verharmlosung des Nationalsozialismus (NS).

In der Langfassung umfasst die Rechtsextremismus-Skala jeweils fünf Statements ${ }^{52}$ pro Dimension, insgesamt also 30 Items. Die hier zugrunde liegende (summierte) Kurzskala REX wurde aus einem Statement pro Dimension gebildet ${ }^{53}$ :

50 Weitere Angaben, auch zur Gewichtung, bei Stöss/Fichter/Kreis/Zeuner 2004: 75 ff.

51 Weitere Angaben bei Decker/Brähler 2006: $25 \mathrm{ff}$.

52 Antwortvorgaben: 1 (lehne völlig ab), 2 (lehne eher ab), 3 (stimme eher zu), 4 (stimme völlig zu), 5 (weiß nicht), 6 (keine Angabe).

53 Details bei Kreis 2007, insbes. S. 23 ff., u. Stöss/Fichter/Kreis/Zeuner 2004, Kap B. 
F062_1 Andere Völker mögen wichtiges vollbracht haben, an deutsche Leistungen reicht das aber nicht heran (CHAU).

F062_2 Es gibt wertvolles und unwertes Leben (DARW).

F062_3 Auch heute noch ist der Einfluss der Juden zu groß (SEM).

F062_4 Wenn Arbeitsplätze knapp werden, sollte man die Ausländer wieder in ihre Heimat zurückschicken (AUS).

F062_5 Wir sollten einen Führer haben, der Deutschland zum Wohle aller mit starker Hand regiert (DIKTA).

F062_6 Der Nationalsozialismus hatte auch seine guten Seiten (NS).

\begin{tabular}{|l|c|c|c|c|c|}
\hline 2a) Item-Skala-Statistiken für die Rechtsextremismus-Statements \\
\hline & $\begin{array}{c}\text { Skalenmittelwert, } \\
\text { wenn Item wegge- } \\
\text { lassen }\end{array}$ & $\begin{array}{c}\text { Skalenvarianz, } \\
\text { wenn Item } \\
\text { weggelassen }\end{array}$ & $\begin{array}{c}\text { Korrigierte } \\
\text { Item-Skala- } \\
\text { Korrelation }\end{array}$ & $\begin{array}{c}\text { Quadrierte } \\
\text { multiple Kor- } \\
\text { relation }\end{array}$ & $\begin{array}{c}\text { Cronbachs } \\
\text { Alpha, wenn } \\
\text { Item weggelas- } \\
\text { sen }\end{array}$ \\
\hline F062_1 & 8,50 & 11,114 &, 490 &, 250 &, 756 \\
F062_2 & 9,10 & 11,251 &, 452 &, 218 &, 764 \\
F062_3 & 8,82 & 10,303 &, 545 &, 302 &, 742 \\
F062_4 & 8,53 & 10,119 &, 563 &, 330 &, 738 \\
F062_5 & 9,04 & 10,622 &, 542 &, 329 &, 743 \\
F062_6 & 9,06 & 10,889 &, 576 &, 354 &, 736 \\
\hline
\end{tabular}

Cronbachs Alpha $=0,780$

\begin{tabular}{|c|c|c|c|c|}
\hline \multirow[t]{2}{*}{ 2b) } & \multicolumn{4}{|c|}{$\begin{array}{l}\text { Korrelationen ( } r \text { ) der Rechtsextremismus-Statements und der } \\
\text { Rechtsextremismus-Skala REX mit dem Index Sexismus SEX } \\
\text { nach Geschlecht }\end{array}$} \\
\hline & & Alle & Männer & Frauen \\
\hline \multicolumn{2}{|c|}{ F062_1 } & ,307 & ,336 & ,260 \\
\hline \multicolumn{2}{|c|}{ F062_2 } & ,269 & ,290 & ,240 \\
\hline \multicolumn{2}{|c|}{ F062_3 } & ,351 & ,392 & ,281 \\
\hline \multicolumn{2}{|c|}{ F062_4 } & ,329 & ,399 & ,234 \\
\hline \multicolumn{2}{|c|}{ F062_5 } & ,251 & ,284 & 184 \\
\hline \multicolumn{2}{|c|}{ F062_6 } & ,260 & ,288 & 199 \\
\hline \multicolumn{2}{|c|}{ REX } & ,424 & ,457 & ,354 \\
\hline
\end{tabular}

Alle Korrelationen sind auf dem Niveau von 0,01 signifikant.

Zur Bestimmung des rechtsextremen Einstellungspotenzials (= die Rechtsextremisten) wurde die Variable REXPOT gebildet (Dummy: Nein / Ja). Ihm werden alle Befragten zugerechnet, die einen Skalenwert oberhalb des arithmetischen Mittels erreichen. Für Tabellen wurde eine Dreierversion (REXPOT3) erzeugt, indem die Häufigkeiten unterhalb des Potenzialbereichs in zwei etwa gleich große Gruppen aufgeteilt wur$\operatorname{den}^{54}$.

54 Die Skalenwerte reichen von 6 bis 24. Zum rechtsextremen Einstellungspotenzial werden die Befragten mit Werten zwischen 16 und 24 gerechnet. Die Dreierversion hat folgende Ausprägungen: niedrig (Werte 6-9), mittel (Werte 10-15) und stark (16-24). "Stark" entspricht dem Einstellungspotenzial, also der Personengruppe, die wir als Rechtsextremisten bezeichnen. 
2c) Zustimmung zu den Statements der Rechtsextremismus-Skalen nach Geschlecht 2005 (\%)

\begin{tabular}{|c|c|c|c|}
\hline Statements & Alle & Männer & Frauen \\
\hline $\begin{array}{l}\text { Andere Völker mögen wichtiges vollbracht haben, an deutsche } \\
\text { Leistungen reicht das aber nicht heran (F062_1) }\end{array}$ & 35 & 38 & 32 \\
\hline Es gibt wertvolles und unwertes Leben (F062_2) & 18 & 19 & 17 \\
\hline Auch heute noch ist der Einfluss der Juden zu groß (F062_3) & 25 & 26 & 23 \\
\hline $\begin{array}{l}\text { Wenn Arbeitsplätze knapp werden, sollte man die Ausländer } \\
\text { wieder in ihre Heimat zurückschicken (F062_4) }\end{array}$ & 37 & 39 & 35 \\
\hline $\begin{array}{l}\text { Wir sollten einen Führer haben, der Deutschland zum Wohle aller } \\
\text { mit starker Hand regiert (F062_5) }\end{array}$ & 21 & 23 & 18 \\
\hline Der Nationalsozialismus hatte auch seine guten Seiten (F062_6) & 16 & 20 & 14 \\
\hline REXPOT & 12 & 15 & 9 \\
\hline
\end{tabular}

\begin{tabular}{|l|c|c|}
\hline 2d) & \multicolumn{3}{c|}{$\begin{array}{c}\text { Fehlende Antworten bei den Rechtsextremis- } \\
\text { mus-Statements nach Geschlecht (\%) }\end{array}$} \\
\hline & Männer & Frauen \\
\hline F062_1 & 5,5 & 9,4 \\
F062_2 & 4,2 & 7,1 \\
F062_3 & 9,2 & 14,6 \\
F062_4 & 6,0 & 6,2 \\
F062_5 & 2,8 & 4,7 \\
F062_6 & 5,4 & 6,9 \\
\hline REX & 19,1 & 25,7 \\
\hline
\end{tabular}

Zur Bestimmung der Konsistenz des rechtsextremen Einstellungsmusters wurde die kumulierte Rechtsextremismus-Skala REXKUM gebildet. Sie reicht von 0 (keinem Statement zugestimmt) bis 6 (allen sechs Statements zugestimmt).

\begin{tabular}{|l|c|c|c|}
\hline 2e) Die Dichte des rechtsextremen Einstellungsmusters nach Geschlecht \\
2005 (\%)
\end{tabular}




\begin{tabular}{|l|c|c|c|}
\hline 2f) & \multicolumn{3}{l|}{$\begin{array}{l}\text { Mittelwerte (mean) der Antwortverweigerer nach Geschlecht } \\
\text { und der Antwortgeber - bezogen auf die Rechtsextremismus- } \\
\text { Skala REX insgesamt - für die einzelnen Rechtsextremismus- } \\
\text { Statements }\end{array}$} \\
\cline { 1 - 2 } & \multicolumn{2}{|c|}{ Antwortverweigerer REX } & \multirow{2}{*}{$\begin{array}{c}\text { Antwort- } \\
\text { geber REX }\end{array}$} \\
\cline { 1 - 2 } & Männer & Frauen & 2,11 \\
F062_1 & 2,48 & 2,34 & 1,51 \\
F062_2 & 1,68 & 1,86 & 1,79 \\
F062_3 & 2,08 & 1,85 & 2,08 \\
F062_4 & 2,86 & 2,50 & 1,57 \\
F062_5 & 2,06 & 1,92 & 1,55 \\
F062_6 & 1,71 & 1,48 & 8,61 \\
\hline REX & $* 99,00$ & $* 99,00$ & \\
\hline
\end{tabular}

* Die Missings der Skala REX sind auf 99 gesetzt.

\section{3) Allgemeine Beurteilung der NPD}

Generelle evaluative Orientierungen gegenüber Parteien (Niedermayer 2005: 83) werden hier mit folgendem Instrument gemessen:

"Und nun zu Ihrer allgemeinen Beurteilung von einzelnen Parteien und Politikern: Stellen Sie sich einmal wie auf diesem Blatt dargestellt - ein Thermometer vor, das aber lediglich von plus 5 bis minus 5 geht, mit einem Nullpunkt dazwischen. Sagen Sie bitte mit diesem Thermometer, was Sie von den einzelnen Parteien halten. +5 bedeutet, dass Sie sehr viel von der Partei halten. -5 bedeutet, dass Sie überhaupt nichts von der Partei halten. Mit den Werten dazwischen können Sie Ihre Meinung abgestuft sagen."

Abgefragt wurden neben den Bundestagsparteien auch die NPD. Die Indizes haben die Ausprägungen von 1 (halte überhaupt nichts von der Partei) bis 11 (halte sehr viel von der Partei). Für NPD-Tabellen wurde in Anlehnung an Niedermayer (2005: 83) eine Dreierversion erzeugt ${ }^{55}$.

\section{4) Der Sexismus-Index (SEX)}

Der Datensatz enthält folgende Statements zur Geschlechtsrollenorientierung ${ }^{56}$ :

F042_1 Männer und Frauen haben von Natur aus unterschiedliche Fähigkeiten, so dass Männer vor allem für den Beruf und Frauen für den Haushalt und Kinder da sein sollten.

F042_2 Frauen und Männer haben heutzutage in Deutschland dieselben Chancen, beruflich etwas zu erreichen.

F042_3 Heutzutage werden Männer auf dem Arbeitsmarkt gegenüber Frauen oft benachteiligt.

F042_4 Männer sind leistungsfähiger als Frauen.

F042_5 Frauen sind einfühlsamer als Männer.

F042_6 Bei der Gleichberechtigung geht es eigentlich darum, dass Frauen mehr Macht bekommen als Männer.

F042_7 Die meisten Männer reden nur von Gleichberechtigung. In Wirklichkeit wollen sie nichts von ihrer Macht an Frauen abgeben.

F060a_5 Die meisten Frauen sind von politischen Fragen überfordert.

55 Beurteilung der NPD: 1 "negativ" (Wert 1), 2 "wohlwollend" (Werte 2-5), 3"positiv" (Werte 6-11).

56 Antwortvorgaben: 1 (trifft überhaupt nicht zu) bis 7 (trifft voll und ganz zu), 8 (weiß nicht), 9 (verweigert). 
F060b_6 Die Politik zur Gleichberechtigung der Frauen ist schon viel zu weit getrieben worden, heute werden die Männer benachteiligt.

Die fett gesetzten Variablen sind Bestandteil des (summierten) Index SEX. Die übrigen Items wurden aufgrund von Faktoren- und Reliabilitätsanalysen ausgesondert.

\begin{tabular}{|l|c|c|}
\hline 4a) & \multicolumn{3}{c|}{$\begin{array}{l}\text { Rotierte Komponentenmatrix für alle Sexis- } \\
\text { mus-Statements }\end{array}$} \\
\cline { 1 - 2 } & \multicolumn{2}{|c|}{ Komponente } \\
\hline \multirow{2}{*}{ F042_1 } & 1 & 2 \\
\hline F042_2 &, 655 &, 155 \\
F042_3 &, 420 &,- 124 \\
F042_4 &, 601 &,- 191 \\
F042_5 &, 690 &, 072 \\
F042_6 &,- 048 &, 753 \\
F042_7 &, 681 &, 096 \\
F060a_5 &,- 040 &, 755 \\
F060b_6 &, 418 &, 333 \\
\hline
\end{tabular}

Extraktionsmethode: Hauptkomponentenanalyse.

Rotationsmethode: Varimax mit Kaiser-Normalisierung. $\mathrm{KMO}=0,769$

4b) Item-Skala-Statistiken für alle Sexismus-Statements

\begin{tabular}{|l|c|c|c|c|c|}
\hline & $\begin{array}{c}\text { Skalenmittelwert, } \\
\text { wenn Item weg- } \\
\text { gelassen }\end{array}$ & $\begin{array}{c}\text { Skalenvarianz, } \\
\text { wenn Item } \\
\text { weggelassen }\end{array}$ & $\begin{array}{c}\text { Korrigierte } \\
\text { Item-Skala- } \\
\text { Korrelation }\end{array}$ & $\begin{array}{c}\text { Quadrierte } \\
\text { multiple Kor- } \\
\text { relation }\end{array}$ & $\begin{array}{c}\text { Cronbachs } \\
\text { Alpha, wenn } \\
\text { Item weggelas- } \\
\text { sen }\end{array}$ \\
\hline F042_1 & 28,74 & 49,651 &, 447 &, 263 &, 561 \\
F042_2 & 27,87 & 56,025 &, 229 &, 084 &, 620 \\
F042_3 & 29,38 & 54,403 &, 335 &, 206 &, 593 \\
F042_4 & 28,83 & 50,016 &, 468 &, 281 &, 556 \\
F042_5 & 26,52 & 61,813 &, 060 &, 096 &, 653 \\
F042_6 & 29,18 & 50,574 &, 467 &, 270 &, 558 \\
F042_7 & 27,09 & 61,464 &, 051 &, 097 &, 659 \\
F060a_5 & 28,17 & 55,253 &, 298 &, 106 &, 602 \\
F060b_6 & 29,34 & 52,698 &, 443 &, 296 &, 568 \\
\hline
\end{tabular}

Cronbachs Alpha $=0,627$ 


\begin{tabular}{|l|c|c|c|c|c|}
\hline 4c) Item-Skala-Statistiken für die Sexismus-Statements des Index SEX \\
\hline & $\begin{array}{c}\text { Skalenmittelwert, } \\
\text { wenn Item weg- } \\
\text { gelassen }\end{array}$ & $\begin{array}{c}\text { Skalenvarianz, } \\
\text { wenn Item } \\
\text { weggelassen }\end{array}$ & $\begin{array}{c}\text { Korrigierte } \\
\text { Item-Skala- } \\
\text { Korrelation }\end{array}$ & $\begin{array}{c}\text { Quadrierte } \\
\text { multiple Kor- } \\
\text { relation }\end{array}$ & $\begin{array}{c}\text { Cronbachs } \\
\text { Alpha, wenn } \\
\text { Item weggelas- } \\
\text { sen }\end{array}$ \\
\hline F042_1 & 14,55 & 33,781 &, 479 &, 259 &, 663 \\
F042_3 & 15,19 & 37,254 &, 394 &, 197 &, 689 \\
F042_4 & 14,64 & 34,173 &, 498 &, 271 &, 656 \\
F042_6 & 15,00 & 34,659 &, 497 &, 263 &, 657 \\
F060a_5 & 13,98 & 39,339 &, 289 &, 096 &, 718 \\
F060b_6 & 15,16 & 35,726 &, 520 &, 285 &, 653 \\
\hline
\end{tabular}

Cronbachs Alpha $=0,713$

a) Das Item ist zwar durch schwache Koeffizienten gekennzeichnet. Da der Index SEX, wie die Rechtsextremismus-Skalen, über sechs Variablen verfügen soll, wurde es aufgenommen, weil es noch bessere Messergebnisse aufweist als F042_2, F042_5 und F042_7.

\begin{tabular}{|c|c|c|c|}
\hline \multirow[t]{2}{*}{ 4d) } & \multicolumn{3}{|c|}{$\begin{array}{l}\text { Korrelationen (r) der Sexismus-Statements und des } \\
\text { Sexismus-Index SEX mit den Rechtsextremismus- } \\
\text { Skalen REX und REXKUM }\end{array}$} \\
\hline & & REX & REXKUM \\
\hline & =042_1 & $\star \star 293$ & $\star \star 270$ \\
\hline & F042_2 & $\star \star *, 192$ & $\star \star \star *, 152$ \\
\hline & F042_3 & **,205 & $\star \star, 191$ \\
\hline & F042_4 & $\star \star, 275$ & $\star * \star 252$ \\
\hline & F042_5 &,- 016 &,- 018 \\
\hline & F042_6 & $\star \star \star 287$ & $\star \star * *, 241$ \\
\hline & F042_7 & ${ }^{\star}, 057$ & ${ }^{\star \star}, 069$ \\
\hline & =060a_5 & $\star * \star 283$ & $\star * \star 273$ \\
\hline & =060b_6 & $\star \star 294$ & $\star * \star 265$ \\
\hline & SEX & $\star \star *, 424$ & $\star * \star 402$ \\
\hline
\end{tabular}

** Die Korrelation ist auf dem Niveau von 0,01 signifikant.

* Die Korrelation ist auf dem Niveau von 0,05 signifikant.

Als Zustimmung zu den einzelnen Statements wurden die Skalenwerte über dem arithmetischen Mittel (4) gewertet $(5,6,7)$. Der Index SEX umfasst die Werte 6 bis 42. Zur Bestimmung des sexistischen Einstellungspotenzials (= die Sexisten) wurde die Variable SEXPOT gebildet (Dummy: Nein / Ja). Ihm werden alle Befragten zugerechnet, die einen Skalenwert oberhalb des arithmetischen Mittels (also 25-42) erreichen. Für Tabellen wurde eine Dreierversion (SEXPOT3) erzeugt, indem die Häufigkeiten unterhalb des Potenzialbereichs in zwei etwa gleich große Gruppen aufgeteilt wurden ${ }^{57}$.

57 Die Dreierversion hat folgende Ausprägungen: niedrig (Werte 6-15), mittel (Werte 16-24) und stark (2542). "Stark" entspricht dem sexistischen Einstellungspotenzial, also der Personengruppe, die wir als Sexisten bezeichnen. 
4e) Zustimmung zu den Statements des Sexismus-Index nach Geschlecht 2005 (\%)

\begin{tabular}{|c|c|c|c|}
\hline Statements & Alle & Männer & Frauen \\
\hline $\begin{array}{l}\text { Männer und Frauen haben von Natur aus unterschiedliche Fähig- } \\
\text { keiten, so dass Männer vor allem für den Beruf und Frauen für } \\
\text { den Haushalt und Kinder da sein sollten (F042_1) }\end{array}$ & 27 & 31 & 24 \\
\hline $\begin{array}{l}\text { Heutzutage werden Männer auf dem Arbeitsmarkt gegenüber } \\
\text { Frauen oft benachteiligt (F042_3) }\end{array}$ & 17 & 20 & 14 \\
\hline Männer sind leistungsfähiger als Frauen (F042_4) & 24 & 32 & 17 \\
\hline $\begin{array}{l}\text { Bei der Gleichberechtigung geht es eigentlich darum, dass Frau- } \\
\text { en mehr Macht bekommen als Männer (F042_6) }\end{array}$ & 17 & 20 & 15 \\
\hline $\begin{array}{l}\text { Die meisten Frauen sind von politischen Fragen überfordert } \\
\text { (F060a_5) }\end{array}$ & 36 & 33 & 39 \\
\hline $\begin{array}{l}\text { Die Politik zur Gleichberechtigung der Frauen ist schon viel zu } \\
\text { weit getrieben worden, heute werden die Männer benachteiligt } \\
\text { (F060b_6) }\end{array}$ & 13 & 17 & 9 \\
\hline SEXPOT & 16 & 21 & 11 \\
\hline
\end{tabular}

\section{5) Der Index Rechtsextremismus - Sexismus (REXSEX)}

\begin{tabular}{|l|c|c|c|c|c|}
\hline 5a) Item-Skala-Statistiken für die Statements von SEX und REX \\
\hline & $\begin{array}{c}\text { Skalenmittelwert, } \\
\text { wenn Item weg- } \\
\text { gelassen }\end{array}$ & $\begin{array}{c}\text { Skalenvarianz, } \\
\text { wenn Item } \\
\text { weggelassen }\end{array}$ & $\begin{array}{c}\text { Korrigierte } \\
\text { Item-Skala- } \\
\text { Korrelation }\end{array}$ & $\begin{array}{c}\text { Quadrierte } \\
\text { multiple Kor- } \\
\text { relation }\end{array}$ & $\begin{array}{c}\text { Cronbachs } \\
\text { Alpha, wenn } \\
\text { Item weggelas- } \\
\text { sen }\end{array}$ \\
\hline f042_1 & 24,98 & 65,947 &, 480 &, 287 &, 760 \\
f042_3 & 25,55 & 71,413 &, 369 &, 185 &, 772 \\
f042_4 & 25,06 & 66,850 &, 490 &, 295 &, 757 \\
f042_6 & 25,44 & 67,242 &, 509 &, 309 &, 754 \\
f060a_5 & 24,40 & 72,016 &, 351 &, 146 &, 774 \\
f060b_6 & 25,56 & 69,112 &, 507 &, 298 &, 755 \\
f062_1 & 25,97 & 77,610 &, 442 &, 284 &, 767 \\
f062_2 & 26,58 & 78,214 &, 393 &, 239 &, 770 \\
f062_3 & 26,29 & 76,035 &, 470 &, 325 &, 763 \\
f062_4 & 26,00 & 76,094 &, 458 &, 345 &, 764 \\
f062_5 & 26,51 & 77,828 &, 398 &, 328 &, 769 \\
f062_6 & 26,53 & 78,404 &, 414 &, 356 &, 769 \\
\hline
\end{tabular}

Cronbachs Alpha $=0,780$ 
Der (summierte) Index REXSEX wurde aus den unter 5 a genannten Statements gebildet. Da SEX über doppelt so viele Ausprägungen (6 - 42) wie REX (6 - 24) verfügt, wurden die Werte von SEX durch zwei geteilt und die von REX um drei verringert. Der Index REXSEX umfasst die Skalenwerte 6 bis $42^{58}$. Zur Bestimmung des rechtsextrem-sexistischen Einstellungspotenzials wurde die Variable REXSEXPO gebildet (Dummy: Nein / Ja). Ihm werden alle Befragten zugerechnet, die einen Skalenwert oberhalb des arithmetischen Mittels (24) erreichen.

\section{6) ANOMIA (Anomie; Orientierungslosigkeit, Macht- und Hilflosigkeit) ${ }^{59}$}

(Summierter) Index aus folgenden Statements:

F061_1 Heute hält sich im Grunde niemand mehr an die Regeln.

F061_2 Die Welt ist so unübersichtlich geworden, dass man gar nicht mehr weiß, wie es weiter gehen soll.

F061_6 Die heutigen Probleme sind so kompliziert, dass die Politik sie nicht mehr lösen kann.

Ausprägungen von 3 (ohne) bis 21 (stark). Zur Potenzialbestimmung: ANOMIAP (Werte 13 - 21); Dummy 0 (nein) / 1 (ja).

\section{7) EFFIINT (Politisches Selbstbewusstsein bzw. subjektive politische Kompetenz) ${ }^{60}$}

(Summierter) Index aus folgenden Statements:

F060a_1 Im Allgemeinen weiß ich recht viel über Politik.

F060a_2 Politische Fragen sind für mich oft schwer zu verstehen (neg).

F060a_3 Ich traue mir zu, in einer Gruppe, die sich mit politischen Fragen befasst, eine aktive Rolle zu übernehmen.

Ausprägungen von 3 (ohne) bis 21 (stark). Zur Potenzialbestimmung: EFFIINTP (geringes politisches Selbstbewusstsein; Werte 3 - 11); Dummy 0 (nein) / 1 (ja).

\section{8) Demokratie}

Statements:

F001 Zunächst geht es nicht um tatsächlich bestehende Demokratien, sondern um die Idee der Demokratie. Was würden Sie, im Vergleich zu anderen Staatsideen, zur Idee der Demokratie sagen. Sind Sie sehr für die Idee der Demokratie [6], ziemlich für die Idee der Demokratie [5], etwas für die Idee der Demokratie [4], etwas gegen die Idee der Demokratie [3], ziemlich gegen die Idee der Demokratie [2], sehr gegen die Idee der Demokratie [1]?

F002 Nun geht es um die Demokratie in der Bundesrepublik. Was würden Sie zu der Demokratie, so wie sie im Grundgesetz festgelegt ist, sagen: Sind Sie damit sehr zufrieden [6], ziemlich zufrieden [5], etwas zufrieden [4], etwas unzufrieden [3], ziemlich unzufrieden [2], sehr unzufrieden [1]?

F003 Und wie zufrieden oder unzufrieden sind Sie - alles in allem - mit der Demokratie, so wie sie in Deutschland funktioniert? Sind Sie damit sehr zufrieden [6], ziemlich zufrieden [5], etwas zufrieden [4], etwas unzufrieden [3], ziemlich unzufrieden [2], sehr unzufrieden [1]?

58 Die Werte 41,5 und 42,0 sind nicht besetzt.

59 Vgl. Six/Wolfradt/Zick 2001; Hüpping 2006 mit weiteren Nachweisen.

60 Vgl. Vetter 2000 mit weiteren Nachweisen. 
Aus diesen Statements wurden zwei Indizes gebildet:

DEMOR Typologie demokratischer Orientierungen

1 Antidemokraten

2 Systemkritische Demokraten

3 Politikkritische Demokraten

4 Zufriedene Demokraten

\section{DEMOZU Demokratiezufriedenheit}

(Summierter) Index aus F001, F002 und F003; Werte 3 (schwach) - 18 (stark).

Zur Potenzialbestimmung: DEMUNZUP (Demokratieunzufriedenheit; Werte 3 - 11);

Dummy 0 (nein) / 1 (ja).

\section{9) Politische Unzufriedenheit}

Die Variable POLUNZU wurde wie folgt gebildet:

- sehr/ziemlich unzufrieden mit den Leistungen der Bundesregierung;

- keine Partei ist geeignet, die genannten drei wichtigsten Probleme zu lösen;

- "Die Politiker kümmern sich nicht darum, was einfache Leute denken" (Zustimmung).

Die Ausprägungen reichen von 0 (keine Unzufriedenheit: keine der fünf Bedingungen erfüllt) bis 5 (starke Unzufriedenheit: alle fünf Kriterien erfüllt). Zur Potenzialbestimmung: POLUNZUP (Politische Unzufriedenheit; Werte 3 - 5); Dummy: 0 (nein) / 1 (ja).

\section{0) Unterschiedliche politische Ordnungsvorstellungen ("Gegensätzliche Meinungen")}

Die Batterie enthält folgende Variablen (jeweils Werte 1 bis 7 ):

F039_11 Eine Position besagt: Der Staat soll stark in die Wirtschaft eingreifen, um eine umfassende soziale Absicherung der Bürger zu garantieren [1]. Die Gegenposition besagt: Der Staat soll wenig in die Wirtschaft eingreifen und die soziale Absicherung der Eigenverantwortung der Bürger überlassen [7].

F039_12 Zum nächsten Thema ist die eine Meinung: Der Staat soll in die Wirtschaft eingreifen, um einen umfassenden Schutz unserer Umwelt zu garantieren [1]. Die andere Meinung ist: Der Staat soll die Wirtschaft nicht durch Maßnahmen zum Umweltschutz behindern [7].

F039_13 Beim nächsten Thema besagt die eine Position: Der Staat soll den Zuzug von Ausländern unterbinden, damit diese den Deutschen nicht die Arbeit wegnehmen [1]. Die andere Position besagt: Der Staat soll den Zuzug von Ausländern zulassen, auch wenn diese dann mit Deutschen um Arbeitsplätze konkurrieren [7].

F039_14 Und wie ist es mit: Jeder soll sich an die traditionellen Formen des Zusammenlebens anpassen [1]. Oder aber: Jeder soll seine eigenen Vorstellungen ausleben [7].

F039_15 Die einen meinen: Wir sollen der deutschen Kultur Vorrang einräumen [1]. Die anderen meinen: Wir sollen kulturelle Vielfalt pflegen [7].

F039_16 Und beim letzten Thema sagen die einen: Es soll eine starke politische Führung geben, die für uns die Entscheidungen trifft [1]. Und die anderen sagen: Politische Entscheidungen sollen aus einem Diskussionsprozess zwischen verschiedenen Gruppen hervorgehen [7].

Die Faktorenanalyse ergibt eine Zweierlösung:

Faktor 1: f039_13 f039_14 f039_15 f039_16

Faktor 2: f039_11 f039_12 
Daher wurden folgende Indizes gebildet:

STANEO Staatsinterventionismus vs. Neoliberalismus; (summierter) Index aus f039_11 und f039_12.

AUTOLIB Autoritarismus vs. Libertarismus;

(summierter) Index aus f039_13, f039_14, f039_15 und f039 16.

AUTO Autoritäre Dispositionen; nur Werte 1 bis 3 jeder Variable;

Dummy: 0 (nein) / 1 (ja).

\section{1) Weitere Variablen}

$\begin{array}{ll}\text { BILDUNG } & \text { Schulabschluss (niedrig, mittel, hoch) } \\ \text { ERWERB } & \begin{array}{l}\text { Erwerbsstatus (Arbeitslose, einfache Arbeiter, Facharbeiter, einfache Angestellte, } \\ \text { verantwortliche Angestellte, Beamte, Selbständige, Rentner, sonstige Nichterwerbs- } \\ \text { personen) }\end{array} \\ \text { ERWERBR } & \begin{array}{l}\text { Erwerbsstatus (Arbeitslose, Arbeiter, Angestellte, Beamte, Selbständige, Nichter- } \\ \text { werbspersonen) }\end{array} \\ \text { EINKOM } & \begin{array}{l}\text { Haushaltsnettoeinkommen (unteres, mittleres, oberes Drittel) } \\ \text { Objektive Schichteinstufung (Selbsteinstufung, korrigiert mit Haushaltsnettoeinkom- } \\ \text { SCHICHT }\end{array} \\ \text { LIRE }[\text { S21]): Unterschicht, Mittelschicht, Oberschicht } \\ \text { LIRE4 } & \text { Links-Rechts-Selbsteinstufung (ideologische Selbstverortung) } \\ \text { POLINT } & \text { Politisches Interesse (überhaupt nicht - sehr stark) } \\ \text { POLDESIN } & \text { Politisches Desinteresse; Dummy 0 (nein) / 1 (ja) }\end{array}$

\section{2) Beschreibung der Beträge des Korrelationskoeffizienten Pearsons $r$}

n.s. Nicht signifikant; es besteht kein signifikanter Zusammenhang.

0,00-0,09 Es liegt keine bzw. keine nennenswerte Korrelation vor (keine Assoziation, kein Zusammenhang), die Variablen korrelieren nicht miteinander.

$0,10-0,19 \quad$ Es liegt eine sehr schwache, sehr geringe Korrelation vor.

$0,20-0,29 \quad$ Es liegt eine schwache, geringe Korrelation vor.

$0,30-0,39 \quad$ Es liegt eine mittlere (ziemlich starke) Korrelation vor.

$0,40-0,49 \quad$ Es liegt eine starke Korrelation vor.

$0,50-0,69 \quad$ Es liegt eine sehr starke Korrelation vor.

$0,70-0,89 \quad$ Es liegt eine fast vollständige, fast perfekte Korrelation vor.

$0,90-1 \quad$ Es liegt eine vollständige, perfekte Korrelation vor. 
13) Ergänzende Tabellen

\begin{tabular}{|c|c|c|c|}
\hline & \multicolumn{3}{|c|}{$\begin{array}{l}\text { Rechtsextremismus in ausgewählten Gruppen nach Geschlecht } \\
2005(\%)\end{array}$} \\
\hline \multicolumn{2}{|c|}{ Gruppenmerkmale } & Männer & Frauen \\
\hline \multirow[t]{5}{*}{ Alter } & $18-24$ & 12 & 9 \\
\hline & $25-34$ & 15 & 8 \\
\hline & $35-44$ & 10 & 6 \\
\hline & $45-59$ & 15 & 7 \\
\hline & $60-$ & 19 & 14 \\
\hline \multirow[t]{3}{*}{ Bildung } & niedrig & 18 & 13 \\
\hline & mittel & 18 & 7 \\
\hline & hoch & 6 & 5 \\
\hline \multirow[t]{3}{*}{ Schicht } & Unterschicht & 19 & 11 \\
\hline & Mittelschicht & 16 & 11 \\
\hline & Oberschicht & 7 & 6 \\
\hline \multicolumn{2}{|l|}{ Anomie } & 23 & 13 \\
\hline \multicolumn{2}{|c|}{ Geringes politisches Selbstbewusstsein } & 18 & 11 \\
\hline \multicolumn{4}{|c|}{ Links-Rechts-Selbsteinstufung } \\
\hline & Links & 16 & 10 \\
\hline & Mitte-Links & 6 & 7 \\
\hline & Mitte-Rechts & 16 & 9 \\
\hline & Rechts & 27 & 16 \\
\hline \multicolumn{2}{|c|}{ Politisches Desinteresse } & 29 & 16 \\
\hline \multicolumn{2}{|c|}{ Unzufriedenheit mit der Demokratie } & 37 & 16 \\
\hline \multicolumn{2}{|c|}{ Politische Unzufriedenheit } & 26 & 14 \\
\hline \multicolumn{2}{|c|}{ Autoritäre Dispositionen } & 24 & 15 \\
\hline \multicolumn{2}{|c|}{ Sexismus } & 35 & 17 \\
\hline \multicolumn{2}{|c|}{ Insgesamt } & 15 & 9 \\
\hline
\end{tabular}

Lesebeispiel: 2005 waren 12 Prozent der Männer im Alter von 18 bis 24 Jahren rechtsextrem eingestellt. Im Durchschnitt aller Befragten waren 15 Prozent der Männer rechtsextrem eingestellt. Die 18-24jährigen Männer waren also in Bezug auf alle männlichen Befragten unterdurchschnittlich anfällig für Rechtsextremismus (-3 Prozentpunkte). 


\begin{tabular}{|c|c|c|c|}
\hline 13b) & $\begin{array}{l}\text { Rechtsextremismus nach aus } \\
2005(\%)\end{array}$ & Grupper & Geschlecht \\
\hline Grupper & nmerkmale & Männer & Frauen \\
\hline Alter & $18-24$ & 6 & 6 \\
\hline & $25-34$ & 15 & 12 \\
\hline & $35-44$ & 15 & 13 \\
\hline & $45-59$ & 26 & 18 \\
\hline & $60-$ & 38 & 51 \\
\hline Bildung & niedrig & 56 & 61 \\
\hline & mittel & 34 & 26 \\
\hline & hoch & 10 & 13 \\
\hline Schicht & Unterschicht & 51 & 36 \\
\hline & Mittelschicht & 36 & 45 \\
\hline & Oberschicht & 13 & 19 \\
\hline Anomie & & 78 & 72 \\
\hline Geringe & s politisches Selbstbewusstsein & 45 & 66 \\
\hline Links-Re & echts-Selbsteinstufung & & \\
\hline & Links & 23 & 20 \\
\hline & Mitte-Links & 13 & 21 \\
\hline & Mitte-Rechts & 35 & 36 \\
\hline & Rechts & 29 & 23 \\
\hline Politisch & les Desinteresse & 20 & 35 \\
\hline Unzufrie & denheit mit der Demokratie & 40 & 26 \\
\hline Politisch & e Unzufriedenheit & 25 & 25 \\
\hline Autoritär & re Dispositionen & 62 & 60 \\
\hline Sexism & & 46 & 21 \\
\hline
\end{tabular}

Lesebeispiel: Von den rechtsextrem eingestellten Männern befanden sich 2005 sechs Prozent im Alter von 18 bis 24 Jahren, 15 Prozent waren 25 bis 34 Jahre alt, ebenfalls 15 Prozent waren 35 bis 44 Jahre alt usw. Unter den rechtsextremen Frauen betrug der Anteil der 18-24jährigen wie bei den Männern sechs Prozent. 20 Prozent der rechtsextremen Männer, aber 35 Prozent der rechtsextremen Frauen waren politisch desinteressiert. 


\begin{tabular}{|l|c|c|c|}
\hline 13c) & \multicolumn{3}{l|}{ Korrelate (r) von Sexismus, Rechtsextremismus und } \\
Rechtsextremismus-Sexismus mit ausgewählten \\
Variablen 2005
\end{tabular}

** Die Korrelation ist auf dem Niveau von 0,01 signifikant.
ALTER
Alter in Jahren
ANOMIA
Orientierungslosigkeit, Macht- und Hilflosigkeit
AUTOLIB
Politische Ordnungsvorstellungen: Autoritarismus vs.
Libertarismus
BILDUNG
Schulabschluss
DEMOZU
EFFIINT
LIRE
Demokratiezufriedenheit
Politisches Selbstbewusstsein
POLINT
POLUNZU
Links-Rechts-Selbsteinstufung
Politisches Interesse
$\mathrm{SCHICHT}$
Politische Unzufriedenheit
STANEO

\begin{abstract}
Politische Ordnungsvorstellungen: Staatsinterventionismus vs. Neoliberalismus
\end{abstract}


13d): Zweitstimmenergebnisse der NPD nach Geschlecht in den Alters-, Bildungs- und Erwerbs- bzw. Berufsgruppen bei der Bundestagswahl 2005 (\%)

\begin{tabular}{|c|c|c|c|}
\hline & Alle & Männer & Frauen \\
\hline \multicolumn{4}{|c|}{ Alter } \\
\hline $18-24$ & 4,3 & 6,4 & 2,0 \\
\hline $25-34$ & 3,0 & 3,4 & 2,2 \\
\hline $35-44$ & 1,8 & 2,5 & 1,1 \\
\hline $45-59$ & 1,1 & 1,5 & 0,7 \\
\hline $60-$ & 0,5 & 0,8 & 0,3 \\
\hline \multicolumn{4}{|c|}{ Bildung } \\
\hline Niedrig & 2,0 & 3,0 & 1,3 \\
\hline Mittel & 2,0 & 3,3 & 0,9 \\
\hline Hoch & 0,7 & 0,8 & 0,6 \\
\hline \multicolumn{4}{|c|}{ Erwerbs- bzw. Berufsstatus } \\
\hline Einfache Arbeiter & 3,6 & 5,6 & 2,2 \\
\hline Facharbeiter & 4,5 & 5,4 & 1,7 \\
\hline Angestellte & 1,0 & 1,2 & 0,9 \\
\hline Beamte* & 0,4 & 0,7 & 0 \\
\hline Selbständige* & 0,5 & 0,6 & 0,3 \\
\hline Arbeitslose & 4,9 & 6,3 & 2,8 \\
\hline Rentner & 0,5 & 0,7 & 0,3 \\
\hline Sonstige Nichterwerbspersonen & 1,4 & 2,2 & a) 1,2 \\
\hline Insgesamt & 1,6 & 2,3 & 0,9 \\
\hline
\end{tabular}

Daten: Wahltagsbefragung Infratest dimap (ARD-Wahlberichterstattung). $N=16.365$.

* Geringe Fallzahlen.

a) Vor allem Hausfrauen und Auszubildende.

Lesebeispiel: Bei der Bundestagswahl 2005 wählten 2,0 Prozent der Frauen im Alter von 18 bis 24 Jahren die NPD. Insgesamt erzielte sie bei allen Frauen 0,9 Prozent. 


\begin{tabular}{|c|c|c|c|}
\hline 13e) & \multicolumn{3}{|c|}{$\begin{array}{l}\text { Die positive Beurteilung der NPD in ausgewählten Gruppen nach } \\
\text { Geschlecht } 2005(\%)\end{array}$} \\
\hline \multicolumn{2}{|c|}{ Gruppenmerkmale } & Männer & Frauen \\
\hline \multirow[t]{5}{*}{ Alter } & $18-24$ & 19 & 17 \\
\hline & $25-34$ & 16 & 16 \\
\hline & $35-44$ & 17 & 10 \\
\hline & $45-59$ & 11 & 7 \\
\hline & $60-$ & 8 & 12 \\
\hline \multirow[t]{3}{*}{ Bildung } & niedrig & 15 & 15 \\
\hline & mittel & 15 & 12 \\
\hline & hoch & 6 & 5 \\
\hline \multicolumn{2}{|c|}{ Arbeitslose } & 23 & 18 \\
\hline \multicolumn{2}{|c|}{ Einfache Arbeiter } & 25 & 38 \\
\hline \multicolumn{2}{|c|}{ Facharbeiter } & 17 & *11 \\
\hline \multicolumn{2}{|c|}{ Einfache Angestellte } & 8 & 13 \\
\hline \multicolumn{2}{|c|}{ Verantwortliche Angestellte } & 12 & 6 \\
\hline \multicolumn{2}{|c|}{ Selbständige } & 12 & 6 \\
\hline \multicolumn{2}{|c|}{ Rentner/Pensionäre } & 8 & 11 \\
\hline \multicolumn{2}{|c|}{ Sonstige Nichterwerbspersonen } & 11 & 11 \\
\hline \multirow[t]{3}{*}{ Schicht } & Unterschicht & 18 & 16 \\
\hline & Mittelschicht & 11 & 11 \\
\hline & Oberschicht & 8 & 7 \\
\hline \multicolumn{4}{|c|}{ Links-Rechts-Selbsteinstufung } \\
\hline & Links & 5 & 5 \\
\hline & Mitte-Links & 9 & 8 \\
\hline & Mitte-Rechts & 15 & 12 \\
\hline & Rechts & 27 & 12 \\
\hline Insgesa & & 13 & 12 \\
\hline
\end{tabular}

* Geringe Fallzahlen.

Lesebeispiel: Von den Männern im Alter von 18 bis 24 Jahren bewerteten 200519 Prozent die NPD positiv. Bei den gleichaltrigen Frauen taten das damals nur 17 Prozent. 


\section{4) Instrumente und ergänzende Tabellen aus der Studie "Rechtsextreme Einstellungen und ihre Einflussfaktoren in Deutschland" von Prof. Dr. Elmar Brähler (Leipzig)}

Zur Studienbeschreibung: Anhang 1.

Die Rechtsextremismus-Skala REX_B[rähler] enthält dieselben sechs Statements wie die Bundestagswahlstudie 2005 (Anhang 2). Zu den Antwortvorgaben: Tabelle 1 Nr. h.

Der Sexismus-Index SEX_B[rähler] wurde aus folgenden beiden Statements gebildet:

z31_03 Die Frauen sollen sich wieder mehr auf die Rolle der Ehefrau und Mutter besinnen.

z31_04 Für eine Frau sollte es wichtiger sein, ihrem Mann bei seiner Karriere zu helfen, als selbst Karriere zu machen.

Für Gewaltbereitschaft stehen folgende Statements zur Verfügung:

z32_01 Ich bin bereit, mich mit körperlicher Gewalt gegen Fremde durchzusetzen.

z32_02 Ich würde selbst nie körperliche Gewalt anwenden, finde es aber gut, wenn es Leute gibt, die auf diese Weise für Ordnung sorgen.

z32_03 Körperliche Gewalt gegen andere gehört ganz normal zum menschlichen Verhalten, um sich durchzusetzen.

z32_04 Ich bin in bestimmten Situationen durchaus bereit, auch körperliche Gewalt anzuwenden, um meine Interessen durchzusetzen.

z32_05 Man muss leider zu Gewalt greifen, weil man nur so beachtet wird.

z32_06 Selber würde ich nie Gewalt anwenden. Aber es ist schon gut, dass es Leute gibt, die mal ihre Fäuste sprechen lassen.

14a) Zustimmung zu den Statements zur Gewaltbereitschaft nach Geschlecht 2006 (\%)

\begin{tabular}{|c|c|c|c|}
\hline Statements & Alle & Männer & Frauen \\
\hline $\begin{array}{l}\text { Ich bin bereit, mich mit körperlicher Gewalt gegen Fremde durch- } \\
\text { zusetzen. }\end{array}$ & 13 & 17 & 10 \\
\hline $\begin{array}{l}\text { Ich würde selbst nie körperliche Gewalt anwenden, finde es aber } \\
\text { gut, wenn es Leute gibt, die auf diese Weise für Ordnung sorgen. }\end{array}$ & 24 & 24 & 24 \\
\hline $\begin{array}{l}\text { Körperliche Gewalt gegen andere gehört ganz normal zum } \\
\text { menschlichen Verhalten, um sich durchzusetzen. }\end{array}$ & 14 & 18 & 11 \\
\hline $\begin{array}{l}\text { Ich bin in bestimmten Situationen durchaus bereit, auch körperli- } \\
\text { che Gewalt anzuwenden, um meine Interessen durchzusetzen. }\end{array}$ & 15 & 20 & 10 \\
\hline $\begin{array}{l}\text { Man muss leider zu Gewalt greifen, weil man nur so beachtet } \\
\text { wird. }\end{array}$ & 9 & 11 & 7 \\
\hline $\begin{array}{l}\text { Selber würde ich nie Gewalt anwenden. Aber es ist schon gut, } \\
\text { dass es Leute gibt, die mal ihre Fäuste sprechen lassen. }\end{array}$ & 21 & 21 & 21 \\
\hline
\end{tabular}

Daten: Brähler, N=4872.

Bei der Faktorenanalyse laden die Variablen z32_01, z32_03, z32_04 und z32_05 auf dem ersten Faktor, die Variablen z32_02 und z32_06 auf dem zweiten Faktor. Der erste Faktor wurde als "aktive Gewaltbereitschaft", der zweite als "passive Gewaltbereitschaft" interpretiert. Die entsprechenden Indizes wurden wie in Abschn. 4 beschrieben konstruiert. Dies gilt ebenso für die Bestimmung der Potenziale. Die übrigen in diesem Zusammenhang verwendeten Variablen (Altersgruppen, Bildung, Erwerbs- bzw. Berufsgruppen, objektive Schichteinstufung, Links-Rechts-Selbsteinstufung) wurden analog zur Bundestagswahlstudie gebildet. 


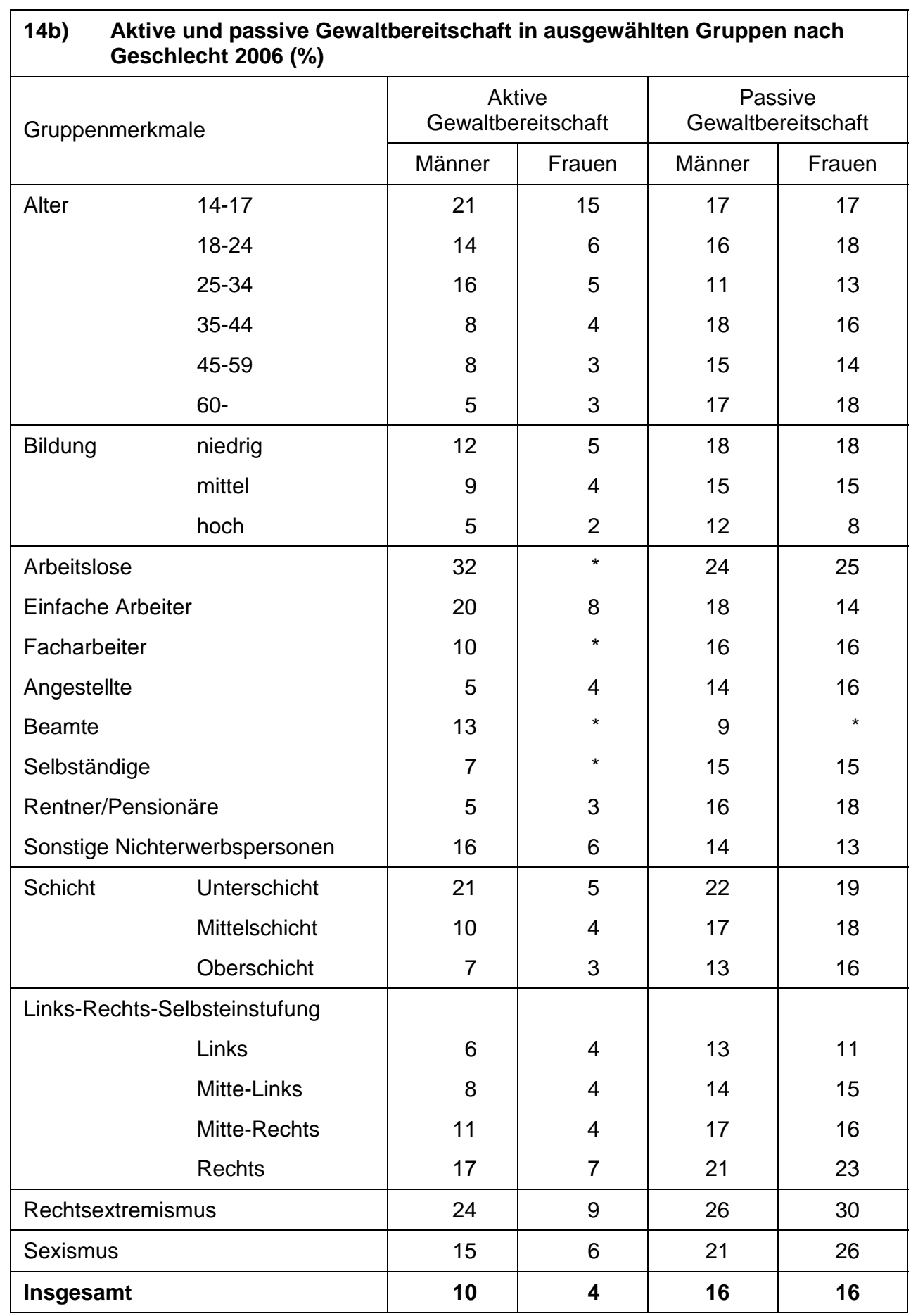

Daten: Brähler, N=4872.

* Geringe Fallzahlen.

Lesebeispiel: Von den Männern im Alter von 14 bis 17 Jahren zeigten 200621 Prozent aktive Gewaltbereitschaft. Insgesamt war das nur bei zehn Prozent der Männer der Fall. 